\title{
Anatomy, taxonomy and phylogenetic relationships of Prestosuchus chiniquensis (Archosauria: Pseudosuchia) from the original collection of von Huene, Middle-Late Triassic of southern Brazil
}

\author{
Julia Brenda Desojo, María Belén von Baczko, and Oliver W.M. Rauhut
}

\begin{abstract}
A review of the type and referred material of von Huene shows that Prestosuchus is a valid taxon represented by, at least, three different species: the lectotype and paralectotype of Prestosuchus chiniquensis, an unnamed species from Brazil (UFRGS-PV0152-T), and the new combination Prestosuchus nyassicus (=Stagonosuchus nyassicus). Several more recently referred specimens are also included within the genus Prestosuchus based on the absence of a vertical crest dorsal to the supracetabular rim; dorsal margin of postacetabular part of ilium concave; marked angle between pubic peduncle/obturator plate and ischial shaft; and elongate posteromedial depression on the distal fibula, making it one of the best known rauisuchian taxa. The phylogenetic analysis recovered a monophyletic Prestosuchidae including Saurosuchus galilei, Luperosuchus fractus, Prestosuchus chiniquensis, Prestosuchus nyassicus, and several specimens referred to the genus Prestosuchus. This clade is supported by the presence of a ridge on the ventral process of the squamosal; anteroventral process of the squamosal perforates the lower temporal fenestra; palpebral bones extensively sutured to each other and to the lateral margin of the frontals; robust, knob-shaped attachment for the musculus iliofibularis on the fibula; and anterior portion of nasals elevated above the skull roof. The identification of this natural group evidenced a remarkable diversity and abundance of basal loricatans in the Middle-Late Triassic continental ecosystems of southern Gondwana.
\end{abstract}

Julia Brenda Desojo. División Paleontología Vertebrados, Museo de La Plata, Paseo del Bosque $s / n^{\circ}$, La Plata, B1900FWA, Buenos Aires, Argentina; Consejo Nacional de Investigaciones Científicas y Tecnológicas (CONICET). julideso@fcnym.unlp.edu.ar María Belén von Baczko. División Paleontología Vertebrados, Museo de La Plata, Paseo del Bosque s $/ \mathrm{n}^{\circ}$, La Plata, B1900FWA, Buenos Aires, Argentina; Consejo Nacional de Investigaciones Científicas y Tecnológicas (CONICET). belen_vb@fcnym.unlp.edu.ar

Desojo, Julia Brenda, von Baczko, María Belén, and Rauhut, Oliver W.M. 2020. Anatomy, taxonomy and phylogenetic relationships of Prestosuchus chiniquensis (Archosauria: Pseudosuchia) from the original collection of von Huene, Middle-Late Triassic of southern Brazil. Palaeontologia Electronica, 23(1):a04. https://doi.org/10.26879/1026

palaeo-electronica.org/content/2020/2917-type-materials-of-prestosuchus 
Oliver W.M. Rauhut. SNSB Bayerische Staatssammlung für Paläontologie und Geologie, Richard-WagnerStr. 10, D-80333, Munich, Germany; Sektion Paläontologie, Department für Geo- und Umweltwissenschaften, Ludwig-Maximilians-Universität Munich, Germany; GeoBioCenter, LudwigMaximilians-Universität Munich, Germany. rauhut@snsb.de

Keywords: Paracrocodylomorpha; Rauisuchia; Prestosuchus; Santa Maria Supersequence; Gondwana

Submission: 26 August 2019. Acceptance: 25 January 2020.

\section{INTRODUCTION}

Pseudosuchian archosaurs (sensu Gauthier and Padian, 1985) constitute one of the most conspicuous groups of Triassic terrestrial tetrapods (Butler et al., 2011). They had a global distribution during this time and represent important faunal elements of all known faunas (Nesbitt, 2011). Although several groups of pseudosuchians constitute well-defined, monophyletic units, such as the phytosaurs, aetosaurs, gracilisuchids, ornithosuchids, erpetosuchids, and crocodylomorphs, "rauisuchians" are often regarded as a waste-basket taxon for a variety of pseudosuchian archosaurs that cannot be referred to any of these groups (see Gower, 2000; Nesbitt et al., 2013a; Ezcurra, 2016). One of the principal problems with "rauisuchians" is our still poor understanding of the alpha taxonomy of the taxa included in this group and their anatomy (Gower, 2000; Brusatte et al., 2010; Nesbitt, 2011), although great advances have been made in this regard in the last decade (see Weinbaum and Hungerbühler, 2007; Gower and Schoch, 2009; Brusatte et al., 2010; Nesbitt, 2011; Lautenschlager and Desojo, 2011; Butler et al., 2011; Lautenschlager and Rauhut, 2015; Lacerda et al., 2016; Lessner et al., 2016; Nesbitt and Desojo, 2017). Moreover, "rauisuchians" consist of large-bodied, short-necked predatory quadrupedal animals (e.g., Prestosuchus chiniquensis von Huene, 1938, Saurosuchus galilei Reig, 1959, Stagonosuchus nyassicus von Huene, 1939, Fasolasuchus tenax Bonaparte, 1981, Luperosuchus fractus Romer, 1971) and long-necked, partially edentulous, bipedal taxa (e.g., Arizonasaurus babbitti Welles, 1947, Sillosuchus longicervix Alcober and Parrish, 1997, Effigia okeeffeae Nesbitt and Norell, 2006, Shuvosaurus inexpectatus Chatterjee, 1993) included in several categories (e.g., Rauisuchidae, Poposauroidae, Ctenosauriscidae) by some authors (e.g., Bonaparte, 1981; Chatterjee, 1985; Parrish, 1993; Gower, 2000; Butler et al., 2009; Nesbitt et al., 2013a). Many of these taxa are represented in South America in sediments ranging from the Middle to the Late Triassic, particularly in Argentina and Brazil (França et al., 2011; Raugust, 2014; Lacerda et al., 2015, 2016, Roberto-da-Silva et al., 2018; Mastrantonio et al., 2019), and are included in different traditional "rauisuchian" groups, such as Poposauroidea, basal Loricata, and Rauisuchidea (Nesbitt and Desojo, 2017).

In 1928/1929, the German palaeontologist Friedrich Freiherr von Huene carried out extensive fieldwork in Triassic rocks in southern Brazil, resulting in the discovery of numerous new vertebrate fossils from these terrestrial deposits (von Huene and Stahlecker, 1931; von Huene, 1938, 1942). The original specimens of von Huene $(1938,1942)$ are kept in the collections of the Bayerische Staatssammlung für Paläontologie und Geologie in Munich, Germany. Among these fossils were several taxa of pseudosuchians, including Prestosuchus chiniquensis von Huene, 1938, Prestosuchus loricatus von Huene, 1938, Procerosuchus celer von Huene, 1938, Hoplitosuchus raui (von Huene, 1938) (originally named as Hoplitosaurus raui by von Huene, 1938 and later as Hoplitosuchus raui by von Huene, 1942 and subsequent authors, e.g., Krebs, 1976; Kischlat, 2000, since Hoplitosaurus was preoccupied, see Lacerda et al., 2016), Rhadinosuchus gracilis von Huene, 1942, and the namebearing taxon of the "Rauisuchia", Rauisuchus tiradentes von Huene, 1938. Although these remains potentially represent one of the most diverse "rauisuchian" faunas known, some of these fossils have not been revised in detail since their original description. Moreover, Barberena (1978) referred a partial skeleton, including a complete huge skull from the same geological unit to Prestosuchus chiniquensis (see also Azevedo, 1991, 1995), and more specimens were referred to the same taxon more recently (Mastrantonio et al., 2013; Raugust, 2014; Lacerda et al., 2016; Roberto-da-Silva et al., 2018; Mastrantonio et al., 2019).

In an overview of "pseudosuchians" (traditionally regarded as all the archosauriforms that were not members of Parasuchia, Proterosuchia, Eryth- 
rosuchia, Crocodylia, Saurischia, or Ornithischia), Krebs (1976) designated lectotypes for Prestosuchus chinquensis and Rauisuchus tiradentes, and considered Prestosuchus loricatus and Procerosuchus celer as further valid taxa of the family Rauisuchidae. Futhermore, Hoplitosuchus raui was considered a nomen dubium, whereas Rhadinosuchus gracilis was thought to be a primitive crocodile. A more detailed revision of this fauna was presented by Kischlat (2000), who considered Prestosuchus chiniquensis, Procerosuchus celer, and Rauisuchus tiradentes as valid "rauisuchian" taxa. In that revision, some of the material included in Prestosuchus loricatus by von Huene (1942) was referred to a new genus, Abaporu loricatus Kischlat, 2000, whereas other material of this taxon was referred to other taxa or not mentioned at all (Lacerda et al., 2016). Furthermore, other material previously referred to Prestosuchus, including that originally referred to Prestosuchus chiniquensis (most probably the paralectotype SNSB-BSPG AS $X X V 7$, although the specimen number was given as "BSPGH 1933 L/7" by Kischlat, 2000, p. 291) and the calcaneum of the type of Prestosuchus loricatus (SNSB-BSPG AS XXV 24; erroneously given as "BSPGH 1933 L/24" by Kischlat) was furthermore described as "Karamuru vorax Kischlat and Barberena" (Kischlat, 2000, p. 290-291). However, both Abaporu and Karamuru are problematic. In the case of the former, the name Abaporu is only mentioned in the title of the section dealing with this taxon, in combination with the species epithet loricatus, thus indicating that this probably represents a new generic name for von Huene's Prestosuchus loricatus, which is confirmed by the brief description and discussion given by Kischlat (2000). Nevertheless, this intention is not made explicit in the text, in violation of ICZN article 16.1. Furthermore, although no type specimen is explicitly designated (in violation of ICZN article 16.4), Kischlat (2000, p. 301) lists "three neural arches (BSPGH 013)" as material of this taxon. However, this number probably refers to specimen SNSBBSPG AS XXV 13 (part of the type specimen of Prestosuchus loricatus), which consists of a single cervical neural arch. Thus, given the violations of ICZN article 16 and the uncertainty about the type material of "Abaporu loricatus", we consider the generic name Abaporu as a nomen nudum. Likewise, Karamuru vorax is assigned to Kischlat and Barberena, although no citation to another paper is given, Kischlat is the sole author of the work in question, and there is no explicit statement that this is a newly proposed taxon (in violation of ICZN arti- cle 16.1). Furthermore, only a list of material included in this taxon (including materials from different collections and material provisionally referred to this taxon) is given, but no type material is explicitly designated, also violating ICZN article 16.4. Thus, we also consider Karamuru vorax to be a nomen nudum (see also Langer et al., 2007, p. 205; Lacerda et al., 2016).

The type material of Hoplitosuchus raui was found to be non-diagnostic, but material referred to this taxon was proposed as a new dinosaurian taxon, Teyuwasu barberenai. It might be worth noting here, that Kischlat (2000, p. 298) assigned the latter species to Kischlat (1999). However, Teyuwasu berberenai Kischlat, 1999, has to be regarded as a nomen nudum, since it was only published in an abstract, which, according to paragraph 9.9 of the ICZN does not constitute a published work. Furthermore, the name was only mentioned in the title, but not in the text of the abstract itself. Nevertheless, Kischlat's (2000, p. 298) dealing with the material might fulfill the requirements of the ICZN (although no type specimen is explicitly designated by Kischlat [2000], this was done by Kischlat [1999]), so that Teyuwasu berberenai Kischlat, 2000, might be considered a formally valid taxon, although the material is not deemed diagnostic and thus the species regarded as a nomen dubium here, in agreement with the revision by Ezcurra (2012). More recently, Teyuwasu barbarenai was considered to be a junior synonym of Staurikosaurus pricei (Garcia et al., 2019), but as the association of the material is doubtful and its preservation is rather poor, we regard any interpretation of possible diagnostic characters as problematic. According to Kischlat (2000, p. 283), Rhadinosuchus gracilis represents a proterochampsid, a view that was supported by recent anatomic and phylogenetic analysis (Desojo et al., 2010; Ezcurra et al., 2015).

The purpose of this work is to present a detailed taxonomic revision, anatomical description, and phylogenetic relationships of the type and referred materials of Prestosuchus from the original collections of von Huene, as part of a larger project revising all of von Huene's "rauisuchian" material from the Triassic of Brazil (Desojo and Rauhut, 2009; Ezcurra et al., 2015; Lautenschlager and Rauhut, 2015; von Baczko et al., 2019). This revision is crucial to assess the taxonomy and phylogenetic position of the "rauisuchids" recently exhumed from Brazil and assigned to Prestosuchus chiniquensis (Mastrantonio et al., 2013; Raugust, 2014; Lacerda et al., 2016; Roberto-da-Silva 
et al., 2016, 2018), as well as to resolve the relationships among Pseudosuchia of several taxa recently discovered or redescribed, such as Mandasuchus tanyauchen Butler et al., 2018, Stagonosuchus nyassicus von Huene, 1939, Pagosvenator candelariensis Lacerda et al., 2018, and Venaticosuchus rusconi Bonaparte, 1970.

\section{GEOLOGICAL SETTING}

The material described by von Huene (1938, 1942) came from two different localities some 15 $\mathrm{km}$ west of the town of Sao Pedro do Sul, Rio Grande do Sul, Brazil, in the area of Chiniquá (Figure 1). The two localities, called "Cynodontier Sanga" and "Weg Sanga" by von Huene, were some $3 \mathrm{~km}$ apart, but obviously placed in the same stratigraphic horizon within the "Rio-do-RastoSchichten" of von Huene and Stahlecker (1931). According to these authors, the lithology of the beds in these localities consists mainly of red mudstones with intercalated sandy parts. These "Riodo-Rasto-Schichten" are considered to be part of the Santa Maria Formation within the Rosário do Sul Group (Andreis et al., 1980). According to Barberena (1978), both localities that have yielded material of Prestosuchus are found in the basal part of the Santa Maria Formation (Figure 2). Zerfass et al. (2003) presented a sequence stratigraphic approach to the Triassic geology of southern Brazil, in which they included the Santa Maria Formation and the overlying Caturrita Formation in a single second order sequence (or supersequence), which they named the Santa Maria Supersequence. According to Langer et al. (2007), both the "Weg Sanga" and the "Cynodontier Sanga" are placed in the Santa Maria Sequence 1. This sequence represents a fining upwards succession and can be subdivided into a coarse-grained basal part, including conglomerates, trough-bedded sandstones and cross-bedded sand- and siltstones, and a transgressive system tract consisting mainly of massive to laminated red mudstones (Zerfass et al., 2003). In agreement with the lithological description pre-

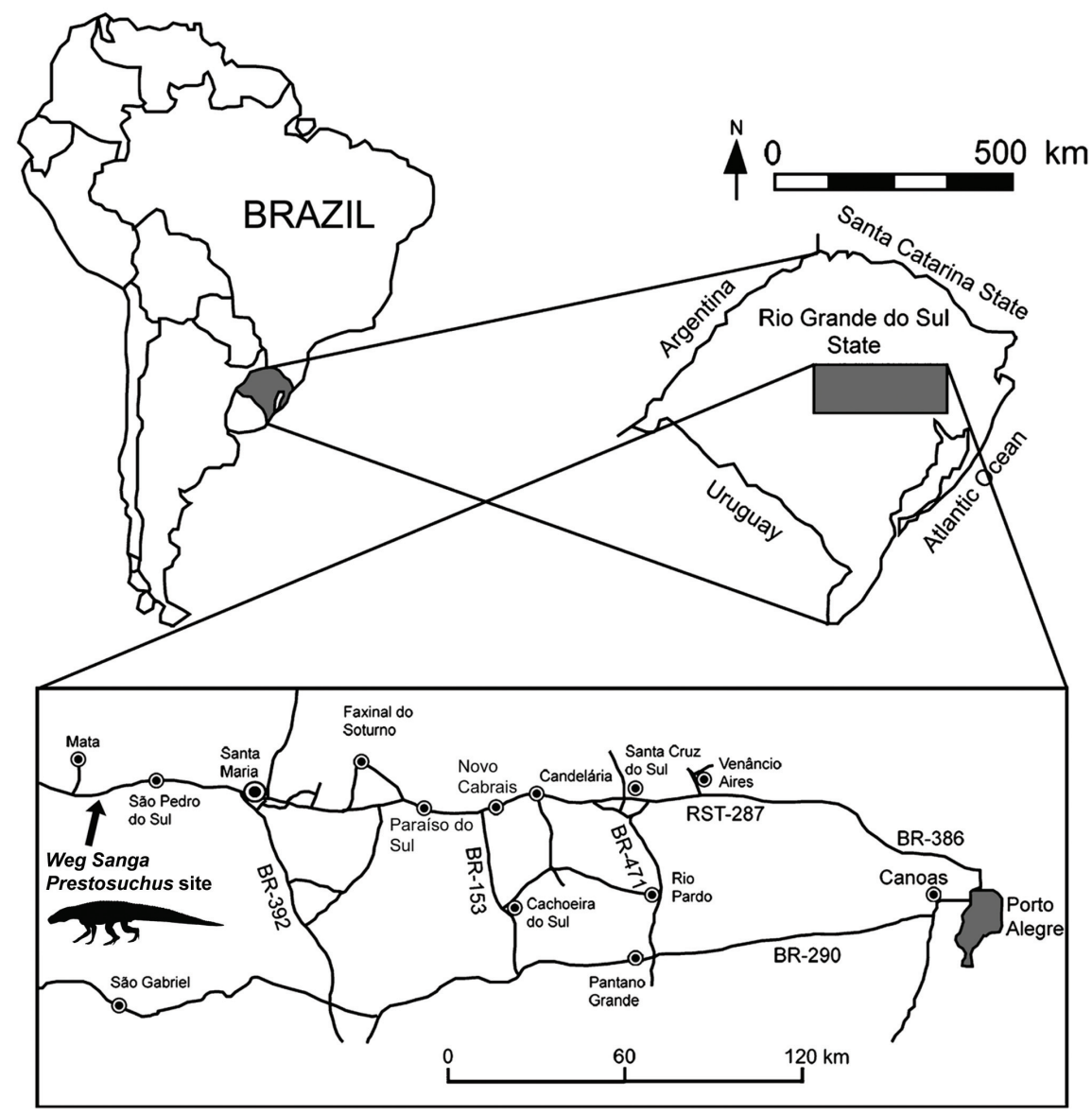

FIGURE 1. Map of Brazil, showing the location of the Prestosuchus chiniquensis-bearing site as indicated by von Huene (1938) within the state of Rio Grande do Sul. Map modified from Reichel et al. (2009). 


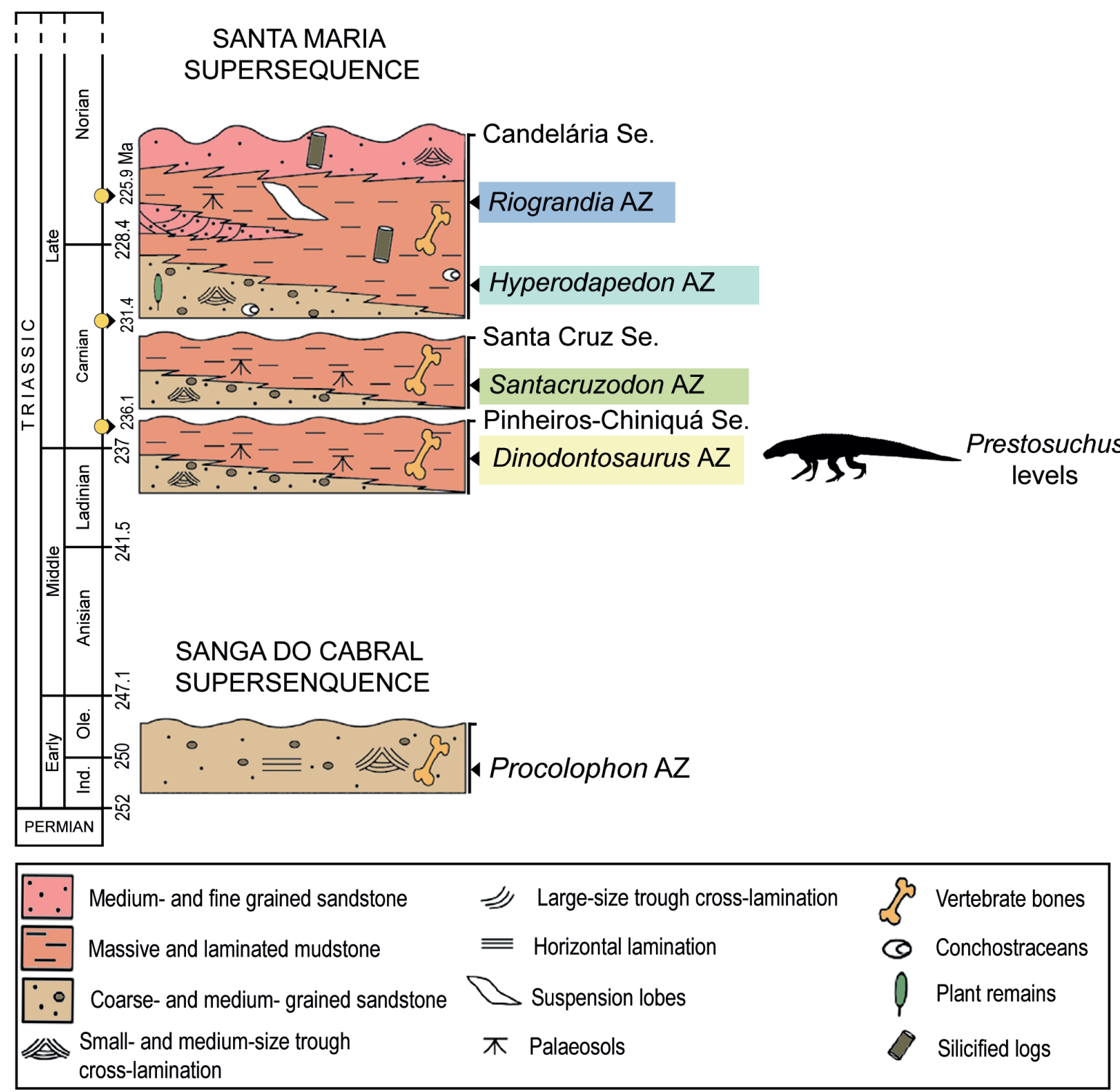

FIGURE 2. Chronostratigraphic column of the Santa Maria Supersequence, showing the Prestosuchus chiniquensisbearing level. Modified from Horn et al. (2014).

sented by von Huene and Stahlecker (1931), the Prestosuchus localities are thus located within the upper, transgressive part of sequence 1 , which is in accordance with Langer et al. (2007). Horn et al. (2014) performed geological studies of the Santa Maria Supersequence and proposed a new succession, the Santa Cruz Sequence, placed between the Candelária Sequence (above) and Pinheiros-Chiniqua (below). Most of the Archosauromorpha, especially the material of Prestosuchus was recovered from the latter, which belongs to the Dinodontosaurus Assemblage Zone (Figure 2).

The age of the localities is more difficult to evaluate. Langer et al. (2007) noted that the fauna from the "Cynodontier Sanga" and the "Weg
Sanga" shows affinities to both the faunas of the late Middle-earlier Late Triassic Chañares Formation and the Late Triassic Ischigualasto Formation of the Ischigualasto-Villa Union Basin of Argentina. The age of the former Argentinean sedimentary unit has been traditionally considered as Ladinian (Bonaparte, 1997; Morel et al., 2001), but modifications in the Triassic time-scale (Muttoni et al., 2004) and recent isotopic data (Marsicano et al., 2015; Ezcurra et al., 2017) led to a reconsideration of this interpretation. Stratigraphic horizons close to the base of the Ischigualasto Formation, belonging to the same basin as the Chañares Formation, have been re-interpreted as Late Carnian in age (Hyperodapedon AZ) (Furin et al., 2006; Martinez 

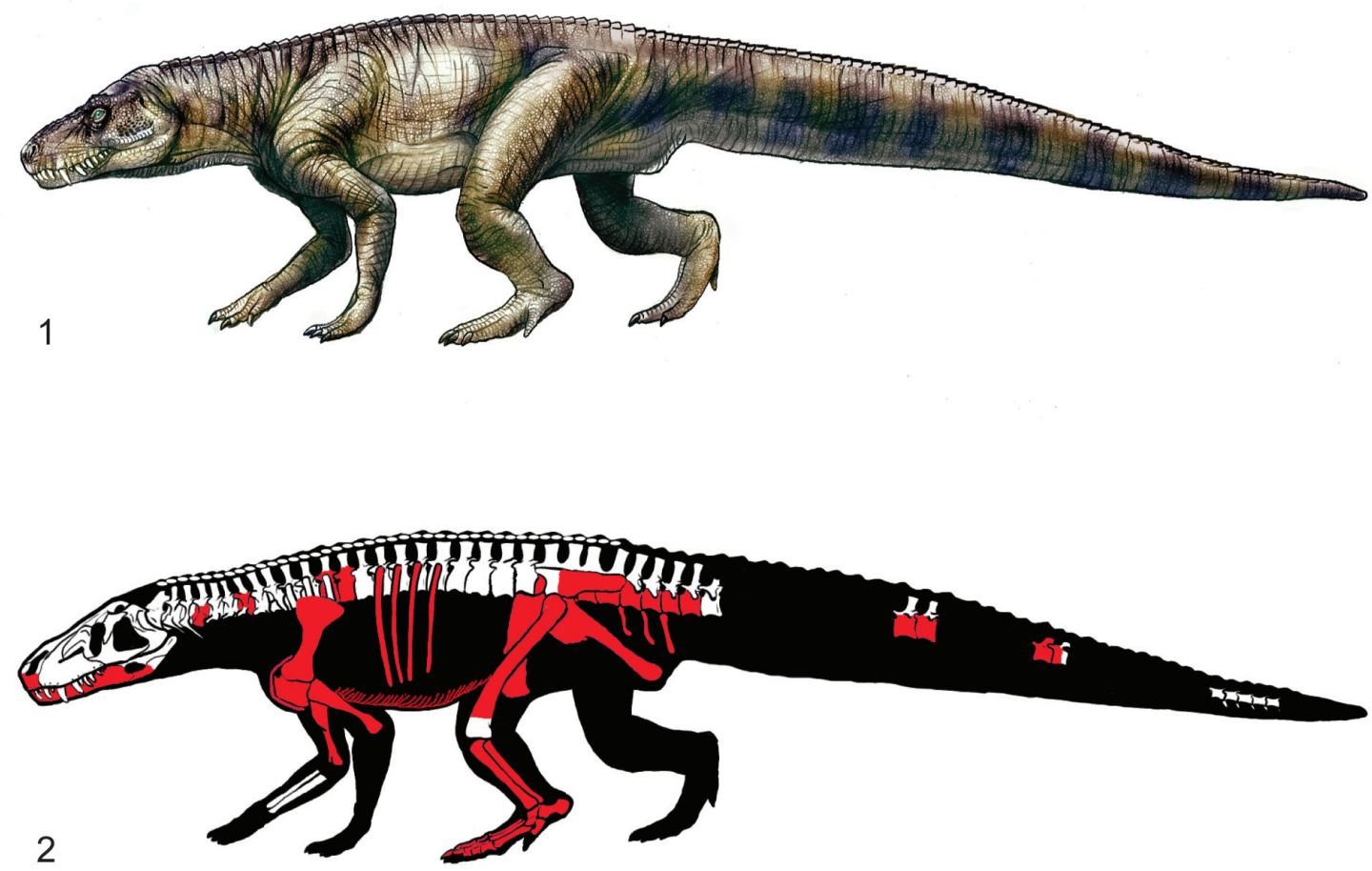

FIGURE 3. Life reconstruction (1) and preserved bones (2) of Prestosuchus chiniquensis. In red the holotype material and in white the referred material known. Drawn by Jorge Gonzales..

et al., 2011). As a result, the underlying Los Rastros Formation must be considered as early or middle Carnian in age. Thus, the Chañares Formation should be Ladinian or earliest Carnian in age, as was suggested by several authors based on the faunistic assemblage (e.g., Desojo et al., 2011) and radioisotopic information (Marsicano et al., 2015; Ezcurra et al., 2017). Accordingly, the Dinodontosaurus AZ of the Pinheiros-Chiniquá Sequence (=Santa Maria Sequence 1) would also be constrained to the late Ladinian-earliest Carnian time span (Melo et al., 2017; Schmitt et al., 2019).

\section{MATERIALS AND METHODS}

The present study deals primarily with the materials described as Prestosuchus chiniquensis n. gen. n. sp. by von Huene $(1938,1942)$. von Huene described two specimens under this name, a partial premaxilla and mandible and partial postcranial skeleton, and an isolated, but articulated sacrum, ilium, and osteoderms (Figure 3). As von Huene did not designate a holotype within this material, the more complete specimen was designated as lectotype by Krebs (1976). All of this material is housed in the Bayerische Staatssammlung für Paläontologie und Geologie in Munich.
Two of the authors (JBD and MBvB) have furthermore studied most of the more recently referred specimens first hand for comparisons.

In the present study, we scored most of the specimens previously assigned to Prestosuchus separately: the lectotype and paralectoptype of Prestosuchus chiniquensis, paralectotype of Prestosuchus loricatus, UFRGS-PV-0152-T, 0156-T, and CPEZ-239b. A few specimens were not considered in this analysis because they are currently under study or have not been described in sufficient detail and could not be studied first hand (Prestosuchus loricatus lectotype: SNSB-BSPG AS XXV 13-24/26-27 and 44-48; Prestosuchus chiniquensis: UFRGS-PV-0629-T, ULBRA-PVT281; Procerosuchus celer). After a preliminary analysis, the specimens of lectotype and paralectotype of Prestosuchus chiniquensis were combined into a single OTU named "P. chiniquensis type series" because both specimens were found in a basal polytomy within Prestosuchidae, which also included the lectotype of Prestosuchus chiniquensis. As these specimens were found in the same geographic and stratigraphic location ("Weg Sanga" + "Cynodontier Sanga") and are basically indistinguishable in the comparable characters, it seems thus very likely that they represent the 
same taxon. The specimens UFRGS-PV-0152-T, 0156-T, and CPEZ-239b were not included in "P. chiniquensis type series" because these have a different geographic and stratigraphic provenance (Vale Verde, Pascual Sanga, and Baum Sanga, respectively; Raugust, 2014) and were tentatively assigned to Prestosuchus chiniquensis, but without detailed justification (Barberena,1978; Nesbitt, 2011; Lacerda et al., 2016; Roberto-da-Silva et al., 2018). The data matrix used in this study was modified from Nesbitt and Desojo (2017), because the latter focused on Paracrocodylomorpha and included a well-sampled "Rauisuchia", which was crucial for exploring the affinities of basal loricatans, such as Prestosuchus, Saurosuchus, and Luperosuchus. We scored Stagonosuchus nyassicus, and the paralectotype of Prestosuchus chiniquensis based on first-hand observations, and added from previous data matrixes the pseudosuchians Mandasuchus tanyauchen (Butler et al., 2018), Pagosvenator candelariensis (Lacerda et al., 2018), Venaticosuchus rusconii (von Baczko et al., 2014), and the aphanosaurs Teleocrater rhadinus, Dongusuchus efremovi, and Yarasuchus deccanensis (Nesbitt et al., 2018). Moreover, seven new characters were included in the data matrix (Appendix 1) and several character states were modified based on direct observations (Appendix 2). The final data matrix included 422 characters and 97 taxa, but was reduced to 92 taxa after the replacement of the individual specimens of von Huene by " $P$. chiniquensis type series" and the removal of a few other OTUs as detailed below. The matrix was scored in Mesquite (Maddison and Maddison, 2018) and analyzed with TNT (Version 1.5) under maximum parsimony criteria. The dataset was analyzed using equally weighted parsimony in TNT (Goloboff et al., 2008a, 2008b) through a heuristic search of 1000 replicates of Wagner trees followed by TBR branch swapping.

In the present study we excluded a priori the following OTUs according to the protocol of Nesbitt and Desojo (2017): Archosaurus rossicus, Lewisuchus admixtus and Pseudolagosuchus major, with the latter two having been combined in a single OTU "Lewisuchus-Pseudolagosuchus", as these taxa are considered to by synonyms (Nesbitt, 2011; Ezcurra et al., 2019).

\section{Institutional Abbreviations}

CPEZ, Coleção de Paleontologia do Museu Paleontológico e Arqueológico Walter Ilha, São Pedro do Sul, Brazil; GPIT, Institut und Museum für Geologie und Paläontologie, Universität Tübingen, Ger- many; MCN, Museu de Ciencias Naturais Fundação Zoobotanica do Rio Grande do Sul, Porto Alegre, Brazil; PIMUZ, Paläontologisches Institut und Museum der Universität Zürich; PVL, Paleontología de Vertebrados, Instituto "Miguel Lillo", San Miguel de Tucumán, Argentina; PVSJ, División de Paleontología de Vertebrados del Museo de Ciencias Naturales y Universidad Nacional de San Juan, San Juan, Argentina; SMNS, Staatliches Museum für Naturkunde, Stuttgart, Germany; SNSB-BSPG, Staatliche Naturwissenschaftliche Sammlungen Bayerns, Bayerische Staatssammlung für Paläontologie und Geologie, Munich, Germany; TTUP, Texas Tech University Museum, Lubbock, Texas, USA; UFRGS-PV, Laboratório de Paleovertebrados, Universidade Federal do Rio Grande do Sul, Porto Alegre, Brazil; ULBRA-PVT, Paleovertebrate Collection of the Universidade Luterana do Brasil, Canoas, Rio Grande do Sul, Brazil; ZPAL, Institute of Paleobiology, Polish Academy of Sciences, Warsaw, Poland.

\section{SYSTEMATIC PALAEONTOLOGY}

\author{
ARCHOSAURIA Cope, 1869 sensu Gauthier and \\ Padian, 1985 \\ PSEUDOSUCHIA Zittel, 1887-1890 sensu \\ Gauthier and Padian, 1985 \\ PARACROCODYLOMORPHA Parrish 1993 sensu \\ Nesbitt, 2011 \\ PRESTOSUCHIDAE Romer, 1966 sensu Nesbitt \\ et al., 2013a \\ PRESTOSUCHUS von Huene, 1938
}

Type species. Prestosuchus chiniquensis von Huene, 1938

Revised diagnosis. The genus Prestosuchus can be defined by the following combination of characters (autapomorphies are noted with ${ }^{*}$ ): presacral vertebrae short and high, ratio length/height being between 0.75 and 1 ; unfused sacral neural spines, but interlocking and posteriorly inclined; absence of a vertical crest dorsal to the supracetabular rim*; dorsal margin of postacetabular part of ilium con-

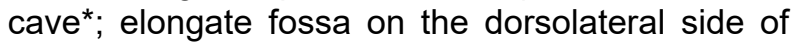
the proximal ischium, defining a dorsal crest on the bone; marked angle between pubic peduncle/obturator plate and ischial shaft*; elongate posteromedial depression on the distal fibula*.

Prestosuchus nyassicus (von Huene, 1939), comb. nov.

Lectotype. GPIT/RE/3831/1-21, right articular and fragmentary postcranial skeleton, including verte- 
brae from all parts of the vertebral column, partial pectoral girdle, partial pelvic girdle, partial fibula.

Paralectotype. GPIT/RE/3832/1-15, probable jugal, sacral and caudal vertebrae, humerus, largely complete pelvic girdle, proximal tibiae.

Horizon and age. Uppermost level of the upper bonebed of the Manda Beds, Anisian, Middle Triassic.

Type locality. Njalila locality, northwestern slope of the Lihandje Mountains, east of Lake Malawi (Lake Nyasa), southwestern Tanzania.

\section{Diagnosis}

Prestosuchus nyassicus differs from Prestosuchus chiniquensis in the following derived characters (modified from Lautenschlager and Desojo, 2011): eighth cervical vertebra with additional infrapre- and infrapostzygapophyseal laminae; postacetabular process of the ilium with a pronounced, boss-like lateral protuberance; dorsolateral crest of the ischium short; round protuberances on the midline of the ventral ischial contact.

\section{Remarks}

In 1939, von Huene described two fragmentary skeletons from the uppermost part of the Manda Beds of the Ruhuhu basin of Tanzania as a new taxon of "thecodont", Stagonosuchus nyassicus. First thought to be a stagonolepid (aetosaur), the taxon was later referred to the Rauisuchidae (von Huene, 1956), but received surprisingly little attention until recently. However, Gebauer (2004) presented a revision of Stagonosuchus nyassicus, redescribing all of the material and presenting several new interpretations of the elements described by von Huene (1939). Recently, Lautenschlager and Desojo (2011) offered additional observations and comments, including a revised diagnosis that included autapomorphic characters of the taxon (see diagnosis).

On the basis of these new data, we evaluated the phylogenetic position of Stagonosuchus nyassicus and found it to be most closely related to the type series of Prestosuchus chiniquensis (see below). As both taxa share numerous, largely apomorphic characters on generic level (see diagnosis of genus), we propose to refer both species to the same genus, Prestosuchus. However, as Prestosuchus nyassicus shows a number of apomorphic characters not seen in Prestosuchus chiniquensis, we retain both taxa as separate species.

A single skull element found with the material was interpreted as a postfrontal by von Huene (1939), but the triradiate shape of this element is unlike any postfrontal found in other archosauromophs (see Nesbitt, 2011). Gebauer (2004) suggested that this element might be a postorbital, which would be more consistent with the triradiate shape. However, there are significant differences with other pseudosuchian postorbitals, in which especially the ventral ramus is usually considerably longer than the other processes, and the ventral ramus and the orbital rim are thickened. Thus, we here tentatively suggest that the element in question might be a partial jugal, but more detailed comparisons would be necessary to clarify its identity.

Prestosuchus chiniquensis von Huene, 1938

1938 Prestosuchus chiniquensis n. g. n. sp.; von Huene: 146-147

1942 Prestosuchus chiniquensis n. g. n. sp.; von Huene: 161-185

non 1942 Prestosuchus chiniquensis (?); von Huene: 185 (Archosauria indet.)

1976 Prestosuchus chiniquensis v. Huene; Krebs: 76

1981 Prestosuchus chiniquensis Huene; Bonaparte: 58-101.

1993 Prestosuchus Huene; Parrish: 296-297; partim

1999 Prestosuchus chiniquensis; Kischlat and Barberena: 53

2000 Prestosuchus; Gower: 450-466; partim

2000 Prestosuchus chiniquensis Huene; Kischlat: 290

2000 Karamuru vorax Kischlat and Barberena; Kischlat: 290-291; nomen nudum

2005 Prestosuchus; Nesbitt: 19-47; partim

2010 Prestosuchus; Brusatte et al.: 222-230; partim

Lectotype. SNSB-BSPG AS XXV 1-3, 5-11, 2841 , and 49, an incomplete postcranial skeleton, anterior part of the lower jaw, right premaxilla, and palatal process of the maxilla.

Paralectotype. SNSB-BSPG AS XXV 7, an incomplete sacrum, right ilium, part of the last dorsal vertebra, and some sacral osteoderms.

Horizon and age. Base of the Santa Maria Formation; Pinheiros-Chiniquá Sequence, probably late Middle-early Late Triassic, Dinodontosaurus AZ.

Type locality. "Weg Sanga", Chiniquá palaeontological site, c. $50 \mathrm{~km}$ west of the city of Santa Maria, Rio Grande do Sul, Brazil.

\section{Revised Differential Diagnosis}

On the basis of the type specimen, Prestosuchus chiniquensis can be distinguished from all other pseudosuchians by the combination of the following characters (autapomorphies noted with 
asterisk): splenial extends to the level of the anterior margin of the second dentary tooth anteriorly; ventral process of the dentary short and arrowshaped, delimiting the anterior third of the external mandibular fenestra; cervical vertebrae with strongly pronounced ventral keel; pronounced, oval incision anterodorsally in the coracoid-scapula suture; low, rounded, anteroventrally projected keel on the lateral surface of the coracoid; pubes with only slight anteroposterior expansion distally; marked dorsal longitudinal depression delimited by a medial crest on the proximal ischium; small distal incision between ischial obturator plate and ischial shaft*; fibula with elongate depression on the posteromedial side distally; pronounced, deep pit on the ventral side of the calcaneal tuber.

\section{Comments}

In contrast to Kischlat and Barberena (1999) and Kischlat (2000), the paralectotype sacrum and ilium is here considered to represent Prestosuchus chiniquensis, since there are no notable differences between this material and the type sacrum and ilium. Kischlat and Barberena (1999) removed this material from Prestosuchus chiniquensis because they noted that the osteoderms included in this specimen are indistinguishable from those of UFRGS-PV-0156-T, which they considered to be distinct from Prestosuchus. However, the supposed differences between Prestosuchus chiniquensis and UFRGS-PV-0156-T noted by Kischlat, 2000, p. 291 could not be confirmed by a detailed comparison of the two specimens by us, and the overlapping elements of both specimens are virtually indistinguishable, including characters used in the diagnosis here, such as the especially strongly keeled cervical vertebrae. The holotype of Procerosuchus celer (SNSB-BSPG AS XXV 131139) was referred to Prestosuchus chiniquensis by Desojo and Rauhut (2008), because it shares the oval incision between coracoid and scapula with the type of Prestosuchus chiniquensis. However, the phylogenetic analysis presented here (see below) failed to place Procerosuchus celer with Prestosuchus chiniquensis. Instead, the former is found in a number of positions within Prestosuchidae and, in some trees, even outside this clade, though phylogenetically close.

The holotype specimen of Prestosuchus loricatus does not share any derived characters with Prestosuchus chiniquensis but differs in many important aspects from the lectotype of the latter, including the morphology of the ischia and calcaneum, and also from material referred to Prestosu- chus chiniquensis in basically all anatomical structures that can be compared (Desojo and Rauhut, 2008). Thus, Prestosuchus loricatus is here removed from the genus Prestosuchus, and the material will be described and revised in detail elsewhere (Desojo et al., personal commun. 2019).

$A$ rather high number of other specimens were referred to Prestosuchus chiniquensis by previous authors: UFRGS-PV-0156-T, a huge complete articulated skull and 31 vertebrates (cervical, dorsal, sacral, and caudals, many with articulated dorsal osteoderms) (Barberena, 1978; Azevedo, 1991) (Figure 3.2 white bones); UFRGS-PV-0629$\mathrm{T}$, almost complete skeleton, comprising a disarticulated skull, complete presacral vertebrae sequence, two sacral and three caudal vertebrae, complete scapular and pelvic girdle, mostly complete appendicular elements, both humeri, parcial left ulna and radius, one left metacarpal of a manus, both femora, a right tibia and fibula, and three isolated phalanges of a pes (Mastrantonio, 2010; Mastrantonio et al., 2013, 2019); UFRGSPV-0473-T, an isolated braincase (Mastrantonio et al., 2013); UFRGS-PV-0152-T, an incomplete skull, vertebral sequence (cervical, dorsal, sacral and caudal elements), complete scapular and pelvic girdles, humerus, proximal portion of an ulna, femora, tibiae and fibulae, complete calcaneum and pes, chevrons and osteoderm cover (Nesbitt, 2011. p. 33; Raugust, 2014); CPEZ-239b, incomplete cranial and postcranial skeleton of at least two individuals (Lacerda et al., 2016); ULBRA-PVT-281, a large, complete skull and a partial postcranial skeleton (Roberto-da-Silva et al., 2016, 2018); MCP146, a pelvic girdle with the last dorsal, two sacral, and three caudal vertebrae preserved in articulation (referred by Bonaparte, 1984); MCZ 4167, composed of a poorly preserved but articulated specimen from the Santa Maria Formation, referable to Prestosuchus, but no other information is available on this specimen (see Lacerda et al., 2016; Parrish, 1993, p. 297). Our phylogenetic analysis confirmed that at least the specimens UFRGS-PV-0152-T, UFRGS-PV-0156-T and CPEZ-239b represent the genus Prestosuchus, but as the former specimen was found to lie outside the node combining Prestosuchus chiniquensis and Prestosuchus nyassicus, the species taxonomy of this genus might be more complex than previously recognized (see discussion).

\section{Description}

Skull and mandible. The skull is only known from a few fragmentary and incomplete elements, 


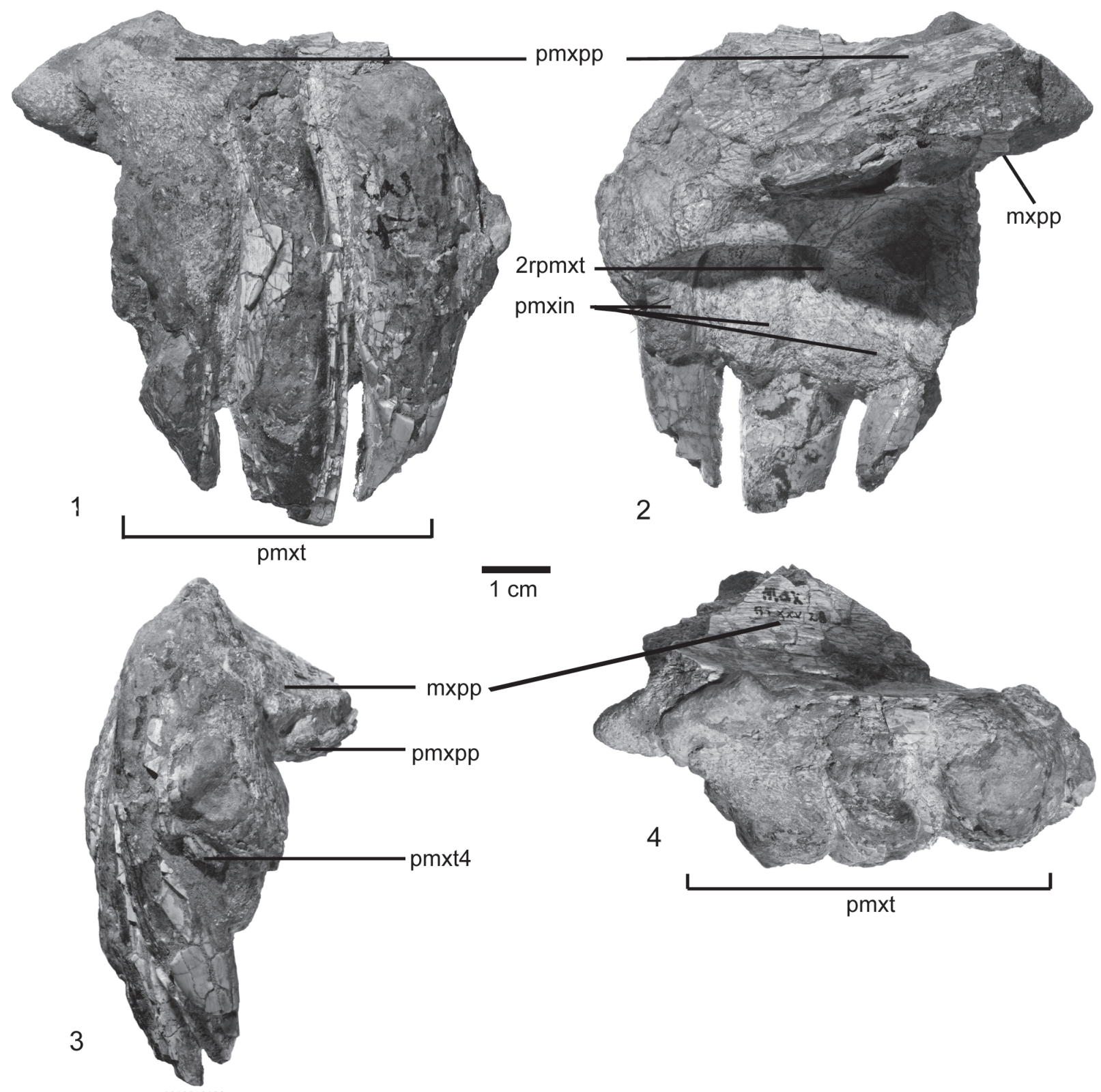

FIGURE 4. Skull material of the lectotype of Prestosuchus chiniquensis SNSB-BSPG AS XXV 28. 1-4, Right premaxilla (SNSB-BSPG AS XXV 28) in 1, lateral; 2, medial; 3, anterior; and 4, dorsal views. Abbreviations: mxpp, maxillary palatal process; pmxpp, premaxillary palatal process; pmxin, premaxillary interdental plate; pmxt, premaxillary teeth; pmxt4, premaxillary tooth number 4; 2rpmxt, replacement premaxillary tooth. Scale bar equals $1 \mathrm{~cm}$.

including the incomplete right premaxilla, and a fragment of the palatal process of the right maxilla (Figure 4.1-4) of the type specimen SNSB-BSPG AS XXV 28. Only the main body of the premaxilla is preserved in medial view (Figure 4.2), the anterior and posterior processes are unknown, and the lateral surface is broken (Figure 4.1). The premaxillary body is quadrangular, as long as high, with a concave ventral margin in lateral view (Table 1), resembling the condition in Saurosuchus galilei
(PVSJ 32), but contrasting with a longer than high subrectangular shape in Rauisuchus tiradentes (SNSB-BSPG AS XXV 60), Batrachotomus kupferzellensis (SNMS 52970), Polonosuchus silesiacus (ZPAL Ab III 563), and Fasolasuchus tenax (PVL 3050). Decuriasuchus quartacolonia presents both conditions, probably because of postmortem distortion of the material (Nesbitt and Desojo, 2017). The palatal process is located at the mid-height of the medial surface, and originates at the level of 
TABLE 1. Measurements (in $\mathrm{mm}$ ) of selected elements of the lectotype and paralectotype materials of Prestosuchus chiniquensis. Asterisk indicates incomplete elements, na: not applicable.

\begin{tabular}{|c|c|c|}
\hline & $\begin{array}{c}\text { Prestosuchus } \\
\text { chiniquensis } \\
\text { Lectotype BSPG AS XXV }\end{array}$ & $\begin{array}{c}\text { Prestosuchus } \\
\text { chiniquensis } \\
\text { Paralectotype XXV } 7\end{array}$ \\
\hline Premaxilla body length & $76.6^{*}$ & \\
\hline Premaxilla body height & $44.8^{*}$ & \\
\hline Larger premaxillar tooth height & $49.2^{*}$ & \\
\hline Larger premaxillar tooth length at base & 16.8 & \\
\hline Lower jaw length & $490^{*}$ & \\
\hline Dentary length & $407^{*}$ & \\
\hline Dentary anterior height & 49.9 & \\
\hline Dentary anterior tooth height & $21.4^{*}$ & \\
\hline Dentary anterior crown height & na & \\
\hline Dentary anterior crown labiolingual width & 10.8 & \\
\hline Dentary anterior root height & na & \\
\hline Dentary largest crown height & na & \\
\hline Dentary largest crown length at base & na & \\
\hline Splenial length & 430 & \\
\hline Splenial height & na & \\
\hline Surangular height & na & \\
\hline Surangular+retroarticular process length & na & \\
\hline Angular length & $180.2^{*}$ & \\
\hline Angular height & 49.8 & \\
\hline Prearticular length & na & \\
\hline Prearticular minimum height & na & \\
\hline Prearticular maximum posterior width & na & \\
\hline External mandibular fenestra length & $83.3^{*}$ & \\
\hline External mandibular fenestra height & na & \\
\hline Retroarticular process length & na & \\
\hline Retroarticular process width & na & \\
\hline Retroarticular process height & na & \\
\hline Lower jaw maximum posterior width & na & \\
\hline 6th cervical centrum anteroposterior length & 52.6 & \\
\hline 7th cervical centrum anteroposterior length & 44.5 * & \\
\hline Dorsal centrum anteroposterior length & $50^{*}$ & \\
\hline 6th cervical dorsoventral height & 69.3 & \\
\hline 7th cervical dorsoventral height & $58.1^{*}$ & \\
\hline Dorsal centrum dorsoventral height & $62.6^{*}$ & \\
\hline 6th cervical lateromedial width & $61.4^{*}$ & \\
\hline 7th cervical lateromedial width & $40.6^{*}$ & \\
\hline Dorsal centrum lateromedial width & $62.2^{*}$ & \\
\hline Anterior neural spine dorsoventral height & & 112 \\
\hline Neural spine 1 sacral dorsoventral height & & 114 \\
\hline Neural spine 2 sacral dorsoventral height & & 123 \\
\hline Posterior neural spine dorsoventral height & 420 & \\
\hline Neural 1 sacral spine anteroposterior length & 50 & 52.2 \\
\hline
\end{tabular}


TABLE 1 (continued).

\begin{tabular}{|c|c|c|}
\hline & $\begin{array}{c}\text { Prestosuchus } \\
\text { chiniquensis } \\
\text { Lectotype BSPG AS XXV }\end{array}$ & $\begin{array}{c}\text { Prestosuchus } \\
\text { chiniquensis } \\
\text { Paralectotype XXV } 7\end{array}$ \\
\hline Neural 2 sacral spine anteroposterior length & 81.6 & 54.8 \\
\hline Neural dorsal spine anteroposterior length & 113.1 & 44.4 \\
\hline Neural spine anteroposterior length & 196 & \\
\hline Dorsal rib length & 155 & \\
\hline Tuberculum length & $67.2^{*}$ & \\
\hline Chevron length BSPG AS XXV 32 & & 77.4 \\
\hline Chevron length BSPG AS XXV 3b 1 & 68.1 & 70.6 \\
\hline Chevron length BSPG AS XXV 3b 2 & 57.1 & \\
\hline Chevron length BSPG AS XXV 3b 3 & 55.8 & \\
\hline Chevron length BSPG AS XXV 3b 4 & 50.6 & \\
\hline 1st sacral centrum anteroposterior length & 44.8 & \\
\hline 2nd sacral centrum anteroposterior length & 40.5 & \\
\hline 1st caudal centrum anteroposterior length & 40.2 & \\
\hline 2nd caudal centrum anteroposterior length & & $70^{*}$ \\
\hline 3rd caudal centrum anteroposterior length & 60.8 & $56.8^{*}$ \\
\hline 4th caudal centrum anteroposterior length & $60.6^{*}$ & \\
\hline 5th caudal centrum anteroposterior length & 69.8 & \\
\hline 6th caudal centrum anteroposterior length & 67.4 & \\
\hline 1st sacral centrum dorsoventral height & 65.2 & \\
\hline 2nd sacral centrum dorsoventral height & 63.2 & \\
\hline 1st caudal centrum dorsoventral height & 60.9 & \\
\hline 2nd caudal centrum dorsoventral height & 69.2 & \\
\hline 3rd caudal centrum dorsoventral height & 70.2 & \\
\hline 4th caudal centrum dorsoventral height & 73.4 & \\
\hline 5th caudal centrum dorsoventral height & 69.4 & \\
\hline 6th caudal centrum dorsoventral height & 65.8 & \\
\hline 2nd sacral lateromedial width & 60.4 & \\
\hline 1st caudal lateromedial width & 55.4 & \\
\hline Iliac blade length & $220^{*}$ & $295^{*}$ \\
\hline Iliac blade dorsoventral height & 69 & 71.7 \\
\hline Anterior iliac process length & & $30.6^{*}$ \\
\hline Posterior iliac process length & 120 & 134.4 \\
\hline Left ischium dorsal length & 345 & \\
\hline Right ischium dorsal length & $320^{*}$ & \\
\hline Height distal ischium end & 53.6 & \\
\hline Left ischium surface for ilium articulation length & 103.8 & \\
\hline Proximal ischium blade length & 45 & \\
\hline Right pubis length & $292^{*}$ & \\
\hline Left pubis length & $239^{*}$ & \\
\hline Left pubis distal end, anteroposterior length & 671 & \\
\hline Right pubis distal end, anteroposterior length & 673 & \\
\hline Left pubis distal end, lateromedial width & 633 & \\
\hline Right pubis distal end, lateromedial width & 620 & \\
\hline
\end{tabular}


TABLE 1 (continued).

\begin{tabular}{|c|c|c|}
\hline & $\begin{array}{c}\text { Prestosuchus } \\
\text { chiniquensis } \\
\text { Lectotype BSPG AS XXV }\end{array}$ & $\begin{array}{c}\text { Prestosuchus } \\
\text { chiniquensis } \\
\text { Paralectotype XXV } 7\end{array}$ \\
\hline Left femur length & 443 & \\
\hline Proximal left femur lateromedial width & 50 & \\
\hline Proximal left femur anteroposterior length & 121.8 & \\
\hline Distal left femur width & 134.7 & \\
\hline Distal left femur length & $61.6^{*}$ & \\
\hline Left femur mid-shaft diameter & 185 & \\
\hline Left scapula length & $280^{*}$ & \\
\hline Right scapula length & $320^{*}$ & \\
\hline Left proximal scapula width & 122 & \\
\hline Right proximal scapula width & $120^{*}$ & \\
\hline Left coracoid length & 230 & \\
\hline Right coracoid length & 200 & \\
\hline Left coracoid dorsoventral width & 120 & \\
\hline Right coracoid width & 122 & \\
\hline Left clavicle length & 198 & \\
\hline Right clavicle length & $135^{*}$ & \\
\hline Interclavicle length & 250 & \\
\hline Interclavicle distal width & 58 & \\
\hline Left humerus proximal width & 128 & \\
\hline Right humerus proximal width & $114.4^{*}$ & \\
\hline Length left humerus head & 51.8 & \\
\hline Lengh right humerus head & $39.2^{*}$ & \\
\hline Left deltopectoral crest length & 55 & \\
\hline Right deltopectoral crest length & $71.8^{*}$ & \\
\hline Left humerus length & $87.4^{*}$ & \\
\hline Right humerus length & $320^{*}$ & \\
\hline Humerus mid-shaft diameter & 140 & \\
\hline Tibia length & 309 & \\
\hline Proximal tibia lateromedial width & 74.2 & \\
\hline Proximal tibia anteroposterior length & 116.6 & \\
\hline Distal tibia width & 43.1 & \\
\hline Distal tibia length & 90.6 & \\
\hline Tibia mid-shaft diameter & 137 & \\
\hline Fibula length & 310 & \\
\hline Proximal fibula lateromedial width & 351 & \\
\hline Proximal fibula anteroposterior length & 567 & \\
\hline Distal fibula width & 420 & \\
\hline Distal fibula length & 581 & \\
\hline Fibula mid-shaft diameter & 105 & \\
\hline Humerus mid-shaft diameter & 140 & \\
\hline Left astragalus width & 124 & \\
\hline Left astragalus length & 61.4 & \\
\hline Left calcaneum width & 83.2 & \\
\hline
\end{tabular}


Desojo, von BAczKo, \& RaUhut: Type materials of PREstosuchus

TABLE 1 (continued).

\begin{tabular}{|c|c|c|}
\hline & $\begin{array}{c}\text { Prestosuchus } \\
\text { chiniquensis } \\
\text { Lectotype BSPG AS XXV }\end{array}$ & $\begin{array}{c}\text { Prestosuchus } \\
\text { chiniquensis } \\
\text { Paralectotype XXV } 7\end{array}$ \\
\hline Left calcaneum length & 74.2 & \\
\hline Left calcaneal tuber length & 31.2 & \\
\hline Left calcaneal tuber width & 59.2 & \\
\hline Left calcaneal tuber height & 58.9 & \\
\hline Left calcaneal shaft length & 47.8 & \\
\hline Left calcaneal shaft height & 48.2 & \\
\hline Metatarsal I length & 99.2 & \\
\hline Metatarsal I proximal width & 56.4 & \\
\hline Metatarsal I proximal height & 17.4 & \\
\hline Metatarsal I distal width & 40.6 & \\
\hline Metatarsal I distal height & 22.8 & \\
\hline Metatarsal I mid-shaft diameter & 73 & \\
\hline Metatarsal II length & 124.2 & \\
\hline Metatarsal II proximal width & 66.1 & \\
\hline Metatarsal II proximal height & 27.8 & \\
\hline Metatarsal II distal width & 39.8 & \\
\hline Metatarsal II distal height & 22.4 & \\
\hline Metatarsal II mid-shaft diameter & 70 & \\
\hline Metatarsal III length & 139 & \\
\hline Metatarsal III proximal width & 67.6 & \\
\hline Metatarsal III proximal height & 19 & \\
\hline Metatarsal III distal width & 34 & \\
\hline Metatarsal III distal height & 20.8 & \\
\hline Metatarsal III mid-shaft diameter & 60 & \\
\hline Metatarsal IV length & 135 & \\
\hline Metatarsal IV proximal width & 61.1 & \\
\hline Metatarsal IV proximal height & 19.4 & \\
\hline Metatarsal IV distal width & 30 & \\
\hline Metatarsal IV distal height & 20 & \\
\hline Metatarsal IV mid-shaft diameter & 70 & \\
\hline Metatarsal V length & 92.1 & \\
\hline Metatarsal V proximal width & 49.8 & \\
\hline Metatarsal V proximal height & 50.4 & \\
\hline Metatarsal V distal width & 27.8 & \\
\hline Metatarsal V distal height & 18 & \\
\hline Metatarsal $\vee$ mid-shaft diameter & 87 & \\
\hline
\end{tabular}

the anterior margin of the second tooth, like in UFRGS-PV-0629-T, Fasolasuchus tenax (PVL 3850), Batrachotomus kupferzellensis (SNMS 52970), and Saurosuchus galilei (PVSJ 32). It is dorsoventrally compressed, projects posteromedially, and is overlapped by the palatal process of the maxilla (Figure 4.4). There are three well-separated interdental plates on the medial side, as well as three poorly preserved teeth and remains of a fourth tooth (Figure 4.3), so that the original number of premaxillary teeth was four, as in the better preserved skull material of UFRGS-PV-0156-T, 0629- 
T, CPEZ-239b, and ULBRA-PVT-281. Furthermore, in medial view an isolated fragment of the tip of a tooth, and a replacement tooth between the 2nd and 3rd interdental plate are also preserved (Figure 4.2). In lateral view, most of the border of the alveoli is broken away, revealing the deep roots of the teeth, which almost reach to the dorsal border of the premaxilla, where it forms the ventral margin of the external nares (Figure 4.1). Only the stout, slightly anteroventrally directed anteromedial process of the maxilla is preserved in articulation with the palatal process of the premaxilla.

The anterior parts of the mandibles of Prestosuchus chiniquensis SNSB-BSPG ASXXV 1 are well preserved and show a wealth of detail (Figure 5). Both hemi-mandibles are anteriorly articulated and incompletely preserved (Table 1). The left hemi-mandible is almost complete up to the external mandibular fenestra, and the right element consists of an anterior portion with five incomplete teeth and seven alveoli (Figure 5.1-2). The mandible is low and long in general shape, with a very slight dorsoventral expansion at the level of the third tooth position (Figure 5.3-4). The mandible symphysis is long $(95.7 \mathrm{~mm})$, subequal in length to the length of the external mandibular fenestra (Table 1), and finishes at the level of the posterior margin of the fifth alveolus (Figure 5.1). Ventrolaterally, the symphysis is formed by the dentary and medially by the splenial (Figure 5.2), which is not possible to determine in the specimens UFRGSPV-0629-T, 0156-T. The dentary is long, with a straight ventral margin, and a rounded anterior end with a small, triangular process dorsally, resembling the condition in UFRGS-PV-0156-T. The anterior end is slightly broader than the posterior part. The dorsal margin of the bone slopes posterodorsally up to the level of the posterior end of the third alveolus, and it is slightly concave over the rest of the bone and towards the surangular. The tooth row extends to a point aproximately $60 \mathrm{~mm}$ anterior to the anterior margin of the external mandibular fenestra, although its exact extent cannot be determined with certainty, since the dorsal border is damaged in this area. Behind the tooth row, the dorsal margin of the surangular is narrow. In lateral view, the dorsal part of the posterior end of the dentary is broken, so nothing can be said about its contacts with the fragmentary anterior region of the surangular. The latter bone is only represented by the dorsoventrally high and transversely flat anterior process, strongly resembling the condition in UFRGS-PV-0629-T and UFRGS-PV-0156-T in these respects. Ventrally, a small incision in the posterior end of the dentary marks the anterior end of the external mandibular fenestra. Below this incision, there is a broad, triangular posterior process that overlaps the anterior end of the angular (Figure 5.3). The ventral margin of this process is convex and confluent with the ventral margin of the dentary. In lateral view, the dentary ventral process is short and arrow-shaped. It overlaps the angular and closely resembles the condition in UFRGS-PV0629-T and UFRGS-PV-0156-T, but contrasts with the longer ventral process of Batrachotomus kupferzellensis (SNMS 52970) and most other taxa. On the lateral side, a row of foramina is placed at approximately half height of the bone below the tooth row anteriorly. These foramina are more closely spaced in the anterior portion and become more widely spaced posteriorly. At the level of the 9th alveolus there is a ridge that leads to a foramen (Figure 5.3); behind this, no other foramina are found.

In medial view, there is a row of well-defined interdental plates that forms the medial border of the alveoli. The interdental plates are separated by narrow, parallel-sided incisions, pentagonal in shape and approximately as high as long in the anterior part; posteriorly, the bases of the interdental plates are largely covered by the splenial (Figure 5.4).

There are 14 alveoli in the left dentary, with a total of 11 teeth preserved, with different development states from the second to the thirteenth alveoli (Figure 5.1, 5.3). The tooth row is straight over most of its length, but the anteriormost tooth is slightly inset towards the mandibular symphysis. The alveoli rapidly increase in size from the first to the third, which is the largest tooth socket, and gradually decrease again posteriorly (Figure 5.1). Tooth replacement seems to be alternating, since replacement teeth are found in the $3^{\text {rd }}, 5^{\text {th }}, 7^{\text {th }}, 9^{\text {th }}$, $11^{\text {th }}$ and $13^{\text {th }}$ alveolus. The total number of dentary teeth is the same as in UFRGS-PV-0629-T; for the specimen UFRGS-PV-0156-T the tooth count is unknown because the mandibles are preserved in occlusion. The tooth count contrasts with a lower number of 11-12 dentary teeth in Batrachotomus kupferzellensis (SMNS 52970) and 13 in Fasolasuchus tenax (PVL 3851), and a higher number of 17 in Decuriasuchus quartacolonia (de França et al., 2013) and 15-16 in Postosuchus kirkpatricki (TTUP 9000) (Mastrantonio et al., 2019).

The angular is incompletely preserved. It is an anteroposteriorly elongate, low bone that forms the 

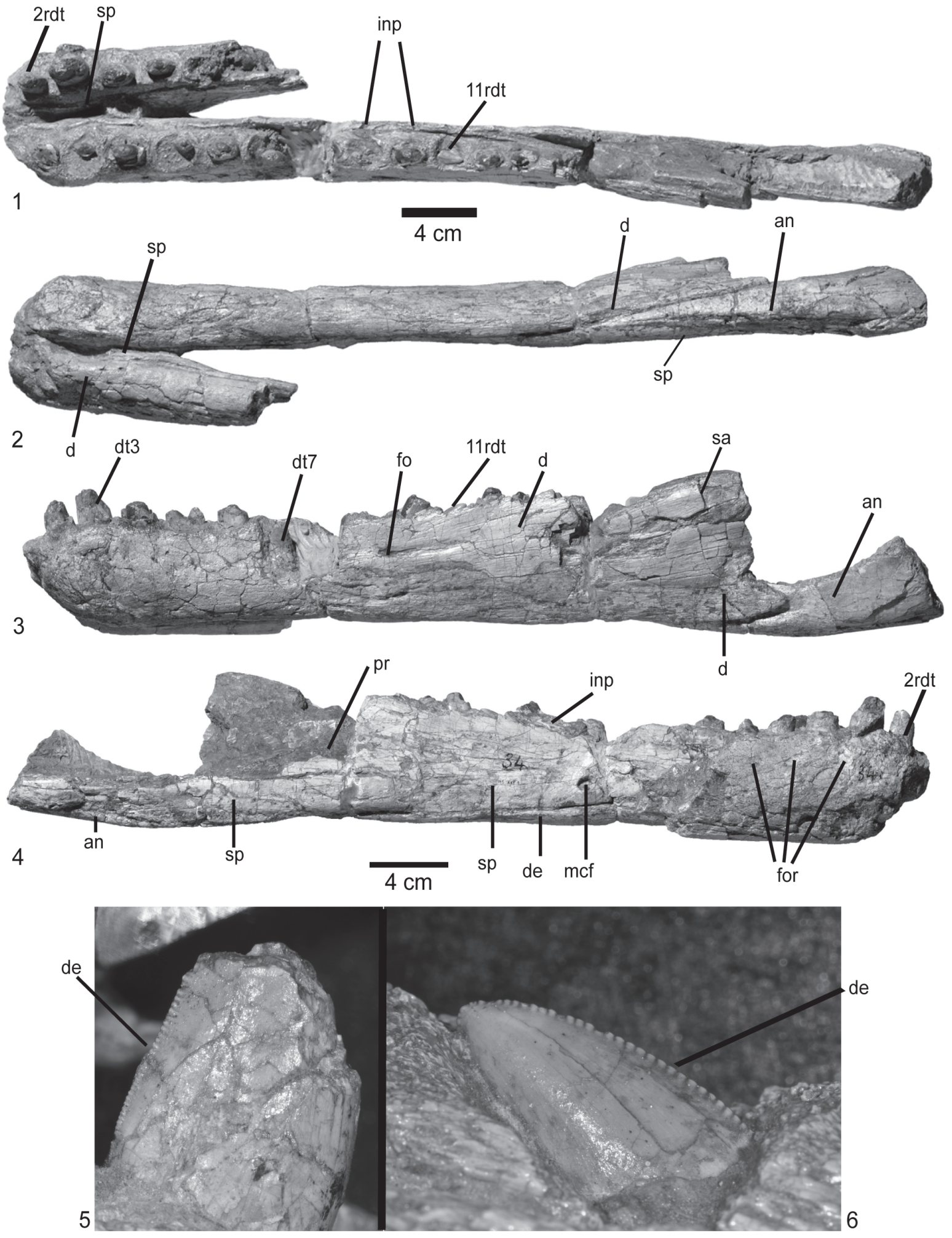

FIGURE 5. Lower jaw (SNSB-BSPG AS XXV 1) in 1, dorsal; 2, ventral; 3, lateral; and 4, medial views. 5, $2^{\text {nd }}$ replacement tooth detail; $\mathbf{6}, 11^{\text {th }}$ replacement tooth. Abbreviations: an, Angular; d, dentary; de, denticles; dt3, dentary tooth 3; dt7, dentary tooth 7; fo, foramen; for, foramina; inp, interdental plate; mcf, meckelian foramen; pr, prearticular; 2rdt, replacement dentary 2 tooth; $11 \mathrm{rdt}$, replacement dentary 11 tooth sa, surangular; sp, splenial. Scale bar equals $4 \mathrm{~cm}$. 
ventral margin of the external mandibular fenestra and the ventral margin of the lower jaw behind the dentary (Figure 5.2-4). At the level of the angular, the mandible bulges slightly ventrally, so that the ventral margin of this bone is convex anteroposteriorly. Towards the posterior break, the bone slightly expands dorsoventrally. The anterior end of the angular is wedged between the dentary and the splenial, resembling the condition in UFRGS-PV0156-T, 0629-T, and Decuriasuchus quartacolonia (MCN-PV10.105c).

In medial view, the splenial forms most of the medial wall of the preserved portion of the lower jaw (Figure 5.4). It is an elongate triangular, platelike bone, which bears a large, elongate oval foramen at the level of the ninth alveolus, close to the ventral suture with the dentary. Anteriorly, the splenial reaches the level of the anterior margin of the second alveolus, resembling the condition in UFRGS-PV-0629-T. Ventrally, the splenial is bordered by a ventromedial lamina of the dentary that obviously encloses the Meckelian canal. Posteriorly, the splenial is broken, but its continuation is indicated by an impression in the sediment infilling the cavity between the medial and lateral elements of the mandible that projects posteroventrally. Another impression dorsal to the splenial corresponds to the anterior end of the prearticular, which was slender and relatively low (Figure 5.4). It forms the ventromedial surface of the mandibular adductor fossa, as can be seen in UFRGS-PV-0629-T, Batrachotomus kupferzellensis (SMNS 80260), and Postosuchus kirkpatricki (TTUP 9000; Weinbaum, 2011).

Dentition. None of the functional teeth preserved in either the premaxilla or dentary are complete, and thus information on tooth shape and morphology largely relies on replacement teeth of the second tooth of the premaxilla (Figure 4.2), and the second right and eleventh left tooth of the dentary (Figure 5). The teeth are conical and labiolingually compressed, but stout. They are recurved posteriorly and have both mesial and distal serrations. The marginal denticles are chisel-shaped and restricted to the apical part on the mesial carina (Figure 5.5-6: de). In the eleventh dentary tooth the denticle size slightly decreases apically (10 mesial denticles per $5 \mathrm{~mm}$ to 13 more apically) and the second right dentary tooth shows 13 distal denticles per $5 \mathrm{~mm}$ (the mesial denticles are smaller at the base). The denticles are continuous over the apex of the crown, with one large denticle forming the apex. The tooth enamel is smooth and no grooves or wrinkles are found adjacent to the serrations.

Axial skeleton. The axial skeleton of the type specimen includes two incomplete and poorly preserved posterior cervical vertebrae, two dorsal vertebrae, two sacrals, and 12 caudal vertebrae (Figures 3, 6). In addition, the paralectotype preserves both sacrals and the first caudal vertebra.

The cervical region is represented by two incomplete, posteriorly smooth, amphi-platycoelous vertebrae. The incomplete cervical vertebra SNSB-BSPG AS XXV 29 consists of a short and high, spool-shaped centrum with an oval posterior articular facet that is slightly higher than wide, and the left diapophysis and parapophysis (Figure 6.13 ). The latter is located at the middle of the centrum height at its anterior margin and articulates with a proximal cervical rib head. On the lateral side of the centrum, a deep depression is located between the diapophysis and parapophysis (Figure 6.1-2: dd). Dorsally and posteriorly this depression is limited by the margins of the centrum and ventrally by a thin lamina of bone that extends from the parapophysis posteriorly to the posterior end of the centrum. The latter transverse lamina also limits a ventral depression between the lateroventral edge of the centrum and the ventral keel (Figure 6.1-2: vd), resembling a similar depression in the cervical centra 6 of UFRGS-PV-0156-T and CPEZ-239b (Lacerda et al., 2016). The laminae of both sides define an almost plain ventral side of the centrum, from which a deep ventral keel arises medially. This keel makes up approximately two-fifths of the height of the centrum. A posterior centrodiapophyseal lamina extends from the posterior margin of the left diapophysis to the centra.

The second cervical vertebra (SNSB-BSPG AS XXV 30) shows the dorsal halves of both articulated facets, the left prezygapophysis and diapophysis, and the postzygapophysis in an unnatural position. As in the other cervical, both articular surfaces are flat to very slightly concave. The neural canal is large and semioval in shape, with a straight ventral margin. The diapophysis is a stout, ventrolaterally directed process that is connected to the centrum by well-developed anterior and posterior centrodiapophyseal laminae. Between these laminae, ventral to the diapophyses, there is a deep depression, the infradiapophyseal fossa, resembling the condition in UFRGS-PV-156-T and CPEZ-239b, Rauisuchus tiradentes (SNSB-BSPG AS XXV 75), and Fasolasuchus tenax (PVL 3850). The prezygapophysis is connected to the centrum by a thin centroprezygapophyseal lamina and is 
supported ventrally by a very much stouter prezygodiapophyseal lamina that extends ventrolaterally and slightly posteriorly to the diapophysis. Between the centroprezygapophyseal, prezygodiapophyseal and anterior centrodiapophyseal laminae, a deep, dorsoventrally elongate, anterolaterally opening infraprezygapophyseal fossa is present, resembling the condition in the 8th cervical vertebra of UFRGS-156-T and Prestosuchus nyassicus (GPIT/ $\mathrm{RE} / 3831$ ). The prezygapophysis is much broader than long, with a flat, oval articular facet, that is only slightly inclined from the horizontal at an angle of approximately $15^{\circ}$. The general morphology of the cervical vertebral centra resembling that of Prestosuchus nyassicus (GPIT/RE/3831), Saurosuchus galilei, Fasolasuchus tenax, Batrachotomus kupferzellensis, Polonosuchus silesiacus, and Rauisuchus tiradentes (SNSB-BSPG AS XXV 75), with an anteroposteriorly short, keeled vertebral centrum, contrasting with longer vertebral centra (at least twice as long as high) in Arizonasaurus babbitti, Sillosuchus longicervix, and Effigia okeeffeae (Nesbitt, 2007).

Two incomplete anterior dorsal vertebrae of the lectotype are preserved in articulation (SNSBBSPG AS XXV 31). As in the cervicals, the centra are amphi-platycoelous. The ventral part of the centrum is not preserved in either of the vertebrae, so it cannot be said if a ventral keel was present. However, a deep lateral fossa is preserved posteroventral to the parapophysis in the more posterior vertebra, and both right parapophyses are preserved in articulation with the heads of the dorsal ribs (Figure 6.7). Although the diapophysis is not preserved completely, the lateral lamination of the vertebra is discernible in the more posterior vertebra. A stout and almost vertical posterior centrodiapophyseal lamina is present, as in Prestosuchus nyassicus (GPIT/RE/3831) and contrasting with Rauisuchus tiradentes, and fuses dorsally with the dorsal part of a similarly well-developed, steeply posterodorsally inclined paradiapophyseal lamina. The latter is present in the specimens ULBRA-PVT-281 (Roberto-da-Silva et al., 2018) and UFRGS-PV-0156-T. A well-developed centroprezygapophyseal lamina can also be identified, and an unusual, accessory lamina is present in the large, but shallow infraprezygapophyseal fossa, resembling the condition in the anterior dorsal vertebrae of UFRGS-156-T. This lamina extends from approximately half height of the paradiapophyseal lamina anterodorsally and meets the prezygapophysis ventrally between the centroprezygapophyseal and prezygodiapophyseal laminae. The infradia- pophyseal fossa is narrow, high triangular in shape, and deep, resembling the condition in UFRGS-0156-T, ULBRA-PTV-281, Rauisuchus tiradentes (SNSB-BSPG AS XXV 119), and Prestosuchus nyassicus (GPIT/RE/3831). There is a posterior depression on the lateral base of the broken postzygapophysis and centropostzygapophyseal lamina, also present in some dorsal vertebrae of Rauisuchus tiradentes (SNSB-BSPG AS XXV 77, $116,119)$. The right prezygapophysis is articulated with the previous postzygapophysis; both are wider than long and generally relatively short anteroposteriorly.

In the paralectotype of Prestosuchus chiniquesis (SNSB-BSPG AS XXV 7), large parts of the last dorsal vertebra are preserved in articulation with the sacrum, but the vertebra is poorly preserved (Figure 7.1-5), even though the articulation with the first sacral is seen in ventral view. The centrum is spool-shaped, and a massive attachment of an anterolateroventrally directed rib is present on the anterior end of the centrum. The neural spine is rectangular, more than twice as high as long and very slightly inclined posteriorly. The spine slightly overhangs the vertebral centrum posteriorly, and the relatively small postzygapophysis is positioned below its posterior base.

The general morphology, with spool-shaped centra, well-marked lateral fossae, paradiapopophyseal and anterior centrodiapophyseal laminae, resembles Batrachotomus kupferzellensis (SMNS 80300), Rauisuchus tiradentes (SNSB-BSPG AS XXV 112, 116), Postosuchus kirkpatricki, Saurosuchus galilei (PVSJ 32), Fasolasuchus tenax (PVL 3850), Prestosuchus nyassicus (GPIT/RE/3831), and Ticinosuchus ferox (PIMUZ 2817).

Only the second sacral vertebra is preserved in articulation with the ilium and the first caudal in the type specimen SNSB-BSPG AS XXV 3a (Figure 7.6-8), but two sacrals are preserved in articulation with the ilium, parts of the last dorsal and the first caudal vertebra in the paralectotype SNSBBSPG AS XXV 7 (Figure 7.1-5). Thus, the number of sacral vertebrae can be established as two, resembling the condition in Saurosuchus galilei (PVSJ 615), Prestosuchus nyassicus (GPIT/RE/ 3831), Ticinosuchus ferox (PIMUZ 2817), contrasting with three sacrals in Batrachotomus kupferzellensis (SMNS 80310) and Arizonasaurus babbitti (Nesbitt, 2005), and more in Sillosuchus longicervix (PVSJ 700) and Effigia okeeffeae (Nesbitt, 2007).

The vertebral centra of the sacrals are spoolshaped and approximately as high as long (Table 


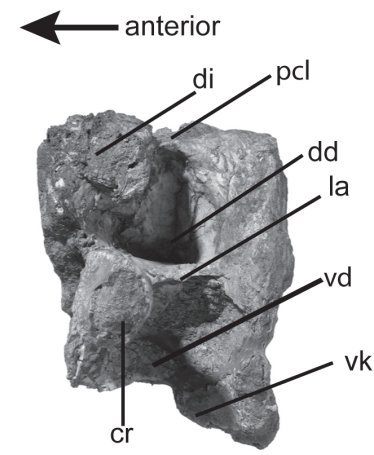

1

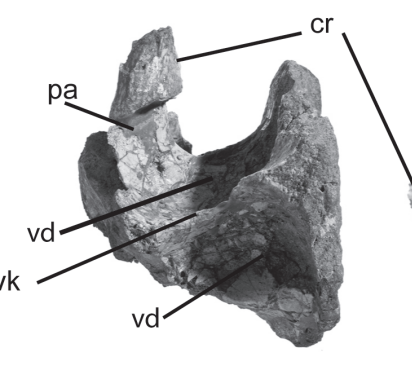

2

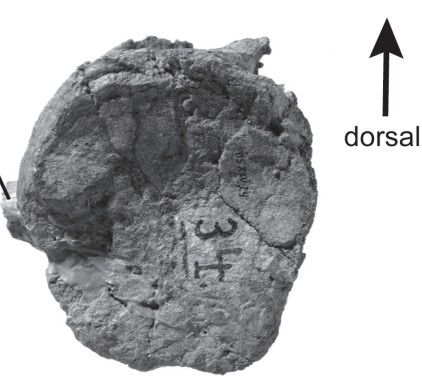

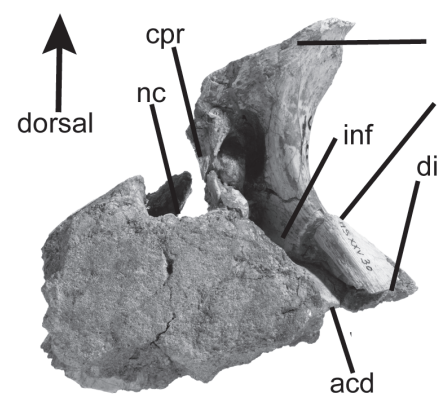

4
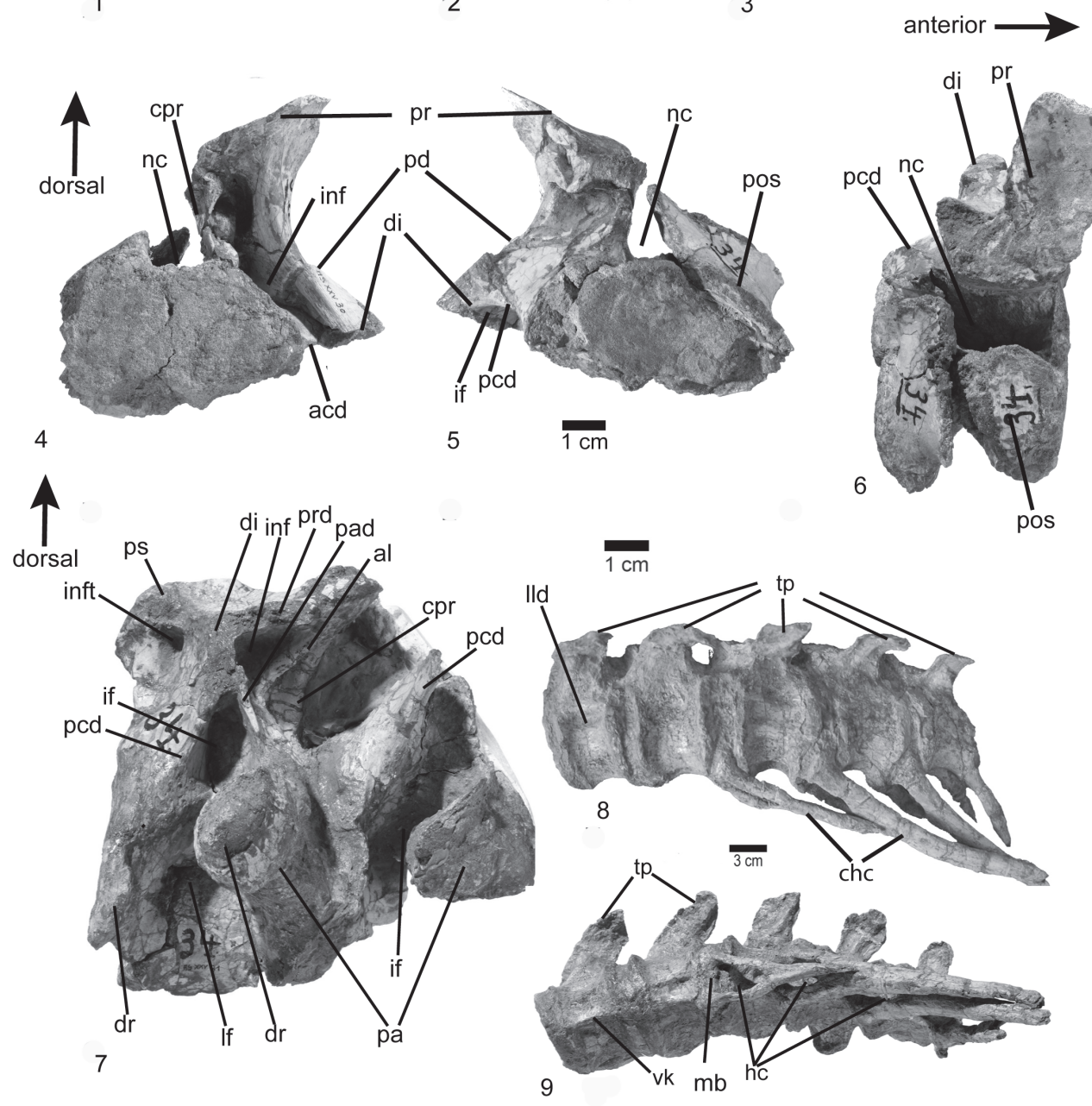

FIGURE 6. Vertebral material of the lectotype of Prestosuchus chiniquensis SNSB-BSPG AS XXV. 1-3, Anterior cervical vertebra (SNSB-BSPG AS XXV 29) in 1, left lateral; 2, ventral; and 3, posterior views. 4-6, Middle cervical vertebra (SNSB-BSPG AS XXV 30) in 4, anterior; 5, posterior; and 6, dorsal views. 7, Anterior dorsal vertebrae (SNSB-BSPG XXV 31) in left lateral view. 8-9, Anterior caudal vertebrae and chevrons (SNSB-BSPG AS XXV 3b) in 8, left lateral; and 9, ventral views. Abbreviations: acd, anterior centrodiapophyseal lamina; al, accessory lamina; chc, chevrons contact; cpr, centroprezygapophyseal lamina; cr, cervical rib; dd, deep depression; di, diapophysis; dr, dorsal rib; hc, hemal canal; if, infradiapophyseal fossa; inf, infraprezygapophyseal fossa; infp, infraposzygapophyseal fossa; Ild, lateral longitudinal depression; If, lateral fossa; mb, medial bridge; nc, neural canal; pa, parapophysis; pad, paradiapophyseal lamina; pcd, posterior centrodiapophyseal lamina; pcl, posterior centroapophyseal lamina; pd, prezygodiapophyseal lamina; pos, postzygapophysis; pr, prezygapophysis; prd, prezygodiapophyseal laminae; ps, postzygapophysis lamina; tp, transverse process; vd, ventral depression; vk, ventral keel. Arrows indicate the orientation. Scale bar equals $1 \mathrm{~cm}$ indicated in the figure. 
1). Both sacrals are of approximately the same length, but the contact between both centra is difficult to determine due to the poor preservation of the paralectotype SNSB-BSPG AS XXV 7. The massive transverse processes are placed on the dorsal part of the centrum, but whereas they are restricted to the anterior half of the centrum in the first sacral, they are placed more towards midlength, and their attachments extend over almost the entire length of the centrum in the second vertebra. The neural arch of the first sacral is relatively shorter anteroposteriorly than that of the second and displaced anteriorly (Table 1). Thus, there is a large opening laterally between the neural arches of the first and second sacral for the passage of the spinal nerve (Figure 7.1-2: osn). A stout lamina extends from the anterior end of the transverse process anterodorsally towards the prezygapophysis. Whereas this lamina is almost entirely dorsally directed in the first sacral, with a concave anterior margin, that of the second sacral extends anterodorsally and has a straight margin, in agreement with the position of the prezygapophysis, which overhangs the vertebral centrum considerably in this vertebra. The pre- and postzygapophyses of the sacral vertebrae are relatively small. As in the last dorsal vertebra, the postzyagpophysis is situated under the posterior base of the neural spine. It is rectangular, more than twice as high as long, and slightly inclined posteriorly. The neural spines of both vertebrae seem to very slightly, expand anteroposteriorly dorsally, that of the second sacral more so than that of the first. At their dorsal tips, the sacral neural spines are expanded transversely to form a spine table, like in the dorsal vertebrae. They articulate with two rows of osteoderms, and each neural spine articulates with two osteoderms of the same row. There are no pits on the lateral surface of the neural arch on the sacral vertebrae, as are present in Batrachotomus kupferzellensis (SMNS 80310) and Prestosuchus nyassicus (GPIT/RE/3831).

The sacral ribs are fused with the sacral transverse processes. They are short and stout, project ventrolaterally and rapidly expand distally. Whereas the first sacral rib is thus hatchet-shaped in dorsal view, the second expands more markedly posteriorly than anteriorly. The distal ends of the ribs meet at approximately the level of the junction of the sacral vertebral centra, and the first sacral rib overlaps the second rib at this point. The first sacral rib articulates with the iliac blade starting at the level of the junction between iliac blade and pubic process of the ilium, near the anterior pro- cess. The second sacral rib contacts the ilium at the level of the posterior margin of the acetabulum, and extends posteriorly to the end of the postacetabular process.

There are 12 caudal vertebrae preserved in the lectotype. The first caudal is articulated with the second sacral vertebra (Figure 7.6-8), caudals 2 to 6 are preserved in articulation with their respective chevrons (Figure 6.8-9), and two blocks with two incomplete posterior caudal vertebrae and another one and a half vertebral centra are present (SNSBBSPG AS XXV 32b).

The first caudal vertebra has a spool-shaped centrum and is shorter than the sacral vertebrae (Table 1). It is stout, ventrally rounded and higher than long. No chevron facets are present in this vertebra (Figure 7.7). A noted longitudinal depression is present laterally on the centrum below the transverse process (Figure 7.7: Ild, tp), resembling the condition in the first caudals of Prestosuchus nyassicus (GPIT/RE/3831). The transverse process is short, rectangular, and posterolaterally and slightly ventrally directed, but does not contact the ilium. The proximal caudals have oval to round articular facets and are higher than long, although there is a slight tendency towards a relative elongation of the centrum towards the end of the articulated series (Table 1). The centra are spoolshaped, with the ventral constriction becoming more noted in more distal elements. The second caudal has a sharp ventral keel, but two ridges are present on the ventral side from the third vertebra onwards, which is also the first caudal that bears a chevron. These ridges define a longitudinal ventral groove and are continuous with the widely separated chevron facets posteriorly, resembling the condition in UFRGS-PV-0156-T, Batrachotomus kupferzellensis (SMNS 80326), and Polonosuchus silesiacus (ZPAL Ab III 563), but different from Prestosuchus nyassicus (GPIT/RE/3831) and Fasolasuchus tenax (PVL 3850). As in the first caudal, the 2nd vertebra has a longitudinal depression laterally on the centrum in SNSB-BSPG AS XXV $3 \mathrm{~b}$ and Polonosuchus silesiacus (ZPAL Ab III 563 ), located under the transverse process, but such a depression is not present in more distal elements (Figure 6.8: Ild). The transverse processes are placed on the neurocentral suture in these proximal caudals. They are flattened and short and project posterolaterally. In ventral view, a low, rounded ridge extends over the transverse processes along their long axes. The distal tips of the transverse processes are slightly flexed ventrally. The distal caudals have elongate centra that are 


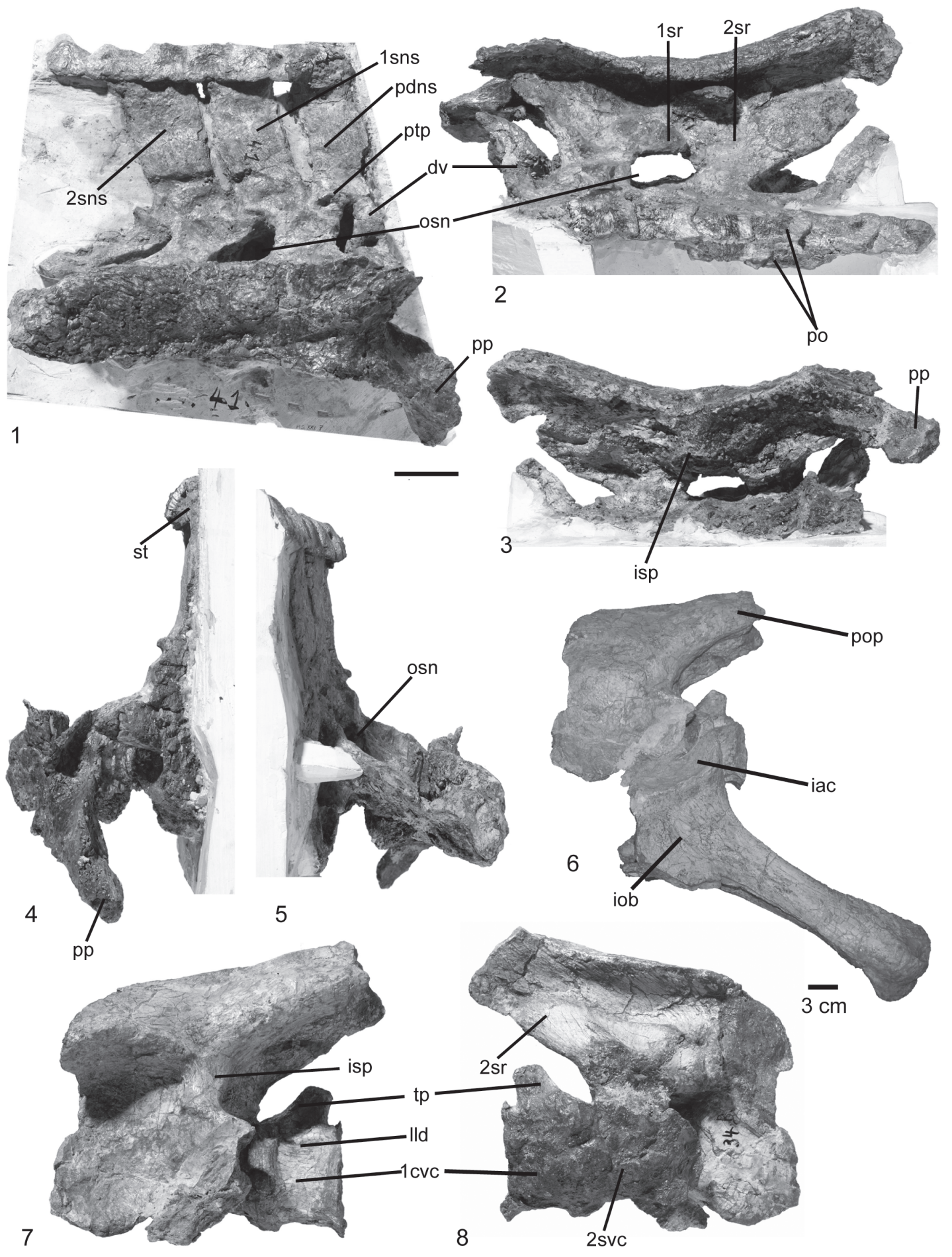

FIGURE 7. Pelvic elements of the paralectotype (1-5) and lectotype (6-8) of Prestosuchus chiniquensis SNSB-BSPG AS XXV. 1-5, Sacral vertebrae, sacral ribs, and right ilium (SNSB-BSPG XXV 7) in 1, right lateral; 2, dorsal; 3, ventral; 4, anterior; and 5, posterior views. 6-8, Left ilium and ischia (SNSB-BSPG XXV 34b/3) in 6, left lateral view; 7, Sacral centra and left ilium (SNSB-BSPG AS XXV 3a) in lateroventral; 8, dorsomedial views. Abbreviations: dv, dorsal vertebra; iac, ischial acetabulum; isp, ischial peduncle; osn, opening for the spinal nerve; pdns, posterior dorsal neural spine; po, paramedian osteoderms; pop, postacetabular process; pp, pubic peduncle; ptp, postzygapophysis; 1sns, first sacral neural spine; 2sns, first sacral neural spine; st, spine table; $1 \mathrm{cvc}$, first caudal vertebra; $1 \mathrm{sr}$; first sacral rib; 2sr, second sacral rib, iob: ischial obturador blate lld: lateral longitudinal depression, tp: transverse process, 2 svs: second sacral centrum. Scale bar indicate in the figure. 
approximately twice as long as high. The centra are spool-shaped and have no lateral depressions, as in Fasolasuchus tenax (PVL 3850), Prestosuchus nyassicus (GPIT/RE/3831).

Dorsal ribs. The proximal and distal segments of three dorsal ribs are preserved (Figure 8.3). The ribs are double-headed, with a long and stout capitulum and a short tuberculum. The articular facet of the tuberculum is circular. The proximal shaft of the ribs is triangular to circular in cross section, it bears a longitudinal depression in the posterior surface and a crest on the anterior surface, just behind the capitum and tuberculum (Figure 8.3: cr.), resembling the condition in CPEZ-239b, Batrachotomus kupferzellensis (SMNS 91044), Rauisuchus tiradentes (SNSB-BSPG AS XXV 87c), and Fasolasuchus tenax (PVL 3850). The distal shaft is also triangular in cross section, with a longitudinal groove on the posteromedial surface, like in some specimens of Batrachotomus kupferzellensis.

Gastralia. Almost the entire gastral basket is preserved in articulation in four blocks, together with rib fragments (Figure 8.1-2). The gastralia occur in individual rows, as in modern crocodiles. They are slender, rod-like bones, and circular in cross section, resembling the condition in ULBRA-PVT-281. Lateral gastralia have robust shafts but taper rapidly laterally. Medially, they also taper gradually, but continue far medially and almost reach the midline. The medial gastralia of either side are fused in the midline, meeting at an angle of about $25^{\circ}$. At the midline fusion, the elements are wide and flattened, but laterally they taper towards their articulation with the lateral gastralia (Figure 8.2). The medial and lateral gastralia overlap extensively, with approximately three-fourths of the length of the lateral gastralia being flanked by the thin lateral extensions of the medial gastralia. A gastral basket is known among pseudosuchians, such as Ticinosuchus ferox (PIMUZ 2917), Postosuchus alisonae (Peyer et al., 2008), Batrachotomus kupferzellensis (SMNS 90018), and mentioned for Arizonasaurus babbitti (Nesbitt, 2005).

Chevrons. Chevrons are preserved from the third caudal onwards (Figure 6.8-9). They are Y-shaped bones, with widely separated proximal articular facets with a medial bridge connecting the facets of either side, as in UFRGS-PV-0152-T. The first chevron is considerably shorter than more distal elements, as in SNSB-BSPG AS XXV 32. In this element the hemal canal accounts for approximately half of its length, whereas it is one-third or less of the length in more distal chevrons. In lateral view, the chevrons are long and rod-like and slightly curved posteriorly. Their distal ends taper and are not expanded anteroposteriorly (Figure 6.8), as in Rauisuchus tiradentes (SNSB-BSPG AS XXV 85b) and Ticinosuchus ferox (PIMUZ 4779). Whereas in the first chevron there is a shallow groove on the anterior surface below the hemal canal, more distal chevrons show a ridge in this area, resembling the condition in Polonosuchus silesiacus (ZPAL Ab III 563).

Osteoderms. Two rows of paramedian osteoderms are preserved over the neural spines of the last dorsal and the sacral vertebrae of the paralectotype (Figure 7.1-2, 4-5). Each osteoderm articulates with the previous element and in the midline. Whereas medially, the medial margins of both osteoderms simply abut each other within one row, the posterior margin of each osteoderm overlaps the anterior margin of the subsequent element. Each osteoderm is heart-shaped and asymmetric, with the medial part being slightly smaller than the lateral. They are acute, with the point projecting anteriorly, whereas the posterior margin is straight or slightly concave. Behind the sacral vertebrae, the paramedian osteoderms continue in a single row of somewhat larger and symmetric individual elements. The osteoderms are ornamented with smooth ridges radiating laterally from an anteroposterior low central protuberance (Figure 8.4). The general morphology and histology of them resemble the condition of asymmetrical paired paramedian osteoderms in UFRGS-PV-0156-T, 0629-T, and CPEZ-239b, contrasting with the symmetrical, leaf-shaped, osteoderms of Rauisuchus tiradentes (SNSB-BSPG AS XXV 94), Fasolasuchus tenax (PVL 3850), Ticinosuchus ferox (PIMUZ 2817), and Batrachotomus kupferzellensis (SMNS 90018), which probably belong to the tail.

Appendicular skeleton. The pectoral girdle of the type is well preserved and articulated, whereas both humeri are incomplete, and nothing is preserved of the antebrachium and manus (Figure 3 ). The pelvic girdle and hindlimb of the type are almost complete, with the ischia, left femur, tibia, fibula, proximal tarsals and pes being completely preserved, and the left ilum and both pubes being represented by incomplete remains (Figure 3 ). A complete, but rather poorly preserved right ilium is known from the paralectotype SNSB-BSPG AS XXV 7.

Scapula and coracoid. Both scapulae of the type are slightly incomplete distally, but the left scapula is articulated with the coracoid, clavicle, and interclavicle. The scapula is rather short and stout (Fig- 

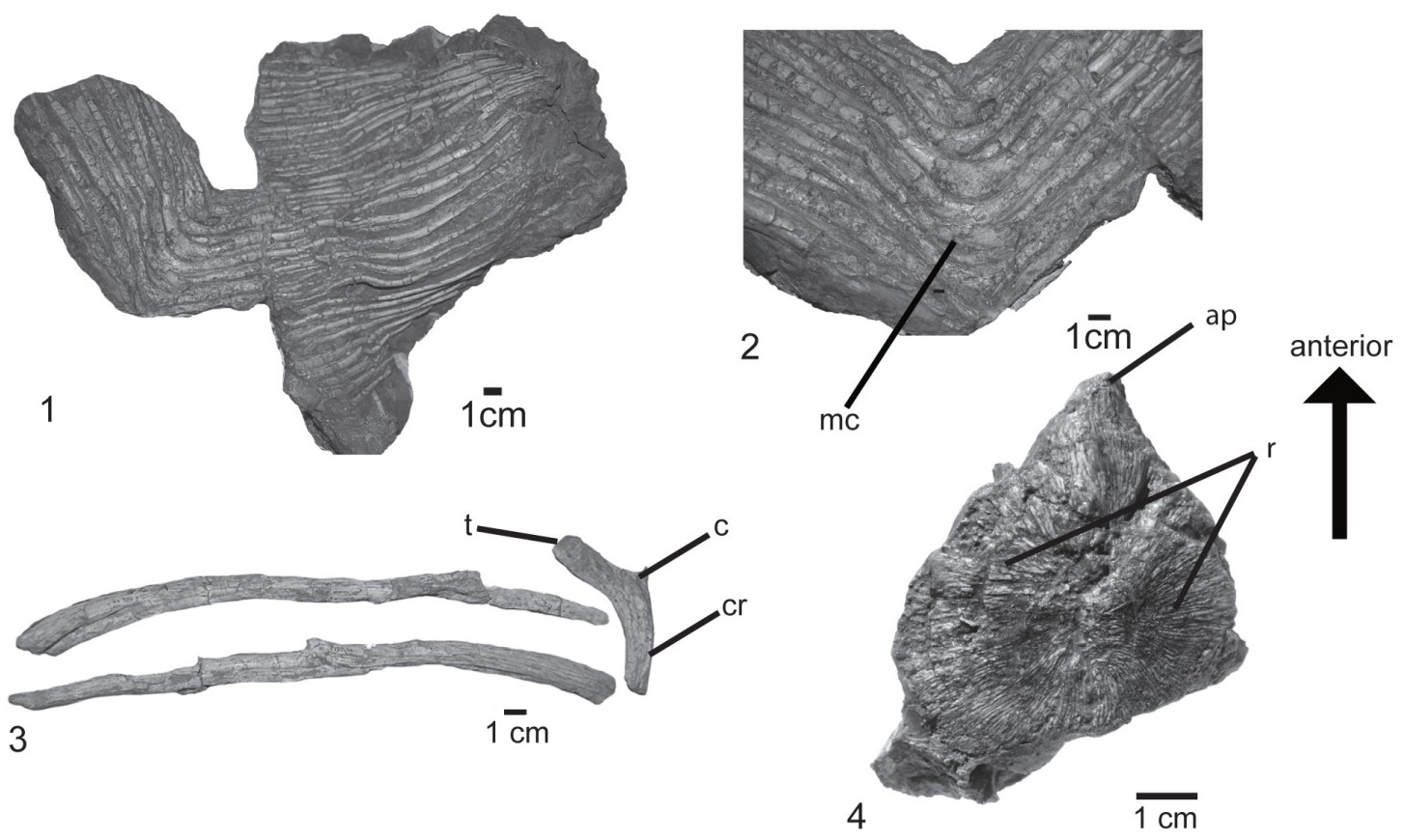

FIGURE 8. Dorsal and ventral ribs of the lectotype and dorsal osteoderm of the paralectotype of Prestosuchus chiniquensis SNSB-BSPG AS XXV. 1-2, Gastralia (SNSB-BSPG AS XXV 5a) in 1, general; 2, close-up views. 3, Dorsal ribs (SNSB-BSPG AS XXV 9, 49) in external posterodorsal view. 4, right last presacral osteoderm (SNSB-BSPG AS XXV 7) in external view. Abbreviations: ap, anterior point; c, capitulum; mc, medial contact; $r$, ridges; $t$, tuberculum. Scale bars equal $1 \mathrm{~cm}$.

ure 9.1-3). The distal expansion is incompletely preserved in all specimens available, but seems to have been rather moderate, being more anterodorsally than posteroventrally expanded (Table 1). The anterodorsal edge and the distal expansion of the scapula are thin flanges of bone, but the posteroventral margin and especially the glenoid region are considerably broadened and massive. The glenoid region is flexed medially in comparison to the scapular shaft. A rugose tubercle is present at the posteroventral margin laterally, where the glenoid region merges into the shaft (Figure 9.2: rt), most probably for the insertion of the $M$. triceps longus lateralis (Meers, 2003), resembling the condition in UFRGS-PV-0152-T, ULBRA-PVT-281, Batrachotomus kupferzellensis (SMNS 80271), Saurosuchus galilei (PVSJ 32), and the supraglenoid buttress of Rauisuchus tiradentes (Lautenschlager and Rauhut, 2015). Distal to this tubercle, the posteroventral margin of the scapular shaft is considerably broadened and shows a slight longitudinal depression, which probably marks the insertion of the $M$. scapulohumeralis caudalis (Figure 9.2: Id). Distal to this depression the margin becomes rapidly thinner towards the distal expansion (Figure 9.1), resem- bling the condition in Saurosuchus galilei (PVSJ 32).

The glenoid portion of the scapula is strongly broadened, and the scapular glenoid articular surface is approximately as broad as long. In total, the scapula makes up approximately one-third of the glenoid articulation, the other two-thirds being formed by the coracoid (Figure 9.2-3), resembling the condition in Rauisuchus tiradentes (SNSBBSPG AS XXV 91). The glenoid facet is slightly concave and directed ventrally and very slightly medially. Anterior to the glenoid facet, the scapular head is broadened where it articulates with the coracoid. The thin flange anterior to the articulation with the coracoid is straight and thin. The acromion process is only moderately expanded anterodorsally and its anteroproximal margin is straight to slightly indented to form the posterior margin of the notch between the scapula and coracoid (Figure 9.1-3: oi). Just distal to this notch, the clavicle articulates with the scapula (Figure 9.1-3). On the lateral side of the acromion process, anterodorsal to the glenoid, a shallow depression is present and bound posteriorly by a low, rounded, semioval rim. In medial view, the acromial part of the scapula is concave anteroposteriorly. A weak acromion is 
present in Batrachotomus kupferzellensis (SMNS 80271), contrasting with the prominent structure in ULBRA-PVT-281 (Roberto-da-Silva et al., 2018).

The coracoid is a large, semioval plate that is considerably longer anteroposteriorly than the acromial portion of the scapula (Table 1). The bone is much longer than high, so that the length/height ratio is approximately $2: 1$. The suture between scapula and coracoid is straight and almost horizontal, with a small concavity in the coracoid just above the glenoid (Figure 9.1-3). It extends from the ventral margin of the notch between the scapula and coracoid towards the glenoid. Anterior to the suture, the dorsal rim of the coracoid extends slightly more anteriorly and forms a small, hooklike projection that defines the anteroventral margin of the notch. Medially, the coracoid is concave in all directions, but the lateral surface is subdivided into a dorsoventrally convex anterior part and a much smaller, dorsoventrally concave posterior region. The posterior concavity is defined by the raised rim of the glenoid dorsally and the thickened ridge of the insertion of the $M$. coracobrachialis anteriorly and ventrally. A large, oval coracoid foramen is present at about half-length of the coracoid, approximately one-fourth of the height of the coracoid separated from the coracoid-scapula suture, resembling the condition in UFRGS-PV-0152-T, CPEZ-239b. There is a low, rounded keel on the lateral surface of the coracoid that runs from the coracoid foramen to the anteroventral margin (Figure 9.1: rk), where the clavicle articulates with the interclavicle (Figure 9.3), resembling the condition in UFRGS-PV-0152-T, ULBRA-PVT-281 (Robertoda-Silva et al., 2018), SNSB-BSPG AS XXV 134, and Batrachotomus kupferzellensis (SMNS 80271). The glenoid articular surface of the coracoid is oval in shape and directed posterodorsally and slightly laterally (Figure 9.3).

Clavicle and interclavicle. Both clavicles are preserved in articulation with the scapula and interclavicle (Figure 9). They are long, rod-like elements with a flattened posterordorsal end. The posteroventral margin of the posterodorsal end, which contacts the scapula, is concave transversely. The shaft of the clavicle is straight over the dorsal three-fourths of the bone, but it flexes abruptly posteroventrally in its lower fourth (Table 1), resembling the condition in Batrachotomus kupferzellensis (SMNS 91050), Ticinosuchus ferox (PIMUZ 2817), and ULBRA-PVT-281 (Roberto-daSilva et al., 2018). Posteroventral to the flexure, the bone rapidly expands to form the flattened, dropshaped articular end for the interclavicle. The pos- teroventral end of the clavicle overlaps the anterior end of the interclavicle posteriorly and abuts the clavicle of the other side medially.

The interclavicle is a flat bone that articulates with both clavicles anteriorly and with the coracoids laterally. It is approximately as long anteroposteriorly as the coracoids (Table 1). The anterior end is slightly expanded transversely at the articulation with the clavicles (Figure 9.1-3). Behind this expansion, the shaft of the interclavicle is narrowest and then gradually widens posteriorly so that the rectangular posterior end is approximately twice as wide as the anterior end. The bone is very slightly convex ventrally over its entire length. There is a conspicuous lateral expansion of the bone at about its mid length that shows a roughened, pitted surface (Figure 9.2: pt). This expansion most probably represents a pathology resulting either from a break or an infection of the bone.

Humerus. The humerus is known from the proximal and distal ends of the right and the proximal end of the left element of the type specimen SNSBBSPG AS XXV 33-34. It is a robust bone. The estimated length of the right humerus of the type is approximately $32 \mathrm{~cm}$ or $74 \%$ of the femur length (Table 1). The proximal end is mediolaterally expanded and is approximately twice as wide as the distal end (Figure 10.1-4). The proximal articular end of the humerus is thickened into a rounded, poorly preserved articular surface, which thins out laterally forming a ridge that becomes the deltopectoral crest (Figure 10.2: dc). Below the articular surface, on the medial side of the proximal end, there is a well-developed, rounded triangular internal tuber (Figure 10.1-2: it). The deltopectoral crest is subtriangular and projects anteroventrally, resembling the condition in CPEZ-239b and UFRGS-PV-0152-T. A large, triangular depression is present on the anterior side of the humerus below the articular end and medial to the deltopectoral crest. The proximal shaft is triangular in cross section, and the distal part is circular. The distal end of the humerus is divided into two condyles, but only the entepicondyle (ulnar) and the proximal surface of the shallow trochlear groove are preserved (Figure 10.4: $\mathrm{tg}$ ). The general morphology and proportions between proximal and distal ends of the humerus resemble that of Prestosuchus nyassicus (GPIT/RE/3832), and contrast with the more gracile bones of Batrachotomus kupferzellensis (SMNS 80276) and Ticinosuchus ferox (PIMUZ 2817).

Ilium. The left ilium of the lectotype has an imperforate acetabulum. The anterior part of the ilium is 


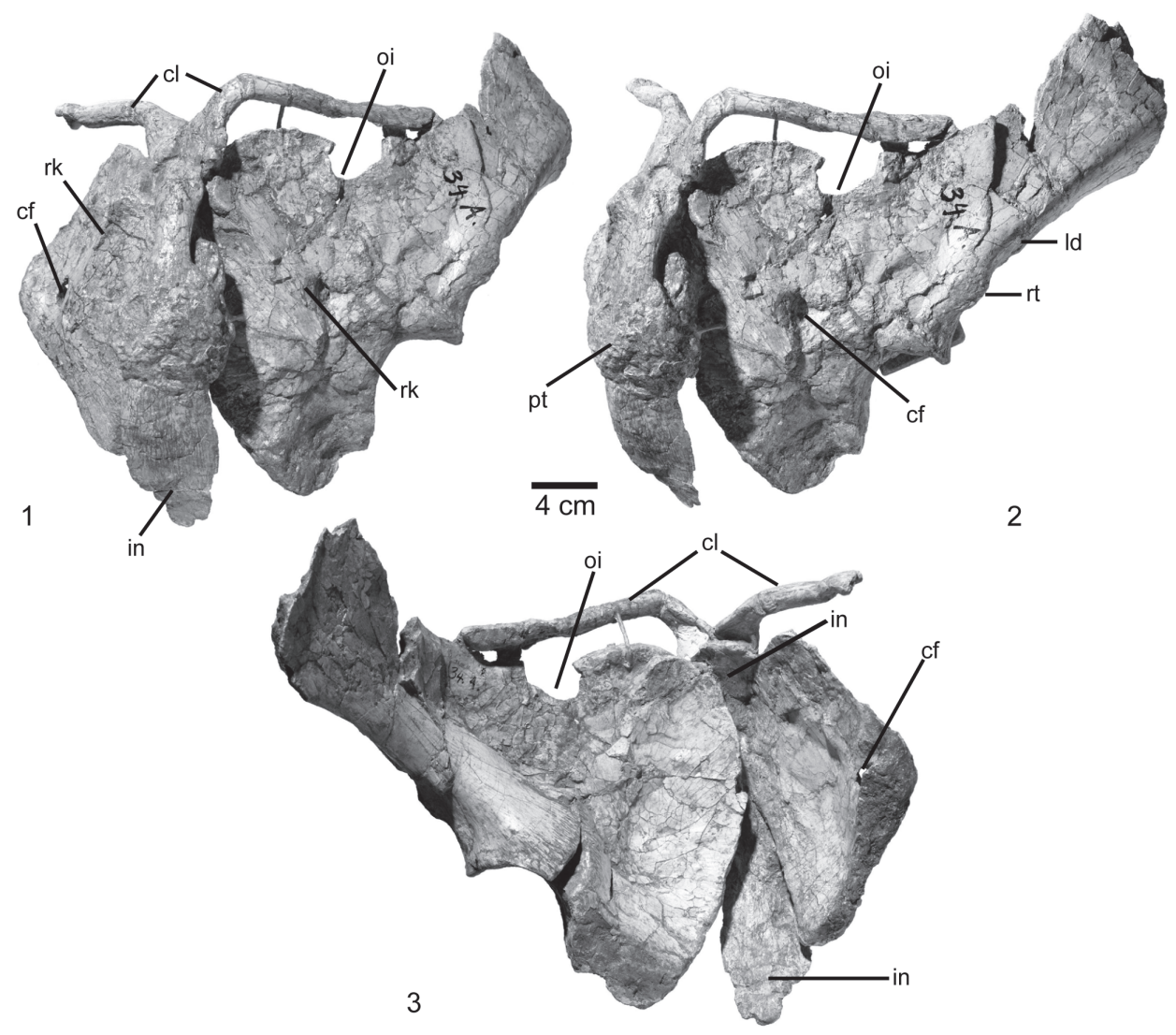

FIGURE 9. Pectoral elements of the lectotype of Prestosuchus chiniquensis SNSB-BSPG XXV 12. 1, Ventrolateral view of left scapula, coracoid, clavicle, and interclavicle; 2, lateral view; and 3, posterodorsal view. Abbreviations: cf, coracoid foramen; cl, clavicle; in, interclavicle; Id, lateral depression; oi, oval incision; pt, pathological tissue; rk, rounded keel; rt, rugose tubercle. Scale bars equal $4 \mathrm{~cm}$.

incomplete, but the postacetabular process, most of the acetabulum and the contact with the ischium are well preserved (Figure 7.6-8). The ilium of the paralectotype SNSB-BSPG AS XXV 7 is complete, but poorly preserved and lacks most of the medial acetabular wall (Figure 7.1-3). In articulation with the two sacral vertebrae, the ilium is inclined lateroventrally so that the acetabulum faces more ventrally than laterally (Figure 7.1, 4-6). The dorsal margin of the deep and large acetabulum is rounded, and defined by a broad supra-acetabular rim, which forms the entire dorsal margin of the acetabulum, but is not as prominent as in Batrachotomus kupferzellensis (SMNS 80269). The iliac blade above the acetabulum is low, approximately half the height of the height of the acetabulum. The postacetabular process extends beyond the first caudal vertebra posteriorly and has a broadened and transversely rounded ventral margin. Thus, the postacetabular process is triangular in cross-section and has a well-developed longitudinal shelf for the attachment of the second sacral rib medially. This shelf extends anteriorly beyond the posterior rim of the ischial peduncle. Dorsally, the iliac blade is sharp and bears marked dorsal striations, resembling the condition in Batrachotomus kupferzellensis (SMNS 80269). The dorsal margin is straight and curves gently ventrally towards the posterior end. The preacetabular process is short and considerably lower than the postacetabular process, resembling the condition in UFRGS-PV-0152-T. It has a pointed anterior end and a moderately developed oblique ridge laterally that runs from its anterodorsal end posteroventrally and becomes less conspicuous above the acetabulum, without a dorsal crest to the supracetabular rim, resembling the condition in Prestosuchus nyassicus (GPIT/RE/3832). The anterior rim of the pubic peduncle extends more anteriorly than ventrally, so that the pubic peduncle extends further anteriorly than the preacetabular process. The anterior margin of the acetabulum on the pubic peduncle is marked, but narrow, so that the acetabulum also extends far anteriorly. The articular facet 
for the pubis faces anteroventrally. The ischial peduncle is slightly shorter than the pubic peduncle and has a very slightly concave articular surface for the ischium. The latter faces posteroventrally and is set at an angle of approximately $70^{\circ}$ towards the pubic articulation. The angle between the two articular surfaces is placed approximately below the mid-length of the acetabulum. A short anterior and long posterior processes, prominent supra-acetabular crest, a waist between the iliac blade and expanded acetabulum region are also present in the ilia of several other taxa, such as Batrachotomus kupferzellensis (SMNS 52970), Saurosuchus galillei (PVSJ 615), Prestosuchus nyassicus (GPIT/RE/3831), and Ticinosuchus ferox (PIMUZ 2817), but contrast with the well-developed crest extending on the anterior and posterior processes of Sillosuchus longicervix (PVSJ 85), Vivaron haydeni (Lessner et al., 2016), and Effigia okeeffeae (Nesbitt, 2007).

Pubis. Of the pubes of the type specimen SNSBBSPG AS XXV 6, only a small part of the proximal obturator blade of the left pubis and the distal shafts of both elements are preserved (Figure 11.1). The proximal part was originally articulated with the ilium (see von Huene, 1942, pl. 18, figure 5 ), and the distal pubes were articulated along the pubic aprons (von Huene, 1942, pl. 19, figure 3), but subsequent damage to the apron does not allow a precise articulation now (Figure 11.1). The articular surface with the ilium is oval and rugose and triangular in cross section. The posterior rim of a large, elongate oval obturator foramen is placed proximally in the obturator plate of the pubis, contrasting with the huge obturator foramen of Fasolasuchus tenax (PVL 3850). The pubic shafts are straight and relatively short. Their anterolateral margin is thickened, and a thin, medially and slightly posteriorly directed lamina of bone extends from this margin to form the pubic apron. The distal end of the pubic shaft is slightly anteroposteriorly expanded to form a rounded, knob-like distal end (Figure 11.1: kde), but a moderate pronounced pubic boot, as in Batrachotomus kupferzellensis (SMNS 80270), Saurosuchus galilei (PVSJ 615), or Postosuchus alisonae (Nesbitt, 2011) is absent. At the level of the distal expansion, there is no pubic apron medially, but the latter ends some $5 \mathrm{~cm}$ above the distal end. The knob-like distal end of SNSB-BSPG AS XXV 6 resembles the condition in Prestosuchus nyassicus (GPIT/RE/3831).

Ischium. Both ischia of the type specimen are well preserved and in articulation (Figure 11.2-4). They are rather short and stout (Table 1). The suture between both elements is visible in dorsal and ventral view over the entire length of both elements. Distally, there is a narrow, shallow groove along the interischial suture, but directly proximal to the distal end, a sharp median ridge arises from this suture. This ridge gradually becomes more conspicuous proximally until it rapidly expands into the ischial obturator blade in the proximal third of the bone. A small, rounded ventral incision is present in its rim at the level where the abrupt expansion of the obturator blade from the shaft starts. Dorsally, the interischial suture is marked by a shallow longitudinal groove, which becomes deeper and wider proximally until the proximal ends of both ischia separate. Lateral to the interischial suture, a marked crest is present on the dorsal side of each ischium. This crest arises proximally from the sharp posterior margin of the iliac peduncle and continues almost to the distal end of the bone, laterally delimited by a longitudinal depression, resembling the condition in Prestosuchus nyassicus (GPIT/RE/3832-13), in which this groove and crest are relatively shorter. A curved raised rim on the lateral side of the proximal ischium marks the posteroventral margin of the acetabulum. The ischium has a large contribution to the acetabulum (Figure 7.6: iac), and the suture between ischium and ilium is placed within the acetabulum. In contrast to the type specimen of "Prestosuchus" Ioricatus (SNSB-BSPG AS XXV 43) and Poposaurus gracilis (Weinbaum and Hungerbühler, 2007), there is no oval depression in this area. The shaft of the ischium is triangular in cross section and becomes more robust distally, contrasting with the thin, plate-like ischium of Batrachotomus kupferzellensis (SMNS 80218) and rod-like ischium of Effigia okeeffeae (Nesbitt, 2007). The distal end is slightly expanded dorsally and ventrally, resembling the condition in Prestosuchus nyassicus (GPIT/RE/3832) and Saurosuchus galilei (PVL 2552) with a moderate ischial boot.

Femur. The left femur is completely preserved, except for the anterior section of the distal end, in the type specimen SNSB-BSPG AS XXV 10. It is a robust bone, $44.3 \mathrm{~cm}$ in length in the type specimen, and both ends are expanded (Table 1). The shaft is oval in cross section and sigmoid in posterior view (Figure 12.1-4). The proximal end has an anteromedially oriented, wedge-shaped femoral head, without a constriction or marked neck between the head and the shaft. There is a groove that runs anteroposteriorly across the proximal surface of the femoral head, resembling the condition in UFRGS-PV-0152-T and UFRGS-PV-0629-T. 

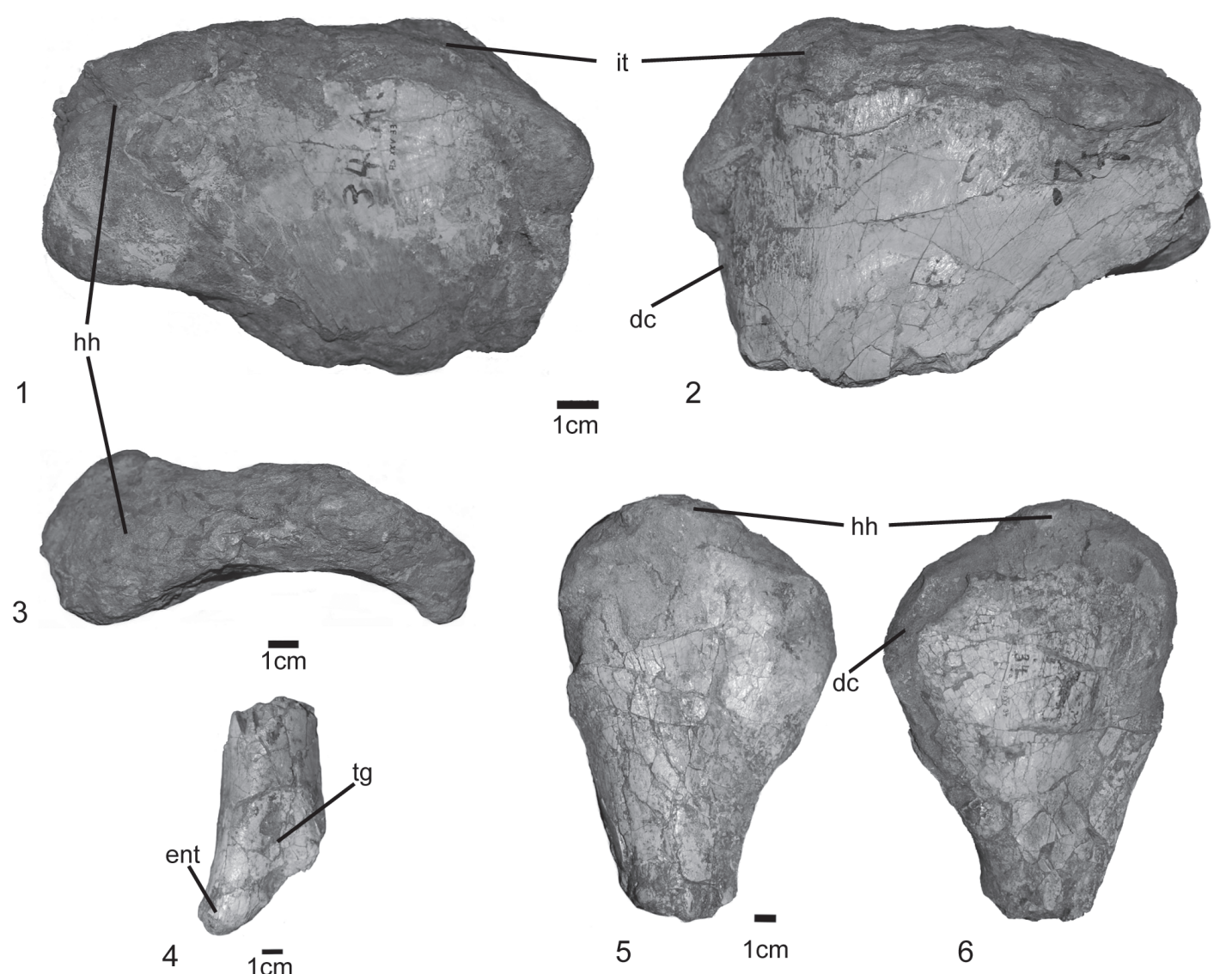

\section{$=$}

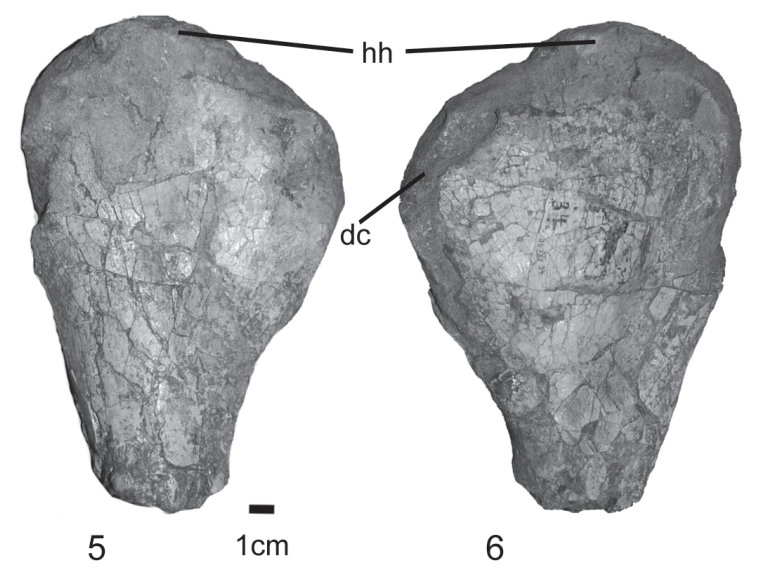

FIGURE 10. Humerus of the lectotype (1-6) of Prestosuchus chiniquensis. 1, proximal end of the left humerus (SNSBBSPG AS XXV 33) in posterior; 2, anterior; and 3, dorsal views. 4, distal end of the right humerus (SNSB-BSPG XXV 35) in anterior view. 5, proximal end of the right humerus (SNSB-BSPG AS XXV 33) in anterior; and 6, posterior views. Abbreviations: dc, deltopectoral crest; ent, entepicondyle; hh, humeral head; it, internal tuber; tg, trochlear groove. Scale bars equal $1 \mathrm{~cm}$.

The greater trochanter is prominent and developed as a stout posterolateral ridge (Figure 12.1-2: plr). Several prominent scars are present on the lateral surface of the proximal femur, close to the greater trochanter, probably for the insertion of the $M$. puboischiofemoralis internus (Figure 12.1: s). The large, well-developed fourth trochanter is represented by an oblique, elongate bulge that runs from the posterior side of the femur mediodistally and is placed just above mid-length of the bone (Figure 12.2). The anterior (cranial), posterior (caudal), and lateral intermuscular lines (Hutchinson, 2001) are absent, but a posteromedial tuber is well developed (Figure 12.3, 5: pmt). The femoral shaft is anteriorly bowed. The distal end of the femur is expanded into a tibial and fibular condyle for articulation with the tibia and fibula and the tibiofibular crest, but the medial surface is incompletely preserved (Figure 12.4: ip). The fibular condyle and tibiofibular crest are concave, separated by the convex surface from the tibial condyle (Figure 12.1-4, 6: fc, tc, tfc). The latter is laterally expanded and articulates with the tibia, resembling the condition in CPEZ-239b. A small popliteal fossa is located on the posteromedial margin (Figure 12.3, $6: \mathrm{f})$. The base of the rounded tibiofibular crest is not well separated from the fibular condyle laterally. The general morphology of SNSB-BSPG AS XXV 10 resembles that of Saurosuchus galilei (PVL 2557), Fasolasuchus tenax (PVL 3850), and Batrachotomus kupferzellensis (SMNS 52970), but the latter is less robust.

Tibia. The left tibia of the type specimen SNSBBSPG AS XXV 11a is completely preserved. This is a robust bone, $30.9 \mathrm{~cm}$ in length, or $69 \%$ of the femur length (Figure 12.7-12). The proximal end is obliquely mediolaterally expanded, with its long axis extending from anterolaterally to posteromedially, and is approximately one and a half times as wide as the distal end (Table 1). The proximal end 

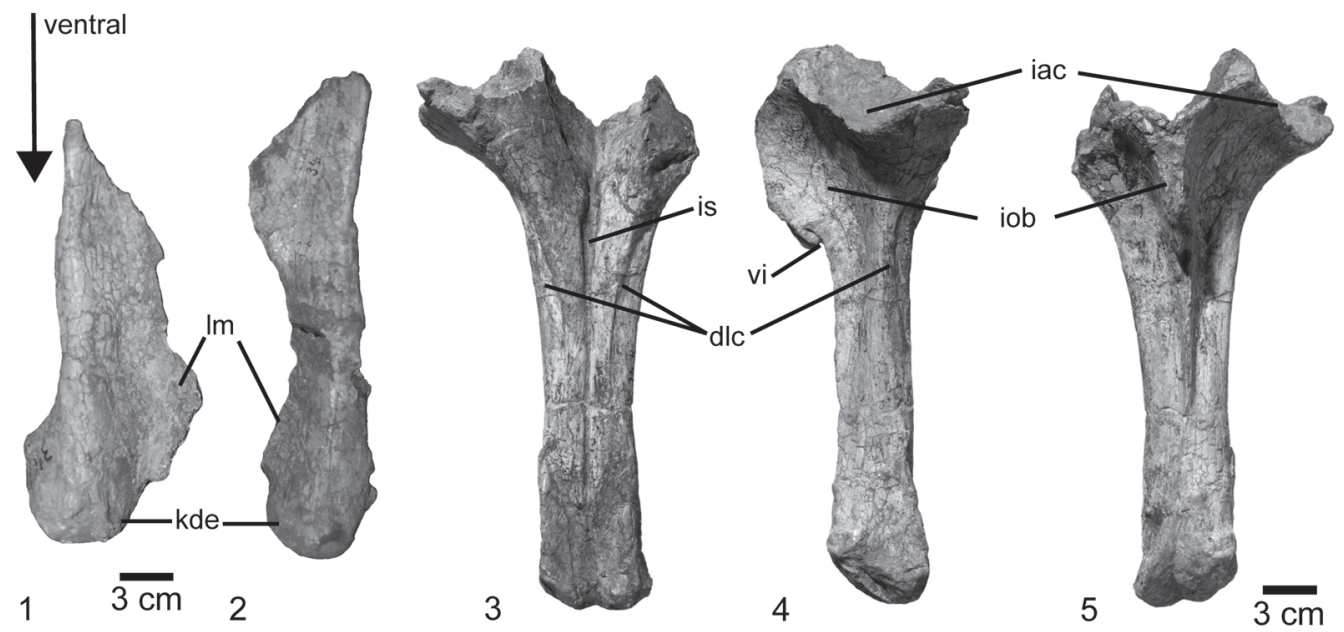

FIGURE 11. Pelvic elements of the lectotype of Prestosuchus chiniquensis SNSB-BSPG XXV. 1, distal ends of right and 2, left pubis (SNSB-BSPG AS XXV 6) in anteromedial view; 3-5, articulated ischia (SNSB-BSPG XXV 3) in 3, dorsal; 4, lateral; and 5, ventral views. Abbreviations: dlc, dorsolateral crest; iac, acetabular contribution; iob, ischial obturator blade; is, interischial suture; kde, knob-like distal end; Im, lamina of bone; vi, ventral incision. Scale bars equal 3 $\mathrm{cm}$.

is expanded mediolaterally, with a slightly oblique orientation of the proximal articular surface, which has two concave articular surfaces for the femur. There are two small knobs on the anterior surface of the tibia, close to the proximal end (Figure 12.9: $\mathrm{kn})$. In the posteromedial surface of the shaft there is a pronounced deep depression, as it also seems to be present in the specimens CPEZ-239b, UFRGS-PV-0152-T, 0629-T, ULBRA-PVT-281, Procerosuchus celer (SNSB-BSPG AS XXV 136), and Batrachotomus kupferzellensis (SMNS 52970), probably representing the site of insertion from the $M$. puboischiotibialis. Proximal to the depression, a weakly developed groove curves posteroproximally. An almost symmetrical, but less steeply inclined groove is present on the posterolateral side of the bone. The shaft is triangular in cross section, with all sides being almost planar and separated by rounded angles, in contrast to the circular cross-section in Batrachotomus kupferzellensis (SMNS 52970) and oval section of Rauisuchus tiradentes (SNSB-BSPG AS XXV 90). The anterior side of the cross-section is considerably shorter than the posteromedial and lateral sides, with the latter being the longest. The shaft is straight in posterior view (Figure 12.10). The distal end is slightly transversely and especially posteriorly expanded. A large, elongate, rugose tubercle is present on the medial side of the distal end (Figure 12.8, 12: $t$ ), while the lateral side is marked by a conspicuous, large, rectangular depression, resembling the condition in UFRGS-PV-152-T, and Saurosuchus galilei (PVL 2557). The distal articular surface is semioval and articulates with the left astragalus with a pronounced anterolateral concavity (Figure 12.7).

Fibula. The left fibula SNSB-BSPG AS XXV 11b is completely preserved, $31 \mathrm{~cm}$ in length (Figure $12.7,13-18)$. It is considerably more slender than the tibia and has proximal and distal ends of similar size (Table 1). The lateral margin of the shaft is slightly bowed. The proximal end has the shape of an isosceles triangle, with the anterolateral side being longer than the medial and posterior sides. On the lateral surface, there is a longitudinal depression close to the proximal end (Figure 12.15: Id). The anterolateral edge of the bone forms a rugose tubercle (Figure 12.15: rt), medial to a small depression, which is bound medially by a rugose area for the contact with the tibia (Figure 12.16-17: tic). The medial side of the fibula is markedly concave anteroposteriorly, and this concavity continues to about the half-length of the bone, some $25 \mathrm{~mm}$ below the level of the distal end of the trochanter for the insertion of the $M$. iliofibularis. The latter is developed as a stout, c. $45 \mathrm{~mm}$ long ridge on the lateral side that extends obliquely from anteroproximal to posterodistally (Figure 12.15, 1718: ilt), as in UFRGS-PV-0152-T, Procerosuchus celer (SNSB-BSPG AS XXV 136), Rauisuchus tiradentes (SNSB-BSPG AS XXV 90), Fasolasuchus tenax (PVL 3580), Saurosuchus galilei (PVL 2557), 


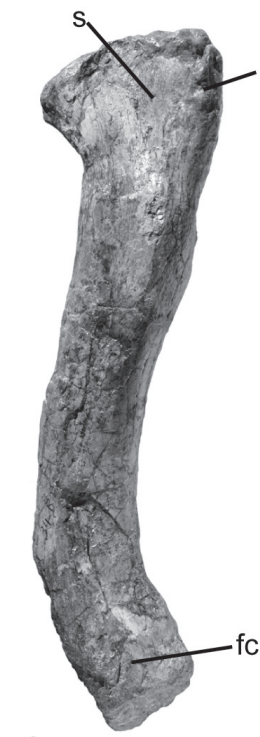

1
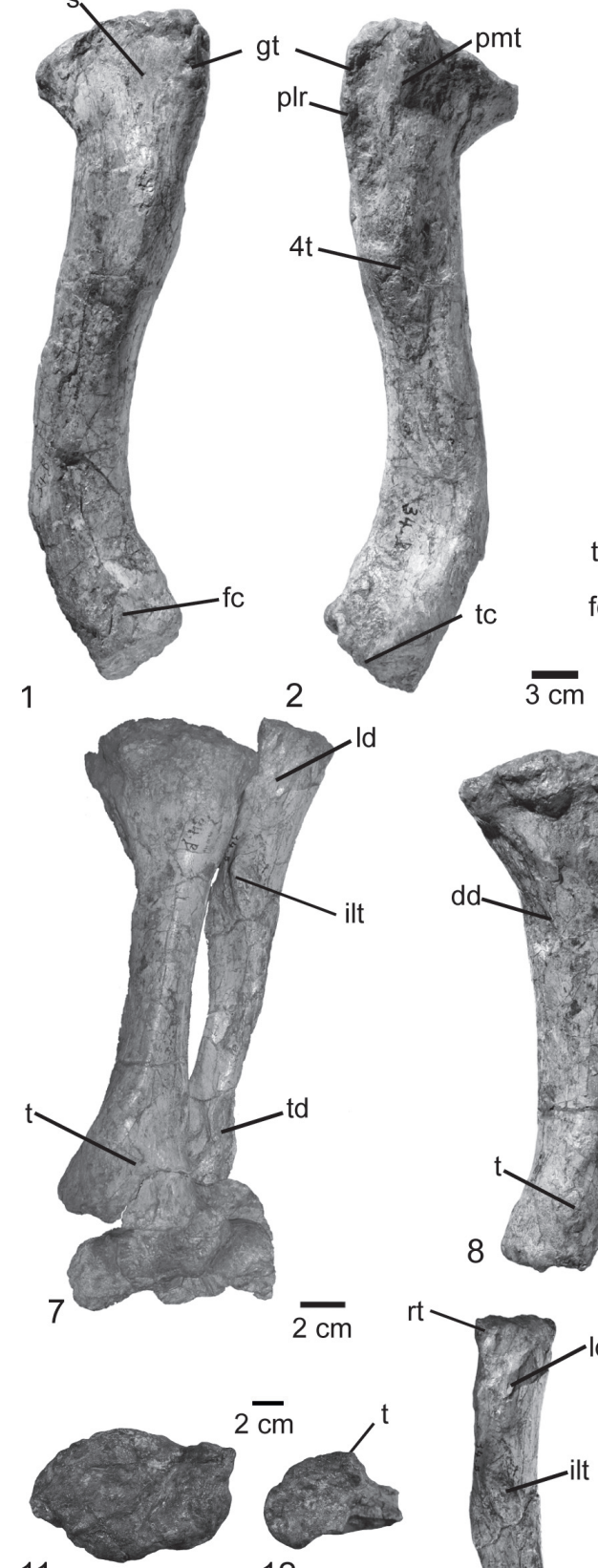

11

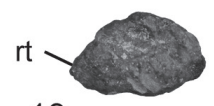

13

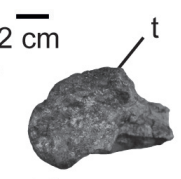

12

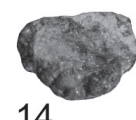

14

8

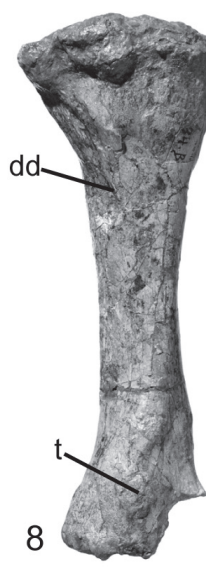

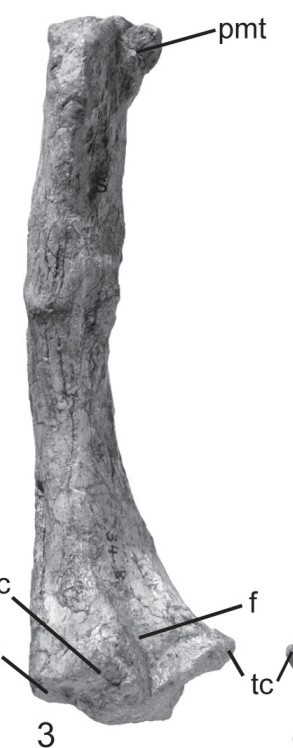
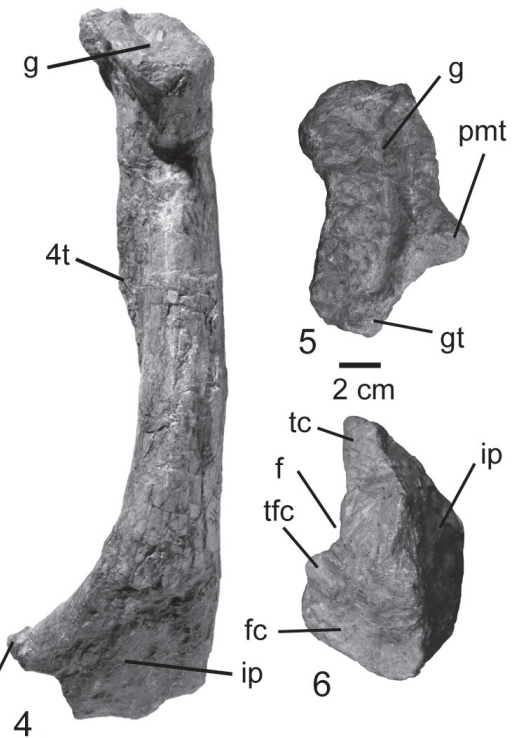

3
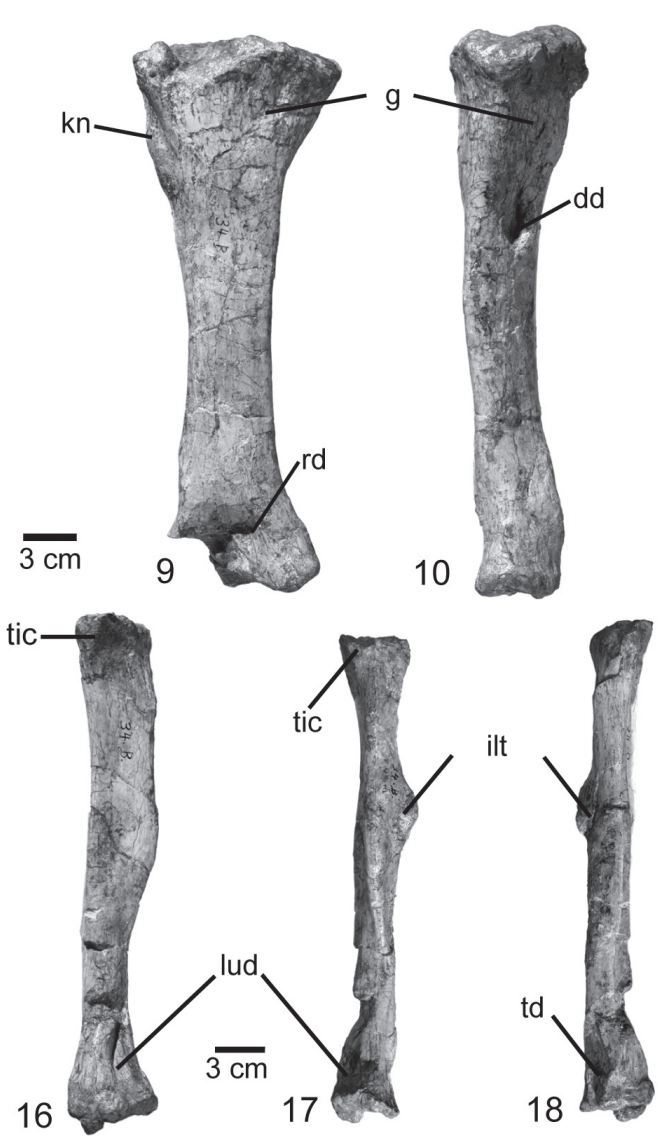

FIGURE 12. Hind limb bones of the lectotype of Prestosuchus chiniquensis SNSB-BSPG AS XXV. 1-6, left femur (SNSB-BSPG AS XXV 10) in 1, anterior; 2, posterior; 3, lateral; 4, medial; 5, proximal, and 6, distal views. 7, articulated left tibia, fibula, and proximal tarsals in anteromedial view. 8-12, left tibia (SNSB-BSPG AS XXV 11a) in 8, medial; 9, lateral; 10, posterior; 11, proximal; and 12, distal views. 13-18, left fibula (SNSB-BSPG AS XXV 11b) in 13, proximal; 14, distal; 15, lateral; 16, medial; 17, posterior; and 18, anterior views. Abbreviations: dd, deep depression; f, popliteal fossa; fc, fibular condyle; g, groove; gt, great trochanter; ilt, iliofibularis trochanter; ip; incompletely preserved surface; kn, knob; Id, longitudinal depression; lud, lunate depression; plr, posterolateral ridge; pmt, posteromedial tuber; rd, rectangular depression; rt, rugose tubercle; s, scars; t, tubercle; td, triangular depression; tc, tibial condyle; tic, tibial contact; tfc, tibiofibular crest; $4 \mathrm{t}$, fourth trochanter. Scale bars are indicated in the figure. 
Batrachotomus kupferzellensis (SMNS 80277), Postosuchus kirkpatricki (TTUP 9002), and less developed in Effigia okeeffeae (Nesbitt, 2007). Its lateral surface is divided into an anteroproximal ridge and a shallow, broad posterodistal depression, resembling the condition in Batrachotomus kupferzellensis (SMNS 80277). From the trochanter, the posterolateral edge of the shaft continues as a broad ridge distally, which demarcates a broad, depressed surface anterolaterally. Both structures fade some $85 \mathrm{~mm}$ proximal to the distal end of the bone, where the shaft reaches its strongest anteroposterior constriction. The distal end of the fibula is roughly triangular in cross-section, with the lateral side being longer than the anteromedial and posteromedial sides (Figure 12.14). A broad, shallow, elongated to triangular depression is present on the anterolateral side of the distal shaft (Figure $12.15,18: \mathrm{td}$ ), and posteromedially, there is a marked, deep, kidney-shaped depression with a raised margin and a flat internal surface (Figure 12.16-17: lud) (= "lunate" depression of Lautenschlager and Desojo, 2011). The anterolateral depression was described by Lautenschlager and Desojo (2011) as a small circular depression in Prestosuchus nyassicus (GPIT/RE/3831-19) and as being present in Rauisuchus tiradentes (SNSBBSPG AS XXV 90), but we consider the latter as an artefact of preservation. On the other hand, the posteromedial depression is also present in UFRGS-PV-0152-T and was named as lunate depression in Prestosuchus nyassicus (GPIT/RE/ 3831-19; Lautenschlager and Desojo, 2011).

The medial side of the distal shaft is strongly convex anteroposteriorly, with a narrow, but deep groove being present on the anteromedial surface, which, however, might be somewhat exaggerated by deformation. The medial surface of the distal end is slightly mediodistally directed and contacts the fibula facet on the lateral side of the astragalus, whereas the larger lateral surface is concave to contact with the rotational surface of the calcaneum.

Pes. An articulated but incomplete pes is preserved in the type specimen (Figure 13). The recovered elements of the left pes consist of the following elements: astragalus, calcaneum, two distal tarsals, five metatarsals, seven phalanges, and three unguals. The pes is plantigrade and the ankle articulation is clearly crocodile-normal (sensu Chatterjee, 1982), the axis of articulation passes between the proximal tarsals, and the astragalus bears a peg-and-socket articulation with the calcaneum. These bones are similar in size, contrasting with a smaller astragalus of Fasolasuchus tenax (PVL 3850), and located in approximately the same plane horizontally, with the astragalus reaching slightly more proximally than the calcaneum (Figure 13.1-6).

Astragalus. The astragalus is complete and well preserved. It was originally articulated with the left tibia, calcaneum, and the distal tarsal three, but the distal end of the tibia is broken, with only a small fragment being preserved in articulation with the astragalus. The tibial facet of the astragalus received the posteromedial articular facet of the tibia. It is subrectangular in shape, slightly longer transversely than anteroposteriorly, and slightly widens medially. It is mostly flat to slightly convex, but the lateralmost part extends as a notable, mound-like structure proximally to articulate with the corresponding concavity in the distal surface of the tibia. The fibular facet is considerably smaller than the tibial facet and set at an angle of approximately $90^{\circ}$ towards the latter, being oriented lateroproximally (Figure 13.1-2). It is trapezoidal in outline, higher anteriorly than posteriorly, and slightly concave anteroposteriorly. On the posterior side of the astragalus, between the rim of the fibular facet and the mound-like eminence of the tibial facet, a pronounced depression is present. In the anterior surface, under the tibial facet, a large, kidney-shaped depression is present laterally, which leads into a large, slit-like foramen (Figure 13.2). On the anteroventral surface, a large depression for articulation with metatarsal II and distal tarsal three is present, and medially there is a smaller facet for articulation with metatarsal I (Figure 13.13 ). The two articular facets are set at approximately a right angle towards each other and are separated by a pronounced, mediodistally extending ridge, resembling the condition in ULBRA-PVT-281 (Roberto-da-Silva et al., 2018), Saurosuchus galilei (2557) and Fasolasuchus tenax (PVL 3850). The posterior surface of the astragalus is flat and flexes posterodistally (Figure 13.4). Not much can be said about the rotation plane of the proximal tarsals, because of their preservation in articulation.

Calcaneum. The calcaneum is an anteroposteriorly elongate bone, with a posteriorly facing tuber and an anterior condyle with a convex dorsal surface for the articulation with the fibula (Figure 13.12). The calcaneal tuber is very broad transversely, rectangular in proximal view and extends some 35 $\mathrm{mm}$ posterior to the fibular condyle. Whereas its lateral margin is squared, there is a marked incision between its posterior expansion and its base medially. The posterior end of the tuber expands 


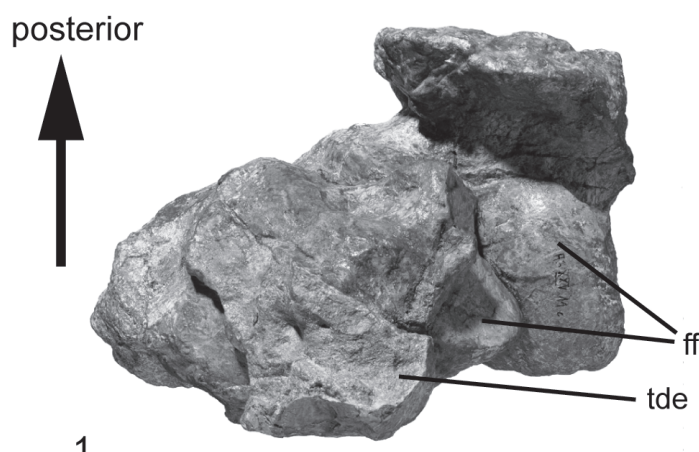

1
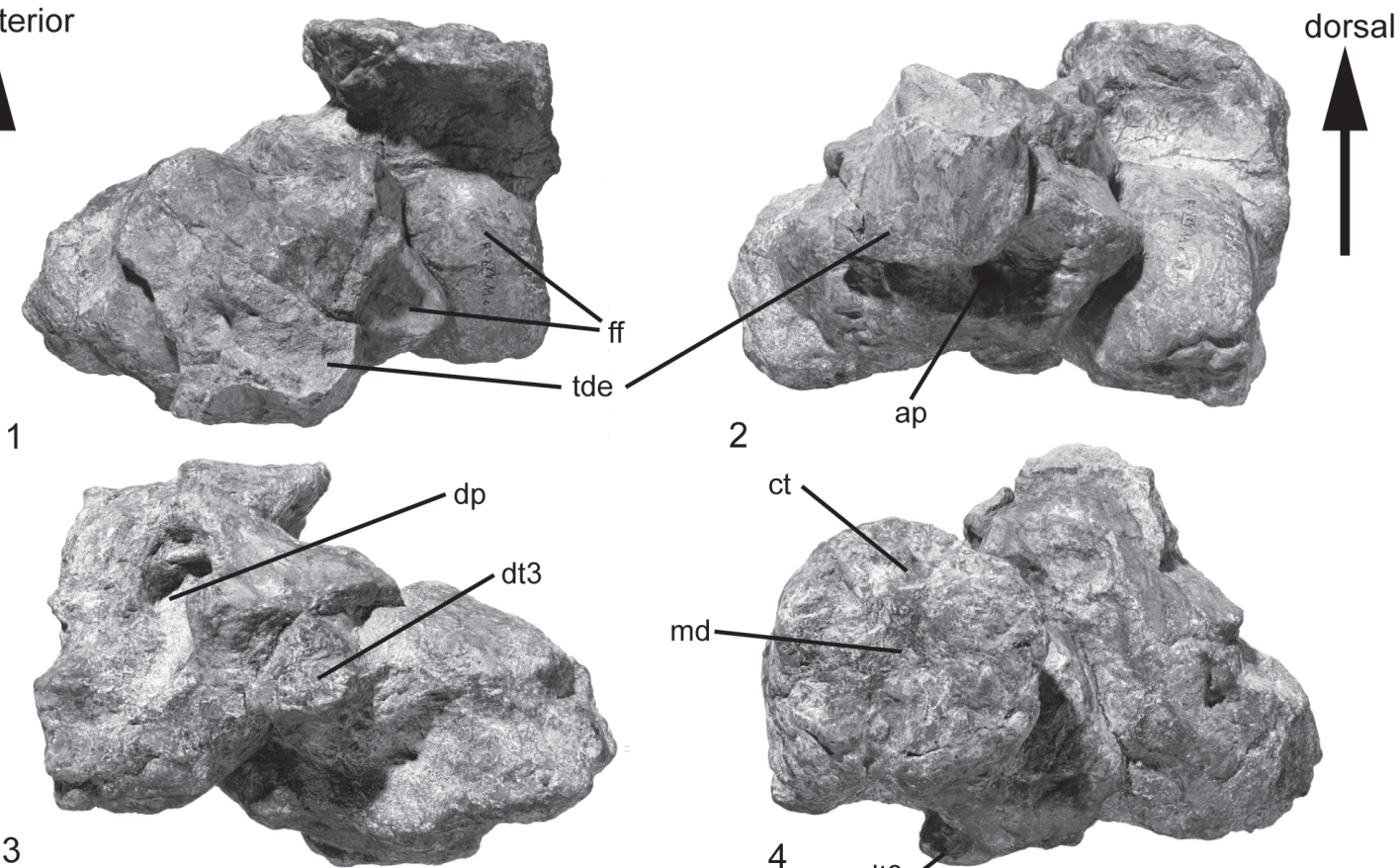

2
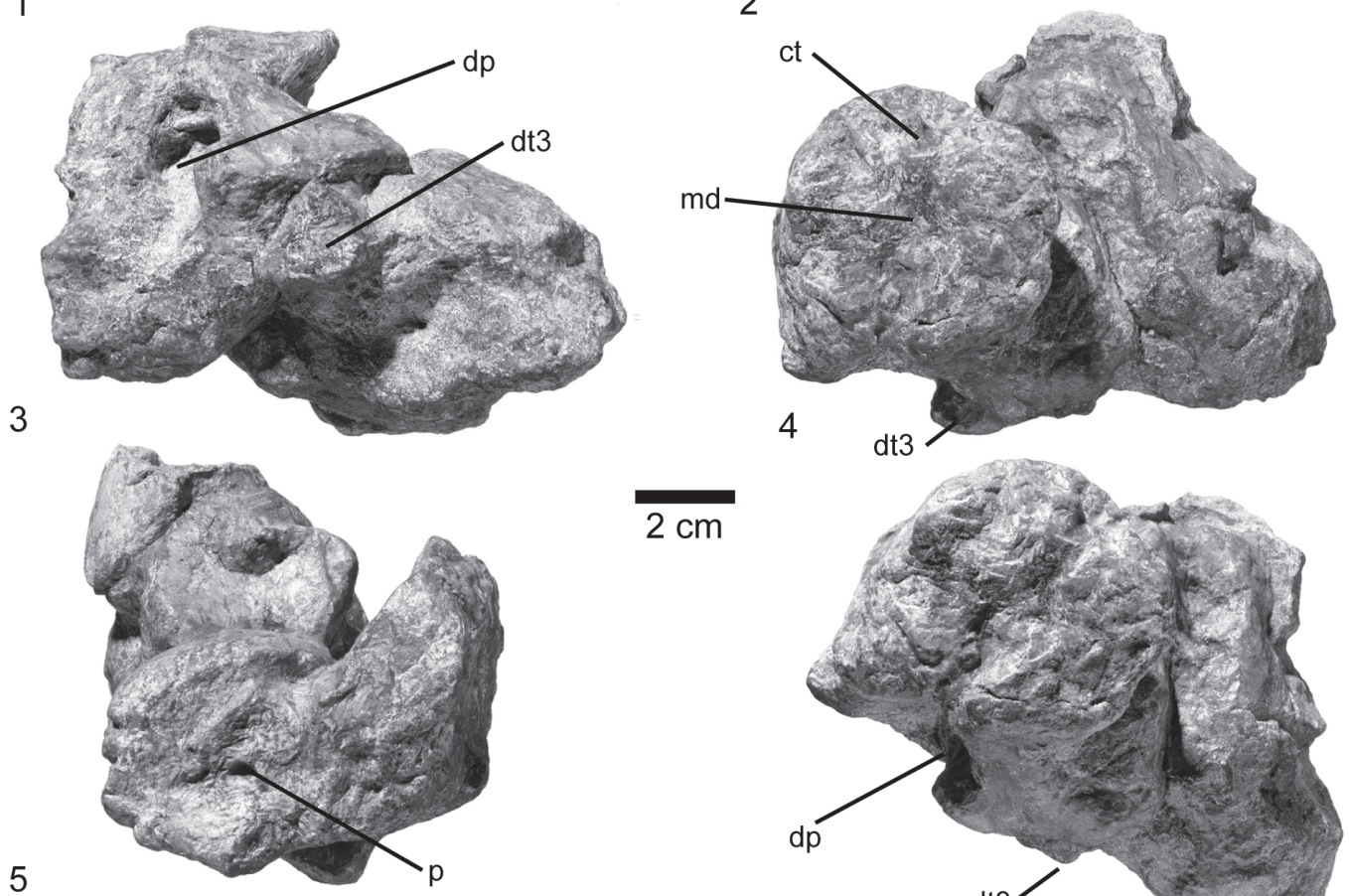

5
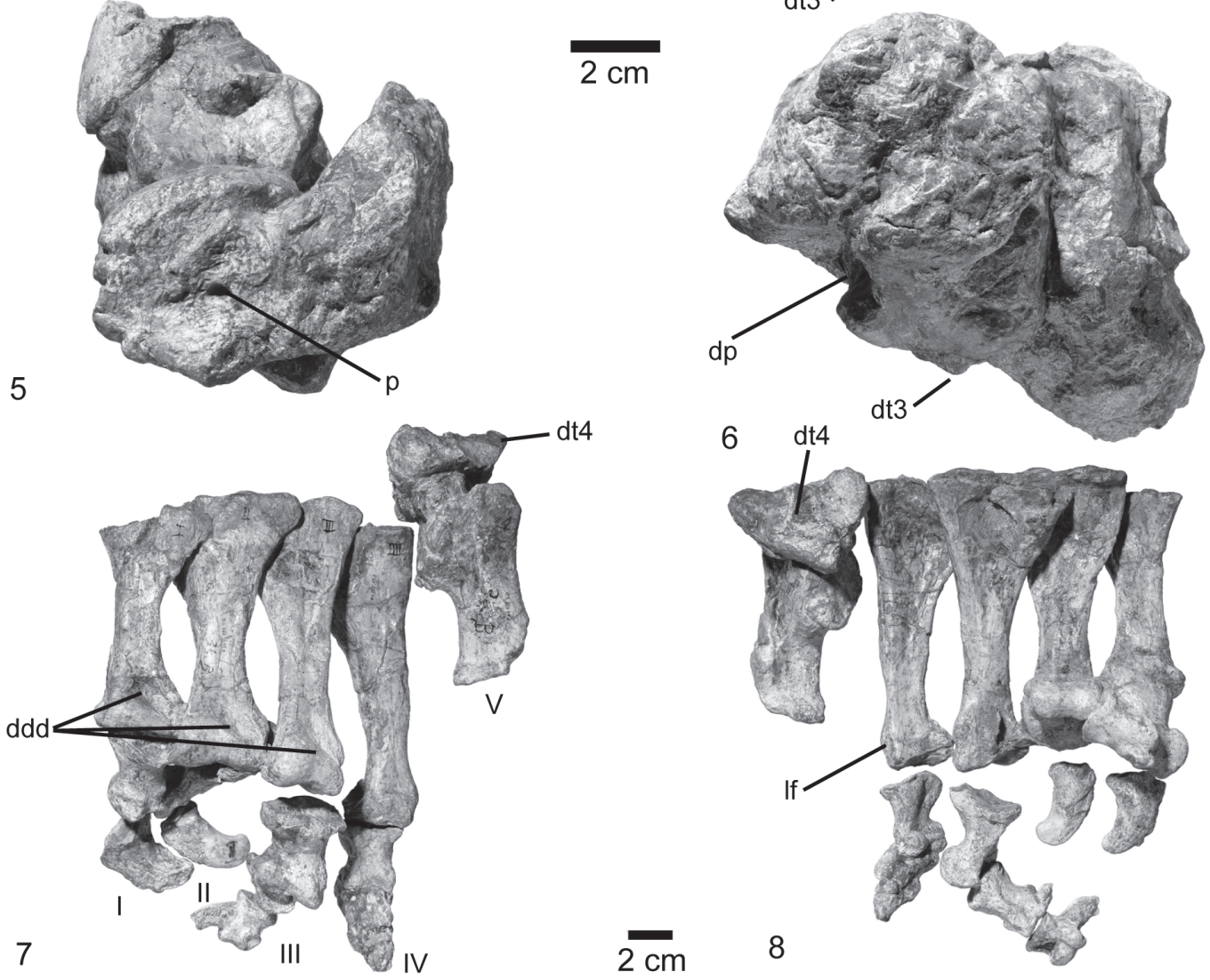

FIGURE 13. Foot bones of the lectotype of Prestosuchus chiniquensis SNSB-BSPG XXV. 1-6, left proximal tarsals (SNSB-BSPG XXV 11c) in 1, dorsal; 2, anterior; 3, ventral; 4, posterior; 5, lateral; and 6, posteroventral views. 7-8, left distal tarsal four, metatarsals, and phalanges of the five digits in articulation (SNSB-BSPG XXV 11e) in 7, dorsal; and 8, ventral views. Abbreviations: ap, anterior pit; ct, calcaneal tuber; ddd, dorsal distal depression; dp, deep pit; $\mathrm{dt}$ 3, distal tarsal three; dt4, distal tarsal four; ff, fibular facet; If, lateral fossae; md, median depression; $\mathrm{p}$, pit; tde, tibial distal end; I-V, digits 1 to 5 . Scale bars indicate in the figure. 
equally dorsoventrally and lateromedially, resulting in a rounded outline in posterior view. The proximodistal expansion is entirely due to a marked, ridge-like proximal expansion of the posteroproximal margin of the tuber. The posteromedial edge of the calcaneal body is expanded medially beyond the medial margin of the tuber to form the facet for the astragalar trochlea. It is slightly smaller than the facet for the fibula on the anterior condyle. The anterior condyle of the calcaneum is strongly convex both anteroposteriorly and mediolaterally, being inclined proximomedially. Anteriorly, it is bordered laterally by a triangular, strongly rugose surface. The flat ventral surface bears an anterior articular facet for distal tarsal four, and metatarsals III and IV. Posterior to this facet, close to the calcaneal tuber in ventral view, there is a large, teardrop-shaped ventral calcanear fossa that deepens posteriorly (Figure 13.3), resembling the condition in Batrachotomus kupferzellensis (SMNS 90018) and Postosuchus (TTUP 9002, Peyer et al., 2008). Medially, this fossa is bordered by a large, distally expanded, triangular tubercle. The lateral surface of the main calcanear body is flat anteriorly and becomes slightly concave posteriorly, where it bears a small, deep pit (Figure 13.5). The general morphology resembles that of the specimens UFRGS-PV-0152-T and ULBRA-PVT-281 (Roberto-da-Silva et al., 2018), but contrast with a calcaneum shaft that is wider than long in Batrachotomus kupferzellensis (SMNS 90018), longer than wide in both species of Postosuchus (TTUP 9002), and a calcaneum tuber that is longer than wide in Saurosuchus galilei (PVL 2557).

Distal tarsal. The two distal tarsals were found articulated with the pes (Figure 13.7-8; see also von Huene 1942, pl. 21, figure 2). In ventral view, the triangular distal tarsal three is located posteriorly at the level of the articulation axis between the astragalus and calcaneus (Figure 13.3-4, 6: dt3). It is a small, semioval element that is slightly concave anteroposteriorly. The bone is higher proximodistally on the anterior side than on its posterior side. Tarsal 4, the larger of the two (three times in size of tarsal 3 ), is narrow transversely, but elongate anteroposteriorly. Its proximal articular surface is subrectangular anteriorly and has an expanded, triangular posterior process on its posteromedial edge. In anteromedial view, the bone has the shape of an isosceles triangle, with the proximal base being very slightly longer than the other two sides, contrasting with the tetrahedral fourth distal tarsal of Saurosuchus galilei (Sill, 1974). As it was found in articulation, the bone was oriented obliquely from anterolateral to posteromedial, and covered distal tarsal three distally.

Metatarsal. The five metatarsals are well preserved and proximal heads of metatarsals I to III are still preserved in articulation and have several phalanges attached distally (Figure 13.7-8). Metatarsal III is the longest of the pes, followed by metatarsal II and IV, which are of subequal length, the latter being very slightly longer, resembling the condition in Saurosuchus galilei (PVL 2557), and contrasting with both species of Postosuchus which show a similar size of metatarsal I to IV (Peyer et al., 2008). Metatarsal I is notably shorter than the other bones, and the strongly modified Mt $\mathrm{V}$ is the shortest element of the metapodium and will be described separately from the other elements. The proximal ends of metatarsals I-IV are expanded medially and laterally, but, whereas this expansion is more or less equally developed in each direction in Mt I-III, Mt IV is mainly medially expanded. In articulation, the lateral side of each proximal end overlaps the medial half of the next metatarsal dorsally. The articular surfaces of the proximal ends are compressed dorsoventrally and expanded mediolaterally. They are obliquely ventromedially-dorsolaterally oriented in the medial metatarsals, but become more mediolaterally oriented in Mt III and IV. Whereas the proximal end is semioval in outline in Mt I, Mt II and III have triangular outlines, with II being considerably more robust than III. Mt IV has an hourglass-shaped proximal outline, with the lateral part being larger than the medial. Triangular outlines are also present in some fragmentary metatarsals of Fasolasuchus tenax (PVL 3850)

The shafts are strongly constricted between the articular ends, with the narrowest portion being placed at approximately two-thirds of the length of the elements. The metatarsals are compressed dorsoventrally, so that the shafts are considerably wider than high. The shaft of Metatarsal II is the most robust of the four principal metatarsals, whereas Mt IV is the most slender. The shafts of Mt I and IV are transversely convex dorsally, but they seem to be slightly concave in Mt II and III. Mt I has a large, elongate by dorsomedial tubercle at about mid-shaft. A large, triangular depression is present ventrally at the proximal end. This depression becomes more marked from metatasal I to IV; in the latter it extends distally to slightly more than half-length of the bone.

The distal ends of metatarsals I to IV are considerably expanded both mediolaterally and dorsoventrally, to form gynglimoidal articular ends. The 
distal end of Mt II is the most robust, followed by Mt I, Mt III, and Mt IV. The distal gynglimus extends further proximally dorsally and is divided into two distinct condyles in Mt II and III, but less so in Mt I and IV. The proximal extent is asymmetrical dorsally, with the articular facet extending further proximally on the medial than on the lateral side. A large, well-developed extensor groove is present proximally to the gynglimus dorsally in metatarsals I and II, but less marked in Mt III and almost absent in Mt IV. Laterally, a rounded tubercle is found at the proximal end of the gynglimus. In Mt III, a welldeveloped, proximodistally elongate collateral ligament groove is present ventral to this tubercle; this area is covered by matrix in Mt I (in which, however, a collateral ligament groove also seems to be present) and II, but this groove is absent in Mt IV. No collateral ligament grooves are present on the medial side of the distal end.

Metatarsal $\mathrm{V}$ is the shortest and most robust element of the metapodium, and has a concave medial margin and an almost straight, only very slightly concave lateral edge, contrasting with the slender, hooked fifth metatarsal of Batrachotomus kuferzellensis (SMNS 90018), Saurosuchus galilei (PVL 2557), and both species of Postosuchus (TTUP 9002). The proximal end is strongly expanded ventrally on its medial side, so that the proximal outline is triangular. Medially, a large, obliquely oval articular surface for the contact with distal tarsal four is present. A small depression is present distally at the base of the proximal expansion on its proximomedial surface. The lateral half of the proximal end forms a proximally rounded lobe that extends slightly more proximally than the medial side. The shaft of Mt $\mathrm{V}$ is flattened dorsomedially, and a large, elongate tubercle is present on its lateroventral margin. The distal end is not expanded, but has a flattened distal articular surface, indicating that at least one phalanx might have been present, although none were preserved with the metatarsal.

Phalange. A number of phalanges were found in articulation or close association with the metatarsals and represent the complete digits I to IV. Thus, although the common digital formula for most reptiles is 2-3-4-5-3, this specimen shows $2-3-4-3-X$, contrasting with the 2-3-4-5-2 suggested for Saurosuchus galilei by Sill (1974) and 2-3-4-6-3 of Postosuchus (Peyer et al., 2008; Weinbaum, 2013). The phalanges are rather short and robust, with a welldeveloped constriction between the articular ends and strongly gynglimoidal distal articular condyles. Although the distal gynglimoidi are well divided into two condyles, the proximal articular surfaces of the pahalanges are generally concave both dorsoventrally and (though less so) transversely, without a central ridge to subdivide two distinct facets. Welldeveloped dorsal extensor grooves and collateral ligament grooves are present in the preungual phalanges. Distally, the phalanges rapidly diminish in size. Digit II is the most robust, with digit III being almost as robust as the latter, and digits I and IV are slightly more slender. Pedal unguals diminish in size from ungual I to ungual IV, with I and II being considerably larger than III and IV, which are of subequal size. The unguals are higher than wide proximally, moderately curved and slightly asymmetrical, so that, in the articulated foot, at least ungual I and II would face slightly medially. A shallow claw groove is present on the medial side, being situated dorsal to the mid-height of the ungual.

\section{DISCUSSION}

\section{The Phylogenetic Position of Prestosuchus chiniquensis}

As noted by Gower and Schoch (2009) a decade ago, the phylogeny of basal pseudosuchians is currently still far from being resolved. These authors mentioned that especially more work on the detailed anatomy and alpha taxonomy of many "rauisuchian" taxa is needed before a robust phylogenetic hypothesis of rauisuchian monophyly and interrelationships can be formulated. The present contribution on the anatomy and systematics of Prestosuchus chiniquensis should be seen as a further step towards this goal. However, we consider recent phylogenetic analyses, such as those presented by Nesbitt $(2003,2007$, 2011), Nesbitt and Norell (2006), Weinbaum and Hungerbühler (2007), Brusatte et al. (2010), Butler et al. (2014), Lacerda et al. (2016), Ezcurra et al. (2017), Nesbitt and Desojo (2017), and Robertoda-Silva et al. (2018), to be important steps on the way towards a better understanding of basal pseudosuchian phylogeny and evolutionary history. These allow formulating hypotheses of homology and also of evolutionary events and trends that can then be tested in the light of new or more complete data. Furthermore, with the aggregation of new taxa and characters and the reassessment of proposed characters, it is to be expected that at least most phylogenetic analyses represent a step forward in this task. Recently, several anatomical and phylogenetic studies concerning Prestosuchus have been carried out (Mastrantonio, 2010; Mas- 
trantonio et al., 2013, 2019; Liparini and Schultz, 2013; Raugust, 2014; Lacerda et al., 2016; Roberto-da-Silva et al., 2016, 2018); however, none of these authors reassessed the original materials recovered by von Huene in detail, and no detailed justification for the referral of new materials to Prestosuchus chiniquensis, based on detailed comparisons with the type specimen, was given.

The main large-scale phylogenetic analysis of archosaurs to include Prestosuchus are those presented by Brusatte et al. (2010) and Nesbitt (2011). Brusatte et al. (2010) found a well-supported Rauisuchia, including the subclades Poposauroidea and Rauisuchoidea. In the latter contribution, Prestosuchus was recovered as a sister taxon of Batrachotomus. However, both nominal species of Prestosuchus ( $P$. chiniquensis and $P$. loricatus) were coded together. On the contrary, Nesbitt (2011) recovered a paraphyletic "Rauisuchia" including a monophyletic grouping of Poposauroidea and Rauisuchidae. In that study, Prestosuchus chiniquensis was represented by the lectotype material and two referred specimens, UFRGS-PV-0152-T, and 0156-T, but Prestosuchus loricatus was not included.

Our phylogenetic analysis resulted in 22815 most parsimonious trees (MPTs) of 1425 steps. The strict consensus tree of these MPTs shows a large polytomy above Euparkeria that includes, apart from several isolated taxa, the following monophyletic subclades: Ornithosuchidae, Gracilisuchidae, Phytosauria, Aetosauria, Poposauroidea, Prestosuchidae, a clade including Batrachotomus and more crownward loricatans, and Avematatarsalia.

The internal relationships of most of these clades follow that found in previous analyses (Nesbitt, 2011; Butler et al., 2011; Nesbitt and Desojo, 2017; Roberto-da-Silva et al., 2018). Prestosuchidae includes the species Saurosuchus galilei, Luperosuchus fractus, Stagonosuchus nyassicus, Prestosuchus chiniquensis, and several specimens that were previously referred to the latter (UFRGSPV-0152-T, UFRGS-PV-0156-T, CPEZ-239b), which are found in a polytomy within this clade.

The species Batrachotomus kupferzellensis and Fasolasuchus tenax are consecutively closer outgroups to higher loricatans, as in Nesbitt (2011). Likewise, the topology of higher loricatans corresponds to that recovered by Nesbitt (2011), including a monophyletic Rauisuchidae and Crocodylomorpha.
The avemetatarsalian branch of the analysis largely corresponds to the results of Nesbitt (2011), with the only differences being the inclusion of aphanosaurians, which were, however, recovered crownwards to Pterosauria here, rather than the most basal clade within Avemetatarsalia (Nesbitt et al., 2017).

Reduced consensus methods considerably improved the resolution of the analysis (Figure 14), mainly by removing the erpetosuchids Parringtonia gracilis and Erpetosuchus granti, the paralectotype of "Prestosuchus" loricatus, and the prestosuchid Luperosuchus fractus and two of the specimens previously referred to Prestosuchus chiniquensis, UFRGS-PV-0156-T and CPEZ-239b.

Removal of these taxa resulted in the placement of Phytosauria as sister taxon to Archosauria (as in Nesbitt, 2011), and a recovery of a monophyletic a Pseudosuchia, with ornithosuchids as the most basal clade, followed by Aetosauria and Gracilisuchidae, outside of Paracrocodylomorpha. The latter clade comprises Ticinosuchus as most basal taxon, followed by a polytomy of Mandasuchus tanyauchen, Poposauroidea and Loricata. At the base of Loricata, prestosuchids are found in a polytomy with Pagosvenator candelariensis and the Batrachotomus-Crocodylomorpha clade (Figure 14).

In order to test the robustness of the MPTs, bootstrap and bremer support analyses were performed. Support for most clades is rather low, as might be expected for a dataset with many fragmentary taxa. Thus, within archosaurs, bootstrap support values above $50 \%$ are mainly found in dinosauriforms (probably due to incomplete character sampling as this clade was not the focus of the current analysis) and some pseudosuchian subclades. The best supported major clade is Poposauroidea with a bootstrap support of $74 \%$, followed by Ornithosuchidae, the clade including Aetosauria + Revueltosaurus, and Crocodylomorpha, which all have $64 \%$ support. Likewise, Bremer support values are low for the majority of clades, again with the exception of many subclades of Avemetatarsalia, which probably reflects selective character selection in this part of the phylogeny, as noted above. Within Pseudosuchia, the highest Bremer support values are found for Ornithosuchidae, Poposauroidea (and several subclades thereof) and the genus Protosuchus, which have a value of three. Gracilisuchids and several subclades of Loricata have a Bremer support of two, including the clade of Fasolasuchus and higher loricatans, the clade including rauisuchids and hig- 
her loricatans, all crocodylomorphs more derived than CM 73372, and several subclades of Crocodylomorpha. The Prestosuchidae have a Bremer support of one.

\section{The Monophyly of Prestosuchidae and Prestosuchid Interrelationships}

As noted above, both the reduced and strict consensus trees recovered a monophyletic Prestosuchidae. The monophyly of this clade is supported by five unambiguous synapomorphies: presence of a ridge on the ventral process of the squamosal (character 51.1); anteroventral process of the squamosal perforates the lower temporal fenestra (character 52.1); palpebral bones extensively sutured to each other and to the lateral margin of the frontals (character 149.1); robust, knobshaped attachment for the $m$. iliofibularis on the fibula (character 339.1); anterior portion of nasals elevated above the skull roof (character 414.1). Two further characters are currently only known in Prestosuchus, and might thus be either synapomorphies of Prestosuchidae or of the genus Prestosuchus or one of its species: the presence of a marked ridge leading from the glenoid to the anteroventral margin of the coracoid (character 229.1; only known in Prestosuchus chiniquensis and UFRGS-PV-0152-T within Prestosuchidae), and the absence of a foramen in the medial side of distal tarsal IV (character 352.0; reversal of a synapomorphy of Gracilisuchidae + Paracrocodylomorpha; only known in Prestosuchus chiniquensis within Prestosuchidae).

Within Prestosuchidae, reduced consensus techniques identified the poorly known Luperosuchus fractus as a problematic taxon, which can occupy a number of positions, as already found by Nesbitt and Desojo (2017). Thus, this species might either be the sister taxon to Saurosuchus galilei, the sister taxon to the genus Prestosuchus, or even within this genus (Figure 14). A posteriori removal of Luperosuchus fractus resulted in a slightly better resolution within the Prestosuchidae, with Saurosuchus galilei being found as sister taxon to a clade including Stagonosuchus nyassicus, Prestosuchus chiniquensis and various specimens referred to the latter; this clade is here considered to represent the genus Prestosuchus, so that we propose the new combination Prestosuchus nyassicus for Stagonosuchus nyassicus (see above). The monophyly of Prestosuchus is rather well supported by seven unambiguous synapomorphies ( ${ }^{*}$ denotes characters that are preserved in the lectotype of Prestosuchus chiniquensis): distal expansion of the paroccipital process (character 108.1); supraoccipital excluded from the dorsal border of the foramen magnum by the exoccipitals (character 126.0); absence of a vertical crest dorsal to the acetabular rim of the ilium* (character 265.0); abrupt change in the angle between the proximal end and the shaft in the ventral margin of the ischium* (character 296.1); medial condyle of the femur tapers to a point medially in distal view* (character 320.0); calcaneal facet on astragalus lies entirely medial to fibular facet* (character 358.0); presence of a lunate fossa on the posteromedial side of the distal fibula* (character 422.1).

Within the genus Prestosuchus, our analysis indicates a more complex species taxonomy than previously recognized. As noted above, the placement of Stagonosuchus nyassicus in a polytomy with several specimens that were hitherto already considered to represent the genus Prestosuchus indicates that this taxon represents an African species of the genus Prestosuchus. On the other hand, removal of UFRGS-PV-0156-T and CPEZ $239 b$ resulted in an ingroup topology that groups Prestosuchus nyassicus with Prestosuchus chiniquensis, to the exclusion of UFRGS-PV-0152T. Furthermore, the specimen UFRGS-PV-0152-T differs from the other two species in a number of characters, probably indicating that at least this specimen represents a different species of Prestosuchus. Thus, more than one species of that genus seems to be present in the Santa Maria Supersequence.

\section{Evolutionary Aspects}

The revision of Prestosuchus chiniquensis has implications for the diversity and ecological importance of large predatory pseudosuchians in the Middle-Late Triassic boundary in southern Gondwana. As noted above, our analysis indicates that Prestosuchus might be represented by more than one species in the Santa Maria Supersequence. Based on the relatively high number of specimens of different sizes referred to the genus, Prestosuchus seems to have been the most abundant large predatory archosaur in this part of Gondwana and probably represented the top of the food chain together with other taxa from Argentina, such as the contemporaneous Luperosuchus fractus (Desojo and Arcucci, 2009; Nesbitt and Desojo, 2017) and the younger Saurosuchus galilei (Sill, 1974; Alcober, 2000; Trotteyn et al., 2011) and Fasolasuchus tenax, and the Brazilian Rauisuchus tiradentes from higher in the Santa Maria Supersequence (Lautenschlager and Rauhut, 2015). 


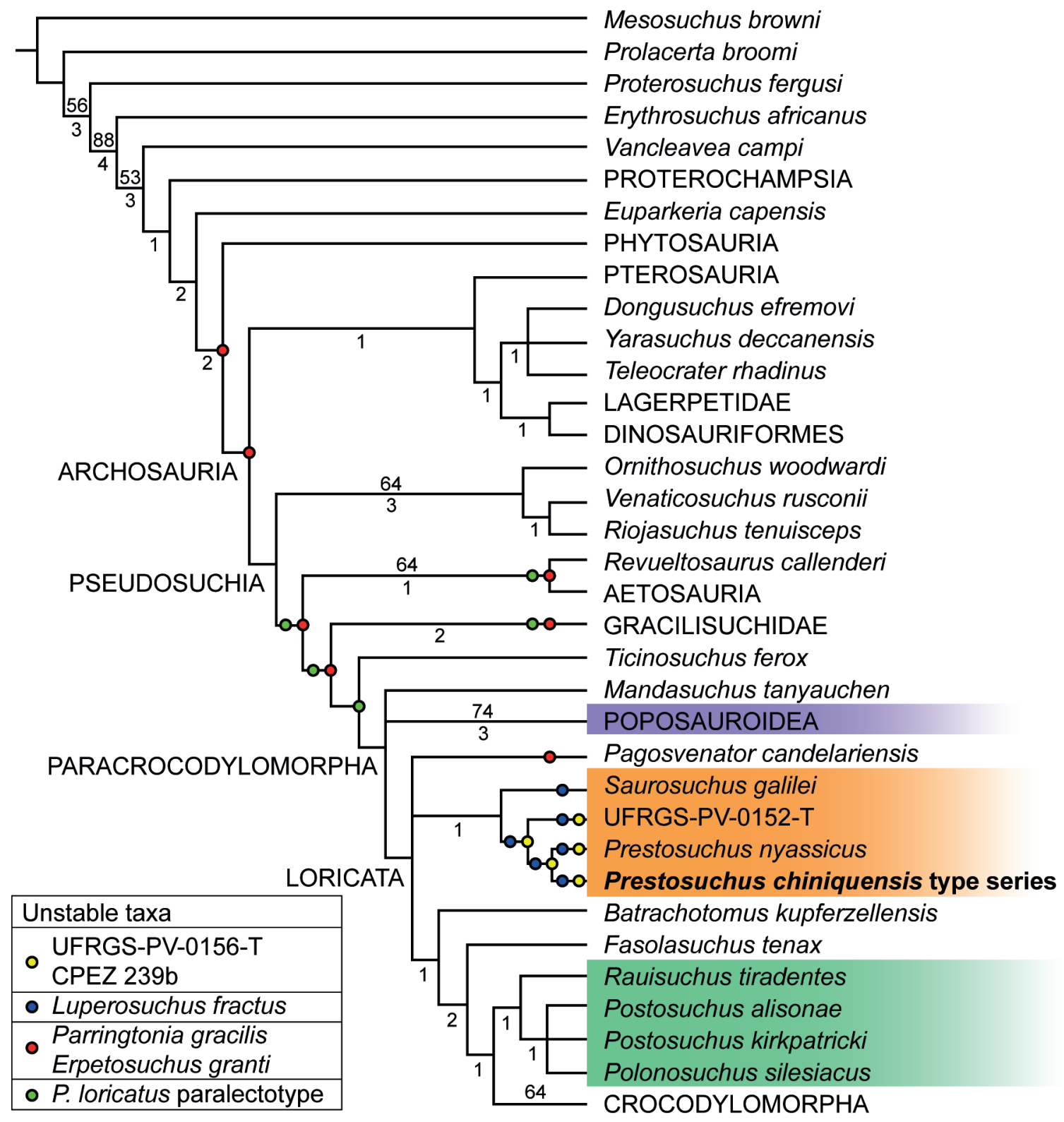

FIGURE 14. Reduced consensus tree of the 22815 most parsimonious trees of 1425 steps; bootstrap values over $50 \%$ indicated above branches and Bremer support indicated below branches. Orange: Prestosuchidae, green: Rauisuchidae, purple: Poposauroidea. Prestosuchus chiniquensis type series indicated in bold. Position of unstable taxa indicated with coloured circles.

In combination with extensive phylogenetic work in recent years, starting with the landmark analysis of Nesbitt (2011), recent discoveries and re-interpretations of "rauisuchian" taxa have shown that there is a rather large number of distinct lineages of predatory pseudosuchians that thrived during the Middle and Late Triassic, including ornithosuchids, gracilisuchids, poposauroids, prestosuchids, erpetosuchids, rauisuchids, and crocodylomorphs (Nesbitt et al., 2013b; Butler et al., 2014, Ezcurra et al., 2017). The diversity of size ranges and cranial and postcranial specialisations exhibited by these different lineages indicate niche partitioning between contemporaneous taxa belonging to different lineages (Stubbs et al., 2013; Turner and Nesbitt, 2013; Foth et al., 2016), but more research on functional and ecological aspects of Triassic pseudosuchians is needed.

Interestingly, with the exception of Prestosuchus nyassicus from Tanzania, prestosuchids are 
so far only known from southern South America, where they seem to represent important faunal components in the latest Ladinian to Carnian. On the other hand, the poposauroids, which are represented by various taxa in the late Middle to Late Triassic of the Northern Hemisphere, seem to be poorly represented in Gondwana, with the rare Sillosuchus longicervix from the Ischigualasto Formation (Carnian) of Argentina (Alcober and Parrish, 1997), two fragmentary sacral series from the Santa Maria Formation (Lacerda et al., 2014), and a new fragmentary specimen from the Lower Elliot Formation of South Africa (Tolchard et al., 2019). Likewise, rauisuchids seem to be more diverse in the Northern Hemisphere, with Rauisuchus tiradentes being the only taxon so far reported from southern Pangaea. This might also indicate some geographic separation of different pseudosuchian lineages, although the rare occurrences of some of these groups in "untypical" areas, as well as the presence of the genus Prestosuchus in both South America and Africa highlight the dispersal potential of basal loricatans. This pattern is clearly seen in several pseudosuchian lineages (aetosaurs, erpetosuchids, ornithosuchids, gracilisuchids) that are well spread over the supercontinent of Pangaea.

\section{CONCLUSIONS}

The anatomical revision of the type specimen of Prestosuchus chiniquensis, together with other material originally collected and described by von Huene $(1938,1942)$ shows that this species is a member of a monophyletic pseudosuchian group, the Prestosuchidae. The latter includes the Carnian Argentinean taxa Saurosuchus galilei and Luperosuchus fractus, as well as the genus Prestosuchus. Particularly, Prestosuchus seems to comprise at least three distinct species, the Ladinian-
Carnian Prestosuchus chiniquensis, the AnisianLadinian Prestosuchus nyassicus from Tanzania, as well as an unnamed species from the Carnian of Brazil (UFRGS-PV-0152-T). This group consists of large short-necked quadrupedal predators that coexisted with more gracile forms represented by basal loricatans (Rauisuchidae) and poposauroids recorded in Middle to Late Triassic continental ecosystems. These results further highlight the diversity and striking abundance of basal loricatans in southern Brazil (Santa Maria Supersequence), which reflects the success of pseudosuchian archosaurs in the Middle to Late Triassic of Gondwana.

\section{ACKNOWLEDGMENTS}

The authors thank numerous curators for access to specimens in their care: $R$. Schoch (SMNS), C. Schultz (UFRGS), A. Hohloch and P. Havlik (GPIT), H. Furrer (PIMUZ), J. Powell (PVL), R. Martinez (PVSJ), E. Vaccari and G. Cisterna (UNLR). For discussion we thank R. Butler, T. Sulej, S. Lautenschlager, M. Ezcurra, B. Mastrantonio, A. Martinelli, A. Sennikov, D. Gower, and S. Nesbitt. We thank J. Gonzalez for the life illustration of figure 3 and $\mathrm{G}$. Janssen for the photographs. JBD was supported by a Humboldt Foundation fellowship to study material in Munich and visit several European and Indian collections, and the same foundation supported a short research visit of OWMR in Argentina. MBvB was supported by a Deutscher Akademischer Austausch Dienst (DAAD) fellowship to study several collections in Europe. Access to the free version of TNT 1.5 was granted by the Willi Henning Society. We also thank the anonymous reviewers for their helpful suggestions that improved the quality of the manuscript.

\section{REFERENCES}

Alcober, O. 2000. Redescription of the skull of Saurosuchus galilei (Archosauria: Rauisuchidae). Journal of Vertebrate Paleontology, 20:302-316. https://doi.org/10.1671/02724634(2000)020[0302:rotsos]2.0.co;2

Alcober, O. and Parrish, J.M. 1997. A new poposaurid from the Upper Triassic of Argentina. Journal of Vertebrate Paleontology, 17(3):548-556. https://doi.org/10.1080/ 02724634.1997.10011001

Andreis, R.R., Bossi, G.E., and Montardo, D.K. 1980. O Grupo Rosário do Sul (Triássico) no Rio Grande do Sul, Brasil. Congresso Brasileiro de Geologia, 31(2):659-673. 
Azevedo, S.A.K. 1991. Prestosuchus chinequensis Huene 1942 (Reptilia, Archosauria, Thecodontia, Proterosuchia, Rauisuchidae), da Formação Santa Maria, Triássico do Estadodo Rio Grande do Sul, Brasil. Unpublished PhD Thesis, Universidade Federal do Rio Grande do Sul, Porto Alegre, Brazil.

Azevedo, S.A.K. 1995. Estudo morfofuncional do aparelho maxilomandibular de Prestosuchus chiniquensis Huene, 1942. Anais da Academia Brasileira de Ciências, 67(1):62-67.

Barberena, M.C. 1978. A huge thecodont skull from the Triassic of Brazil. Pesquisas, Institute de Geociências, Universidade Federal do Rio Grande do Sul, Porto Alegre, 9:62-75.

Bonaparte, J.F. 1970. Annotated list of the South American Triassic tetrapods, p. 665-682. In Haughton, S.H. (ed.), Second Gondwana Symposium, Proceedings and Papers. Council of Scientific and Industrial Research, Cape Town and Johannesburg.

Bonaparte, J.F. 1981. Descripción de "Fasolasuchus tenax" y su significado en la sistemática y evolución de los Thecodontia. Revista del Museo Argentino de Ciencias Naturales "Bernardino Rivadavia", 3:55-101.

Bonaparte, J.F. 1984. Locomotion in rauisuchid thecodonts. Journal of Vertebrate Paleontology, 3(4):210-218. https://doi.org/10.1080/02724634.1984.10011976

Bonaparte, J.F. 1997. El Triásico de San Juan, La Rioja: Argentina y sus dinosaurios. Museo Argentino de Ciencias Naturales "Bernardino Rivadavia", Buenos Aires, Argentina.

Brusatte, S.L., Benton, M.J., Desojo, J.B., and Langer, M.C. 2010. The higher-level phylogeny of Archosauria (Tetrapoda: Diapsida). Journal of Systematic Palaeontology, 8(1):3-47. https:// doi.org/10.1080/14772010903537732

Butler, R.J., Barrett, P.M., Abel, R.L., and Gower, D.J. 2009. A possible ctenosauriscid archosaur from the Middle Triassic Manda Beds of Tanzania. Journal of Vertebrate Paleontology, 29(4):1022-1031. https://doi.org/10.1671/039.029.0404

Butler, R. J., Brusatte, S.L., Reich, M., Nesbitt, S.J., Schoch, R.R., and Hornung, J.J. 2011. The sail-backed reptile Ctenosauriscus from the latest Early Triassic of Germany and the timing and biogeography of the early archosaur radiation. PLoS One, 6(10):e25693. https://doi.org/ 10.1371/journal.pone.0025693

Butler, R.J., Nesbitt, S.J., Charig, A.J., Gower, D.J., and Barrett, P.M. 2018. Mandasuchus tanyauchen, gen. et sp. nov., a pseudosuchian archosaur from the Manda Beds (? Middle Triassic) of Tanzania. Journal of Vertebrate Paleontology, 37(S1):96-121. https://doi.org/ 10.1080/02724634.2017.1343728

Butler, R.J., Sullivan, C., Ezcurra, M.D., Liu, J., Lecuona, A., and Sookias, R.B. 2014. New clade of enigmatic early archosaurs yields insights into early pseudosuchian phylogeny and the biogeography of the archosaur radiation. BMC Evolutionary Biology, 14(1):128. https:// doi.org/10.1186/1471-2148-14-128

Chatterjee, S. 1982. Phylogeny and classification of thecodontian reptiles. Nature, 295(5847):317. https://doi.org/10.1038/295317a0

Chatterjee, S. 1985. Postosuchus, a new thecodontian reptile from the Triassic of Texas and the origin of tyrannosaurs. Philosophical Transactions of the Royal Society of London Series B, 309:395-460. https://doi.org/10.1098/rstb.1985.0092

Chatterjee, S. 1993. Shuvosaurus, a new theropod. National Geographic Research and Exploration, 9:274-285.

Cope, E.D. 1869. Synopsis of the extinct Batrachia, Reptilia and Aves of North America. Transactions of the America Philosophical Society, 14(1):1-252.

de França, M.A., Langer, M.C., and Ferigolo, J. 2013. The skull anatomy of Decuriasuchus quartacolonia (Pseudosuchia: Suchia: Loricata) from the middle Triassic of Brazil. Geological Society, London, Special Publications, 379(1):469-501. https://doi.org/10.1144/SP379.8

Desojo, J.B. and Arcucci, A. 2009. New material of Luperosuchus fractus (Archosauria: Crurotarsi) from the Middle Triassic of Argentina: the earliest known South American Rauisuchian. Journal of Vertebrate Paleontology, 29:1311-1315. https://doi.org/10.1671/ 039.029 .0422

Desojo, J.B., Ezcurra, M.D., and Schultz, C.L. 2011. An unusual new archosauriform from the Middle-Late Triassic of southern Brazil and the monophyly of Doswelliidae. Zoological Journal of the Linnean Society, 161:839-871. https://doi.org/10.1111/j.10963642.2010.00655.x

Desojo, J.B. and Rauhut, O.W.M. 2008. New insights on 'rauisuchian' taxa (Archosauria: Crurotarsi) from Brazil. Symposium of Vertebrate Palaeontology and Comparative Anatomy, Dublin, Ireland, 12:31. 
Desojo, J.B. and Rauhut, O.W.M. 2009. The taxonomic status and phylogenetic position of the late Triassic Brazilian rauisuchian Prestosuchus. Journal of Vertebrate Paleontology, 29:8788A.

Desojo, J.B., Rauhut, O.W.M., and Ezcurra, M.D. 2010. Revision of the holotype of Rhadinosuchus gracilis (Archosauriformes: Proterochampsidae) from the early Late Triassic of southern Brazil. Zitteliana, 29:28.

Ezcurra, M.D. 2012. Comments on the taxonomic diversity and paleobiogeography of the earliest known dinosaur assemblages (late Carnian-earliest Norian). Historia Natural, Tercera Serie, 2(1):49-71.

Ezcurra, M.D. 2016. The phylogenetic relationships of basal archosauromorphs, with an emphasis on the systematics of proterosuchian archosauriforms. PeerJ, 4:e1778. https:// doi.org/10.7717/peerj.1778

Ezcurra, M.D., Desojo, J.B., and Rauhut, O.W.M. 2015. Redescription and Phylogenetic relationships of the proterochampsid Rhadinosuchus gracilis (Diapsida: Archosauriformes) from the early Late Triassic of Southern Brazil. Ameghiniana 52(4):391-417. https://doi.org/ 10.5710/AMGH.28.04.2015.2867

Ezcurra, M.D., Fiorelli, L.E., Martinelli, A.G., Rocher, S., von Baczko, M.B., Ezpeleta, M., Taborda, J.R.A., Hechenleitner, E.M., Trotteyn, M.J., and Desojo, J.B. 2017. Deep faunistic turnovers preceded the rise of dinosaurs in southwestern Pangaea. Nature Ecology \& Evolution, 1(10):1477. https://doi.org/10.1038/s41559-017-0305-5

Ezcurra, M.D., Nesbitt, S.J., Fiorelli, L.E., and Desojo, J.B. 2019. New specimen sheds light on the anatomy and taxonomy of the early Late Triassic dinosauriforms from the Chañares Formation, NW Argentina. The Anatomical Record. https://doi.org/10.1002/ar.24243

Foth, C., Ezcurra, M.D., Sookias, R.B., Brusatte, S.L., and Butler, R.J. 2016. Unappreciated diversification of stem archosaurs during the Middle Triassic predated the dominance of dinosaurs. BMC Evolutionary Biology, 16(1):188. https://doi.org/10.1186/s12862-016-0761-6

França, M.A.G., Ferigolo, J., and Langer, M.C. 2011. Associated skeletons of a new middle Triassic "Rauisuchia" from Brazil. Naturwissenschaften, 98(5):389. https://doi.org/10.1007/ s00114-011-0782-3

Furin, S., Preto, N., Rigo, M., Roghi, G., Gianolla, P., Crowley, J.L., and Bowring, S.A. 2006. High-precision U-Pb zircon age from the Triassic of Italy: implications for the Triassic time scale and the Carnian origin of calcareous nannoplankton and dinosaurs. Geology, 34;10091012. https://doi.org/10.1130/0091-7613(2007)35[146:huzaft]2.0.co;2

Garcia, M.S., Mueller, R.T., and Dias-da-Silva, S. 2019. On the taxonomic status of Teyuwasu barberenai Kischlat, 1999 (Archosauria: Dinosauriformes), a challenging taxon from the Upper Triassic of southern Brazil. Zootaxa, 4629(1):146-150. https://doi.org/10.11646/ zootaxa.4629.1.12

Gauthier, J. and Padian, K. 1985. Phylogenetic, functional, and aerodynamic analyses of the origin of birds and their flight, p. 185-197. In Hecht, M.K., Ostrom, J.H., Viohl, G., and Wellnhofer, P. (eds.), The Beginning of Birds. Freunde des Jura-Museums, Eichstätt.

Gebauer, E.V.I. 2004. Neubeschreibung von Stagonosuchus nyassicus v. Huene, 1938 (Thecodontia, Rauisuchia) aus der Manda-Formation (Mittlere Trias) von Südwest-Tansania. Neues Jahrbuch für Geologie und Paläontologie, Abhandlungen, 231:1-35.

Goloboff, P.A., Farris, J.S., and Nixon, K.C. 2008a. TNT, a free program for phylogenetic analysis. Cladistics, 24:774-786. https://doi.org/10.1111/j.1096-0031.2008.00217.x

Goloboff, P.A., Farris, J.S., and Nixon, K.C. 2008b. TNT: tree analysis using new technologies. http://www.zmuc.dk/public/phylogeny.

Gower, D.J. 2000. Rauisuchian archosaurs (Reptilia, Diapsida): an overview. Jahrbuch für Geologie und Paläontologie, Abhandlungen, 218:447-448. https://doi.org/10.1127/njgpa/218/ 2000/447

Gower, D.J. and Schoch, R.R. 2009. Postcranial anatomy of the rauisuchian archosaur Batrachotomus kupferzellensis. Journal of Vertebrate Paleontology, 29:103-122. https:// doi.org/10.1080/02724634.2009.10010365

Horn, B.L.D., Melo, T.M., Schultz, C.L., Philipp, R.P., Kloss, H.P., and Goldberg, K. 2014. A new third-order sequence stratigraphic framework applied to the Triassic of the Paraná Basin, Rio Grande do Sul, Brazil, based on structural, stratigraphic and paleontological data. Journal of South American Earth Sciences, 55:123-132. http://doi.org/10.1016/j.jsames.2014.07.007 
Hutchinson, J.R. 2001. The evolution of femoral osteology and soft tissues on the line to extant birds (Neornites). Zoological Journal of the Linnean Society, 131:169-177. https://doi.org/ 10.1111/j.1096-3642.2001.tb01314.x

Kischlat, E.E. 1999. A new dinosaurian rescued from the Brazilian Triassic: Teyuwasu barberenai, new taxon. Paleontologia em Destaque, Boletim Informativo da Sociedade Brasileira de Paleontologia, 14(26):58.

Kischlat, E.E. 2000. Tecodôncios: A Aurora dos Arcossáurios no Triássico, p. 246-272. In Holz, M. and De Ros, L.F. (eds.), Paleontologia do Rio Grande do Sul, Porto Alegre. Universidade Federal do Rio Grande do Sul, Porto Alegre.

Kischlat, E.E. and Barberena, M.C. 1999. Prestosuchus chiquensis (Crurotarsi, Archosauria) does not need a neotype! Paleontologia em Destaque, Boletim Informativo da Sociedade Brasileira de Paleontologia, 14(26):53.

Krebs, B. 1976. Pseudosuchia, p. 40-98. In Kuhn, O. (ed.), Handbuch der Palaeoherpetologie, Teil 13: Thecondontia. Gustav Fischer-Verlag, München.

Lacerda, M.B., Franca, M.A., and Schultz, C.L. 2018. A new erpetosuchid (Pseudosuchia, Archosauria) from the Middle-Late Triassic of Southern Brazil. Zoological Journal of the Linnean Society, 184(3):804-824. https://doi.org/10.1093/zoolinnean/zly008

Lacerda, M.B., Mastrantonio, B.M., Fortier, D.C., and Schultz, C.L. 2016. New insights on Prestosuchus chiniquensis Huene, 1942 (Pseudosuchia, Loricata) based on new specimens from the "Tree Sanga" Outcrop, Chiniquá Region, Rio Grande do Sul, Brazil. PeerJ, 4:e1622. https://doi.org/10.7717/peerj.1622

Lacerda, M.B., Preto, F.A., Schultz C.L., Langer, M.C., and França, M.A.G. 2014. The first record of Poposauridae for Brazil, Late Triassic Caturrita Formation. Abstract volume of the 74th Annual Meeting of the Society of Vertebrate Paleontology, Berlin, Germany, p. 164.

Lacerda, M.B., Schultz, C.L., and Bertoni-Machado, C. 2015. First 'Rauisuchian' archosaur (Pseudosuchia, Loricata) for the Middle Triassic Santacruzodon Assemblage Zone (Santa Maria Supersequence), Rio Grande do Sul State, Brazil. PLoS ONE, 10(2):e0118563. https:/ /doi.org/10.1371/journal.pone.0118563

Langer, M.C., Ribeiro, A.M., Schultz, C.L., and Ferigolo, J. 2007. The continental tetrapodbearing Triassic of South Brazil, p. 201-218. In Lucas S.G. and Spielmann J.A. (eds.), The Global Triassic. New Mexico Museum of Natural History, Albuquerque.

Lautenschlager, S. and Desojo, J.B. 2011. Reassessment of the Middle Triassic rauisuchian archosaurs Ticinosuchus ferox and Stagonosuchus nyassicus. Paläontologische Zeitschrift, 85(4):357-381. https://doi.org/10.1007/s12542-011-0105-1

Lautenschlager, S. and Rauhut, O.W.M. 2015. Osteology of Rauisuchus tiradentes from the Late Triassic (Carnian) Santa Maria Formation of Brazil, and its implications for rauisuchid anatomy and phylogeny. Zoological Journal of the Linnean Society, 173(1):55-91. https:// doi.org/10.1111/zoj.12196

Lessner, E.J., Stocker, M.R., Smith, N.D., Turner, A.H., Irmis, R.B., and Nesbitt, S.J. 2016. A new rauisuchid (Archosauria, Pseudosuchia) from the Upper Triassic (Norian) of New Mexico increases the diversity and temporal range of the clade. PeerJ, 4:e2336. https://doi.org/ 10.7717/peerj.2336

Liparini, A. and Schultz, C.L. 2013. A reconstruction of the thigh musculature of the extinct pseudosuchian Prestosuchus chiniquensis from the Dinodontosaurus Assemblage Zone (Middle Triassic Epoch), Santa Maria 1 Sequence, southern Brazil. Geological Society, London, Special Publications, 379(1):441-468. https://doi.org/10.1144/SP379.20

Maddison, W.P. and Maddison, D.R. 2018. Mesquite: A Modular System for Evolutionary Analysis. Version 3.51. http://www.mesquiteproject.org

Marsicano, C.A., Irmis, R.B., Mancuso, A.C., Mundil, R., and Chemale, F. 2015. The precise temporal calibration of dinosaur origins. Proceedings of the National Academy of Sciences, 113(3):509-513. https://doi.org/10.1073/pnas.1512541112

Martinez, R.N., Sereno, P.C., Alcober, O.A., Colombi, C.E., Renne, P.R., Montañez, I. P., and Currie, B.S. 2011. A basal dinosaur from the dawn of the dinosaur era in southwestern Pangaea. Science, 331(6014):206-210. https://doi.org/10.1126/science.1198467

Mastrantonio, B.M. 2010. Descrição osteológica de materiais cranianos e pós-cranianos de Prestosuchus chiniquensis (Archosauria, Rauisuchia) do Meso-Triássico do RS (Biozona de Dinodontosaurus, Formação Santa Maria) e considerações filogenéticas sobre os rauissúquio. Unpublished PhD Thesis. Universidade Federal do Rio Grande do Sul, Porto Alegre, Brazil. 
Mastrantonio, B.M., von Baczko, M.B., Desojo, J.B., and Schultz, C.L. 2019. The skull anatomy and cranial endocast of the pseudosuchid archosaur Prestosuchus chiniquensis from the Triassic of Brazil. Acta Palaeontologica Polonica, 64(1):171-198. https://doi.org/10.4202/ app.00527.2018

Mastrantonio, B.M., Schultz, C.L., Desojo, J.B., and Garcia, J.B. 2013. The braincase of Prestosuchus chiniquensis (Archosauria: Suchia). Geological Society, London, Special Publications, 379(1):425-440. https://doi.org/10.1144/SP379.10

Meers, M.B. 2003. Crocodylian forelimb musculature and its relevance to Archosauria. The Anatomical Record, Part A, 274:891-916. https://doi.org/10.1002/ar.a.10097

Melo, T.P., Martinelli, A.G., and Soares, M.B. 2017. A new gomphodont cynodont (Traversodontidae) from the Middle-Late Triassic Dinodontosaurus assemblage zone of the Santa Maria Supersequence, Brazil. Palaeontology, 60(4):571-582. https://doi.org/10.1111/ pala.12302

Morel, E.M., Artabe, A.E., Zavattieri, A.M., and Bonaparte, J.F., 2001. Cronología del Sistema Triásico, p. 227-257. In Artabe, A.E., Morel E.M., and Zamuner A.B. (eds.), El Sistema Triásico en la Argentina, Fundación Museo de La Plata "Fransisco P. Moreno", La Plata.

Muttoni, G., Kent, D.V., Olsen, P.E., Di Stefano, P., Lowrie, W., Bernasconi, S.M., and Hernandez, F.M. 2004. Tethyan magnetostratigraphy from Pizzo Mondello (Sicily) and correlation to the Late Triassic Newark astrochronological polarity time scale. Geological Society of America Bulletin, 116:1043-1058. https://doi.org/10.1130/B25326.1

Nesbitt, S.J. 2003. Arizonasaurus and its implications for archosaur divergence. Proceedings of the Royal Society of London, Series B, 270:234-237. https://doi.org/10.1098/rsbl.2003.0066

Nesbitt, S.J. 2005. The osteology of the pseudosuchian Arizonasaurus babbitti. Historical Biology, 17:19-47. http://doi.org/10.1080/08912960500476499

Nesbitt, S.J. 2007. The anatomy of Effigia okeeffeae (Archosauria, Suchia), theropod-like convergence, and the distribution of related taxa. Bulletin of the American Museum of Natural History, 302:1-84. https://doi.org/10.1206/0003-0090(2007)302[1:taoeoa]2.0.co;2

Nesbitt, S.J. 2011. The early evolution of archosaurs: relationships and the origin of major clades. Bulletin of the American Museum of Natural History, 352:1-292. https://doi.org/ 10.1206/352.1

Nesbitt, S.J., Brusatte, S.L., Desojo, J.B., Liparini, A., De França, M.A., Weinbaum, J.C., and Gower, D.J. 2013a. Rauisuchia. Geological Society, London, Special Publications, 379(1): 241-274. https://doi.org/10.1144/SP379.1

Nesbitt, S.J., Butler, R.J., Ezcurra, M.D., Barrett, P.M., Stocker, M.R., Angielczyk, K.D., Smith, R.M.H., Sidor, C.A., Niedźwiedzki, G., Sennikov, A.G., and Charig, A.J. 2017. The earliest bird-line archosaurs and the assembly of the dinosaur body plan. Nature, 544(7651):484. https://doi.org/10.1038/nature22037

Nesbitt, S.J., Butler, R.J., Ezcurra, M.D., Charig, A.J., and Barrett, P.M. 2018. The anatomy of Teleocrater rhadinus, an early avemetatarsalian from the lower portion of the Lifua Member of the Manda Beds (Middle Triassic). Journal of Vertebrate Paleontology, 37(S1):142-177. https://doi.org/10.1080/02724634.2017.1396539

Nesbitt, S.J. and Desojo, J.B. 2017. The osteology and phylogenetic position of Luperosuchus fractus (Archosauria: Loricata) from the latest Middle Triassic or earliest Late Triassic of Argentina. Ameghiniana, 54(3):261-282. http://doi.org/10.5710/AMGH.09.04.2017.3059

Nesbitt, S.J., Desojo, J.B., and Irmis, R.B. 2013b. Anatomy, phylogeny and palaeobiology of early archosaurs and their kin. Geological Society, London, Special Publications, 379(1):1-7. https://doi.org/10.1144/SP379.21

Nesbitt, S.J. and Norell, M.A. 2006. Extreme convergence in the body plans of an early suchian (Archosauria) and ornithomimid dinosaurs (Theropoda). Proceedings of the Royal Society of London, Series B, 273:1045-1048. https://doi.org/10.1098/rspb.2005.3426

Parrish, J.M. 1993. Phylogeny of the Crocodylotarsi, with reference to archosaurian and crurotarsan monophyly. Journal of Vertebrate Paleontology, 13:287-308. https://doi.org/ 10.1080/02724634.1993.10011511

Peyer, K., Carter, J.G., Sues, H.D., Novak, S.E., and Olsen, P.E. 2008. A new suchian archosaur from the Upper Triassic of North Carolina. Journal of Vertebrate Paleontology, 28(2):363-381. https://doi.org/10.1671/0272-4634(2008)28[363:ansaft]2.0.co;2 
Raugust, T. 2014. Descrição e análise filogenética de um novo material de Rauisuchia (Archosauria, Crurotarsi) da Formação Santa Maria, Triássico Médio Sul-RioGrandense, Brasil. Unpublished PhD Thesis. Instituto de Geociências, Universidade Federal do Rio Grande do Sul, Porto Alegre, Brazil.

Reichel, M., Schultz, C.L., and Soares, M.B. 2009. A new traversodontid cynodont (Therapsida, Eucynodontia) from the Middle Triassic Santa Maria Formation of Rio Grande do Sul, Brazil. Palaeontology, 52:229-250. https://doi.org/10.1111/j.1475-4983.2008.00824.x

Reig, O.A. 1959. Primeros datos descriptivos sobre nuevos reptiles arcosaurios del Triásico de Ischigualasto (San Juan, Argentina). Revista de la Asociación Geológica Argentina, 13:257270.

Roberto-da-Silva, L., Franca, M.A., Cabreira, S.F., Mueller, R.T., and Dias-da-Silva, S. 2016. On the presence of the subnarial foramen in Prestosuchus chiniquensis (Pseudosuchia: Loricata) with remarks on its phylogenetic distribution. Anais da Academia Brasileira de Ciências, 88(3):1309-1323. https://doi.org/10.1590/0001-3765201620150456

Roberto-da-Silva, L., Müller, R.T., de França, M.A.G., Cabreira, S.F., and Dias-da-Silva, S. 2018. An impressive skeleton of the giant top predator Prestosuchus chiniquensis (Pseudosuchia: Loricata) from the Triassic of Southern Brazil, with phylogenetic remarks. Historical Biology. https://doi.org/10.1080/08912963.2018.1559841

Romer, A.S. 1966. Vertebrate Paleontology. 3rd Edition. University of Chicago Press, Chicago.

Romer, A.S. 1971. The Chañares (Argentina) Triassic reptile fauna. VIII. A fragmentary skull of a large thecodont, Luperosuchus fractus. Breviora, 373:1-8.

Schmitt, M.R., Martinelli, A.G., Melo, T.P., and Soares, M.B. 2019. On the occurrence of the traversodontid Massetognathus ochagaviae (Synapsida, Cynodontia) in the early late Triassic Santacruzodon Assemblage Zone (Santa Maria Supersequence, southern Brazil): Taxonomic and biostratigraphic implications. Journal of South American Earth Sciences, 93:36-50. https://doi.org/10.1016/j.jsames.2019.04.011

Sill, W.D. 1974 The anatomy of Saurosuchus galilei and the relationships of the rauisuchid thecodonts. Bulletin of the Museum of Comparative Zoology, 146:317-362.

Stubbs, T.L., Pierce, S.E., Rayfield, E.J., and Anderson, P.S. 2013. Morphological and biomechanical disparity of crocodile-line archosaurs following the end-Triassic extinction. Proceedings of the Royal Society B: Biological Sciences, 280(1770):20131940. https:// doi.org/10.1098/rspb.2013.1940

Tolchard, F., Nesbitt, S.J., Desojo, J.B., Viglietti, P., Butler, R.J., and Choiniere, J.N. 2019. 'Rauisuchian' material from the Lower Elliot Formation of South Africa: implications for Late Triassic biogeography and biostratigraphy. Journal of South American Earth Sciences, 160:103610. https://doi.org/10.1016/j.jafrearsci.2019.103610

Trotteyn, M.J., Desojo, J.B., and Alcober, O.A. 2011. Nuevo material postcraneano de Saurosuchus galilei Reig (Archosauria: Crurotarsi) del Triásico Superior del centro-oeste de Argentina. Ameghiniana, 48(1):13-28. https://doi.org/10.5710/AMGH.v48i1(265)

Turner, A.H. and Nesbitt, S.J. 2013. Body size evolution during the Triassic archosauriform radiation. Geological Society, London, Special Publications, 379(1):573-597. https://doi.org/ 10.1144/SP379.15

von Baczko, M.B., Desojo, J.B., and Pol, D. 2014. Anatomy and phylogenetic position of Venaticosuchus rusconii Bonaparte, 1970 (Archosauria, Pseudosuchia), from the Ischigualasto Formation (Late Triassic), La Rioja, Argentina. Journal of Vertebrate Paleontology, 34(6):1342-1356. https://doi.org/10.1080/02724634.2014.860150

von Baczko, M.B., Desojo, J.B., and Rauhut, O.W.M. 2019. New and old materials of the MiddleLate Triassic pseudosuchian Prestosuchus chiniquensis and the validity of "Prestosuchidae". Program and abstracts of the XVII Conference of the European Association of Vertebrate Paleontologists, Brussels, Belgium, p. 15.

von Huene, F. 1938. Die fossilen Reptilien des südamerikanischen Gondwanalandes. Neues Jahrbuch für Mineralogie, Geologie und Paläontologie, 1938:142-151.

von Huene, F. 1939. Ein grosser Stagonolepide aus der jüngeren Trias Ostafrikas. Neues Jahrbuch für Geologie und Paläeontologie, Beilage-Bände Abt. B, 80:264-278.

von Huene, F. 1942. Die fossilen Reptilien des südamerikanischen Gondwanalandes. Ergebnisse der Sauriergrabungen in Südbrasilien 1928/29. C.H. Beck, München, Germany. von Huene, F. 1956. Paläontologie und Phylogenie der niederen Tetrapoden. Veb G. Fischer, Jena. 
von Huene, F. and Stahlecker, R. 1931. Geologische Beobachtungen in Rio Grande do Sul. Neues Jahrbuch für Mineralogie, Geologie und Paläontologie, 1931:1-82.

Weinbaum, J.C. 2011. The skull of Postosuchus kirkpatricki (Archosauria: Paracrocodyliformes) from the Upper Triassic of the United States. PaleoBios, 30(1): 18-44.

Weinbaum, J.C. 2013. Postcranial skeleton of Postosuchus kirkpatricki (Archosauria: Paracrocodylomorpha), from the upper Triassic of the United States. Geological Society, London, Special Publications, 379(1):525-553. https://doi.org/10.1144/sp379.7

Weinbaum, J.C. and Hungerbühler, A. 2007. A revision of Poposaurus gracilis (Archosauria: Suchia) based on two new specimens from the Late Triassic of the southwestern U.S.A. Palaöntologische Zeitschrift, 81:131-145. https://doi.org/10.1007/BF02988388

Welles, S.P. 1947. Vertebrates from the Upper Moenkopi Formation of the Northern Arizona. University of California Publications in Geological Sciences, 84:1-56.

Zerfass, H., Lavina, E.L., Schultz, C.L., Vasconcellos Garcia, A.J., Faccini, U.F., and Chemale, F. Jr. 2003. Sequence stratigraphy of continental Triassic strata of Southernmost Brazil: a contribution to Southwestern Gondwana palaeogeography and palaeoclimate. Sedimentary Geology, 161:85-105. https://doi.org/10.1016/s0037-0738(02)00397-4

Zittel, K.A. 1887-90. Handbuch der Palaeontologie. Abteilung Palaeozoologie. R. Oldenbourg, Munich and Leipzig. 
Desojo, von BAczko, \& Rauhut: Type materials of PREstosuchus

\section{APPENDIX 1}

\section{Data matrix}

Mesosuchus_browni

?1000?0000000?1000000?0000?00?100000?000 $00000 ? 000000000001000000000 ? ? 0 ? 000000000$ $000000000 ? 0000010000000000000000000 ? ? ? 00$ 0?00010?0?0??000?000?000000???0000000000 0??000001??0?0010??00?000100000?00000000 $0000000000000000000010 ? 000000 ? ? ? ? 0 ? ? 0000$ ?0000000?00????00?0000?00??0?00000000000 $000 ? ? 00000000000000 ? ? ? 00000000000 ? 0 ? ? 000$ $000000000000000000 ? ? 10001000 ? ? 0 ? ? 00000 ? 0$ $000000 ? ? 0000000000 ? 00000000000 ? 0000 ? 0000$ 0??????????0?000??????

Prolacerta_broomi

$0000020000 ? 00 ? 0000000 ? 0000 ? 00 ? 100000 ? 000$ $000000000000000000000000000 ? ? 0 ? 000000000$ $000000000 ? 000000000000000000000000000000$ 0?00000??00??000?0000000010??100000?0000 $0 ? 00000000000000000010110000000000001000$ $0000000000000000000010 ? 00000000000000000$ $0000000000000000000000 ? 00 ? ? 0 ? 00000000000$ 000??00000000000000???00000000000?0??000 $000000000000000000 ? ? 100010000 ? ? ? ? ? 0000 ? 0$ 000000??0000000000?0000000000000000?1000 0??????????0?00???????

Archosaurus_rossicus

????03010?????????????????????????????

????????????????????????????????????????

???????????????????????????????????????? ???????????????????????????????????????? ???????????????????????????????????????? ???????????????????????????????????????? ???????????????????????????????????????? ???????????????????????????????????????? ???????????????????????????????????????? ???????????????????????????????????????? ??????????????????????

Proterosuchus $000003010000000000000 ? 000020001000000000$ $0000000000000000000000100000 ? 13000000000$ $0000000100010000000000000000000000000 ? 00$ $000001000000 ? 00101001100000 ? ? 100 ? 0000000$ $0000000100000000000 ? 00000000000000001000$ $000000000000000 ? 000010 ? 000000 ? ? 0 ? 0 ? 00000$ ?000000??000?0?0??0000?00??0?00000000000 $000 ? ? 00000000000000 ? ? ? 00000000000 ? 0 ? ? 000$ $000000000000000000 ? 0100000000000000000 ? 0$ 000000??0000000000?0000000000000000?1000 0??????????0000???????

Erythrosuchus_africanus 0100020000020000000000000020000000000000 ?000000000000000000000100000110100000000
0000000100011100100000000000000000000000 $010000000000000111000100100 ? ? 00000000000$ $0001000100000111000 ? 00 ? 00000000 ? 00010000$ $001000000000 ? ? ? 0100100 ? 0000001 ? 0001001 ? 0$ 0??0?00??01??0????0?00?00??1010000000000 000??000000000000000100000000000010??000 $0000000000000000000010001100000 ? 000000 ? 0$ $00 ? 0 ? 0001000000000 ? 010000 ? 000000101 ? 000 ?$ 0???????????000?100-00

Vancleavea_campi $1100020000100 ? 100000000000 ? 00 ? 000000 ? ? ? 0$ ?00100000?00000?00000010?000?10000000100 000????????1???????????0?00000???00??0?? ?????10??????00??00100??110??10?0000?0?0 0??10011000001??1???00?001?00?000?0?0000 ???000000000???010010?????0??00001000000 000000???00??0?0??010??00??0?00000000?00 0????00???0000000?0010000000000000???100 ?00000000000000000??1000110???????0000?0 $001000001000000000 ? 01000000 ? 0 ? 00 ? ? ? ? 00 ? ?$ 1?1?100011?2?0000????0

Chanaresuchus_bonapartei $10000200000001000000000000[0$ 1]000000000000000010011000000100000001000 $00010000100000000000010 ? 0 ? 11011000000000$ 000000000000000 ??0??0???0000011101000011 $0 ? ? 0000000000000010001000001011000000000$ $000000000000000010000000 ? 0 ? ? ? 0100100 ? 000$ 000000010000000?????????????????????00? ?1000000000000000??000000000000000100010 0000000110010000000000000000000100101011 000????00000?00000100010000000?0?0100000 01000011000020100?0?0001??000??00-00

Tropidosuchus_romeri $10 ? ? 0 ? 000000000000000 ? 0000[0$ 1]0000?0000001??0010011000000100000001000 00?100001000000000?001??????011?00?0?0?0 0000??0?0?????0?????0??????0011101?00011 0??00??00??0??00?1?001000?01011000100000 $0000000 ? ? 0000000100000000 ? 0 ? ? 0100100 ? 000$ 0000000100???????????????????????????00? ?1?00000000000000??000000?00000000100010 $0000000010010000 ? 00000000000000100101011$ 000???000000?0001010001000000010?0100000 010000110?0020100?0??000??000??00-00

Euparkeria_capensis $0100000000 ? 00000000000000020001000000000$ $0000000100000000000000100000[0$

1] 100001000000000000100011101100000000000 000000000000001001000000000111000000100 ? ?000000000100001000100000101000000000000 $0010000010000010000000000010100000 ? 00000$ 
$0000010000000000000 ? ? 010 ? 0 ? 00 ? 0100 ? 00 ? ? 1$ $000000000000000 ? ? 00000000000000010001000$ $0000001001000000000000000000000000 ? 00100$ $0000000000 ? 1000010001000000110 ? 010000000$ $0000100 ? 0000110100100000001 ? ? 00-00$

Parasuchus hislopi

??00030001000110001000000020000000000000 ?000010100000?00000000100000010000001000 $00000001 ? ? 0111121100000000000000000 ? ? ? ? 00$ 0?00?????0??0011111?000110??100?00?00?100 ?1?011000001111?0000?00000001000011000001 $000000 ? ? 00010001000 ? 001000000000000000 ? 0$ 0000??00????00?0?00?00??10?000?000000000 ??00?0000000000001000?00000000010010?00? 0?00000??0000001000100100??0??00000??000 $010 ? 110 ? 0010111 ? 11000000000001000 ? 0011100$ ?00000?00--???????

Smilosuchus_gregorii ??00030001000110001000000020000000000000 0000010100000000000000100000010000001000 $00000001 ? ? 011 ? 1211000001 ? 0000000000 ? ? ? 00$ 0??0?10???0??00111210000110??100?00000110 $00100110000 ? 1111 ? ? ? 00 ? 0000000100001 ? 00000$ $10000001000010100000 ? 001000000000000000$ ? ?????????????????????00??100000000000000 $0 ? ? 0000000000000001000000000000010010000$ 00000000?00000001100100???????000000?100 $0010011010010111 ? 1100001 ? ? ? ? 00 ? ? ? ? 00 ? 2110$ 0??0000?00--0??????

Pseudopalatus_pristinus ??00030001000110001000000020000000000000 0000010100000000000000100000010100001000 $0000000 ? 0 ? 0111121100000100000000000000000$ $01001000000000111210000110 ? ? 100 ? 000001100$ ?100110000?111100000000000001000011000001 000000??00010100000?00100000000000000??? 000???00000?0???100?00??1000000000000000 ??00000000000000010000000000000100100000 $00000000000000011001001000001000000 ? 1000$ $010011 ? 10010111 ? 1100001000000100 ? 00021100$ 10000010?--0??????

Gracilisuchus_stipanicicorum $01030100000000[0$ 1]000000000001000010000100000101001100000 1 -

$010000100110111100100100000 ? ? 001 ? ? ? ? 1 ?[1$

2]21101?010??0[0 1]000???[0 1]????????0?10????0?001210000001[0 1]0??000100000?000?10001000001111?0010000 $00000100001100000100000000 ? ? ? ? ? 1 ? ? ? ? ? ? ? ?$ ??????????????????????????????????????00 ??1000000000000010???2000010000?00010001 0000000?01001?100?0000????000001000???00 $1 ? 00001100000 ? 1000011111020011221 ? 1100000$ 000000100?00001111000?010?100-0?0-00
Turfanosuchus_dabanensis $00030200000 ? 00 ? 000000 ? 000000000 ? 00001000$ ?110?00100020100000000100010110000100000 000?0???0???100211010000000?000002?????0 01100?00?00??0012100?0001?0??00??000?0?0 00?1000100000101??0??0????000?1000??10?0 001000000?00??????1??????????0000?001???

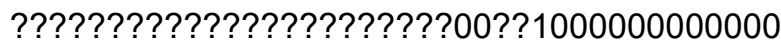

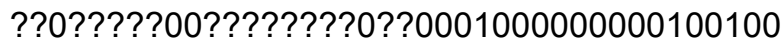
00?000000000000010??101??????????00000?? $001010 ? 110[1$

2]0011221?1????????0???????00??1111??00?1 ??2000??????

Yonghesuchus_sangbiensis

??030200?001000000?00?000000000?????1000 ????100????0???-

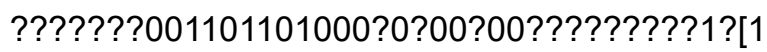
2]21?01?010???????????????????0?????????

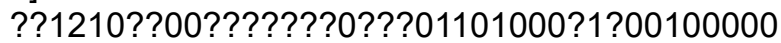
101???????????????????1????????????????? ???????????????????????????????????????? ???????????????????????????????????????? ???????????????????????????????????????? ???????????????????????????????????????? ???????????????????????????????????????2 ??0??????

Ornithosuchus_longidens

??00000100001000000000000000?001100?0000 ?000000100000?00000001100000010000000000 00001001000???????????????0000?????????? ??????0??????00121000200110??00?000000?1 000?0001000001111??????0??0001100???10100 ?10?0?0?1?000101001010010000000??00???0? 0?0100???0??0???????0?00??10000000001000 $10 ? ? 00 ? 0001000000 ? 11000 ? 00100000110010 ? 0$ 0?0?0?0?1000000??1????0???????????0????? ????1?21010010120???000?????????????1?21 10000100010000??00-0?

Riojasuchus_tenuisceps 0000000100001000000000000000110110000000 0000000100000000000001100000010000000000 $000010010 ? 011 ? 2211010000 ? 000000 ? ? 00 ? ? ? ? ?$ 0??0??0??????00121000200110??00?00000011 $00010001000001111000000000000111000 ? 10100$ 0?010010???????100101011?00000001001100? 0001000?00??0????0?0??00??10000000001000 ?0??0?000????0?0?01100010010000001001010 $0 ? 0000001 ? 000001011001001000000100000 ? 10$ $00011021010010120 ? 1100000000000100 ? 00021$ 1000020001?0100?0???0

Venaticosuchus_rusconii

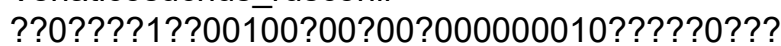
???????????????????????????0????00????? 00?010010?0?0??21101?0???0????????????? 
Desojo, von BAczKo, \& RaUhut: Type materials of PREstosuchus

???0???????????121???2???????00??200000? 002??00100000111???????????????????????? ???????????????????????????????????????? ???????????????????????????????????????? ???????????????????????????????????????? ???????????????????????????????????????? ???????????????????????????????????????? ????????????0??0??????

Revueltosaurus_callenderi 0003020000030011000000100120100100000000 0010000100000100000000100110112000100000 $000000010 ? 01112211010000000000 ? 00200 ? ? 00$ 02100??????0?0012100?00011???00000000010 $000100120000 ? 1111000000001000020000110100$ $01000000000 ? 0101001010010000000000011011$ 000?0???000????0??????00???0000000000000 00??000000000000001100010000000001001000 $0000000010000001000001001 ? 00000100000 ? 10$ 000110110110102210110?000000?00??0?00??11 001?211012001??0????

Stagonolepis_robertsoni $00000210000 ? 00110000000111001001000 ? ? 0 ? 1$ $000010010000010000001110011 ? ? 1 ? 001 ? 00000$ $01000001 ? 101 ? ? 221101000000 ? 0001002 ? 01100$ $0 ? ? 00 ? ? 01020 ? 0012100001011 ? ? ? 000 ? 21101 ? 0$ 00?101000010?1111???????0?000010001110100 010000000??001?1011???0100000000000????? 00010???01000000?0100?00??10100000000000 0???00?0000000000?11000?00000000010010?0 0?00000????0000??11001001????????00????? ???11???0?1????????10?00000?0??10?0000?1 1001121101?100?[0 1]0??00

Aetosaurus ferratus $0000011000000011 ? 0000 ? 011000100 ? 000 ? 100 ?$ ?00010010?0001000??011110110112000100010? 100000???????221?01?000?00000??????????0 ??0?1???????001210000101110000??21??1?00 0?101010010?1111??????????????????????0? 0100000???000101?01010010000000000011011 000?00??00000????0100?0[0

1]??10?000000000000???00?0000000000011000 1000000000100100?0?00000?10?000010???0?? 0??????????????????????????1?1?2?1?????? ??????????0????21?00112110121001?0???0

Longosuchus_meadei

??001?????0?001?000000011000100?00000001 0000??01?0??01??0000?11???1?1????11000?0 0??0?00?0001?12211010000000000100200?100 02100?00?02000012100001011???0?002110100 $000101000010 ? 11110 ? 00000 ? ? 00001000 ? ? 1010$ 00?000000??0???01011?1001000000000001101 1000100000000000?00100?00??1010000000000 000??00?000?000?000110001000000000100100 0000000001000000101100?0010?00???00000?1
$000111011021010221 ? 110000000000010 ? ? 00021$ 100112110121000??????

Ticinosuchus_ferox

?????????????000?000000?0000010??????0?0 ???0???????????????????????????????????? ???????????????????????????????????????? ?????????????001210???0?????0?0??00????? 00????01000001??1???0?0000?000?0?0111000 0??0000001000??010???100?00??0000?0011?? 0000100??000?0?00?0100?????10?0?0?000000 ?00??0??0?10?100?1011??0?0??00??0?1001?? ???0???00?0?0000?000??100100?????000?0?1 $000011 ? 11011010221 ? 110000 ? 000000100 ? ? ? ? 21$ 110000001000????00-0?

Qianosuchus_mixtus 1000130000010100000100011010000100000000 ?000000100000000000000?00000110000100000 0000000??10???02??01?00????000?????????? ???0?????????0012100?000110??00??00??0?? $0001 ? 001 ? 00 ? 01111 ? 0 ? 1 ? 1000000000 ? 010000 ?$ 01??0010?10?001010010????0??00000?00???? ???????????????????????010?10?0020000000 $001000110010 ? 10 ? 010 ? ? 000 ? 00000000 ? 1001 ? ?$ ???000?00???0??0??00??00110????????000?? $00 ? ? 1 ? ? 11011010221 ? 110000 ? 00 ? 000101 ? 0002$ 111?000001001101?0????

Xilousuchus_sapingensis ?0001200000?00000001000110000001??0??0?? ???????????????????????????????????????? ????????????1100110100000000?000000001?0 01100?00000?00?12100??????????0000011010 00??0001000001??1000?010010000000110???? ???????????????????????????????????????? ???????????????????????????????????????? ???????????????????????????????????????? ???????????????????????????????????????? ???????????????????????????????????????2 ????????????000???????

Arizonasaurus_babbitti ???01???0?0??0000001000110000001?00????? ?000?00100?00000000000100000?10000100000 0000?0010???1100110100000000000000001100 01100?00000100012100?000?1????0000011010 $00 ? 1000100000111100010 ? 0000000001110010 ? 1$ 11000100???00??1001?10010000???????????? ??????????????????????01001010020000?000 $11100211010110001 ? 10000100000000110011000$ 100?0??????????????????????????????????? ??????????????????????????????????????0? ??????????0?????????

Poposaurus_gracilis_holotype ???????????????????????????????????????? ???????????????????????????????????????? ???????????????????????????????????????? 
????????????????????????????????????????

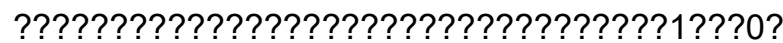
??1???1?0??????????????????????????????? ???????????????????????11111??0120000???? ?????????1011?????10000?00000000?1001??? ???????????????????????????????????????? ???????????????????????????????????????? ?????????????????1000

Poposaurus gracilis yale

?????200??0?0???00??00?????????????????? ???????????????????????????????????????? ???????????????????????????????????????? ??????????????????0????????????????????? ??????010?0001??1??????0???00?0010100001 1110111?00110??0?00??1001?000010000011000 $000100 ? ? 0000000020100 ? 1111110012 ? 00010001$ $110021101011000 ? 01000010000000011001 ? ? 001$ $0000001 ? 00000 ? 0001010 ? 1001001 ? 00001 ? 1000$ 111011011011121?11000000?00?0101000[0 1]10???????0??0??????1000

Lotosaurus adentus

?00004?0000200?0?1001?001100001000000000 0000000000000001000000100000110001100000 000?????0??111021111000000000000000????00 1100?00000??00121001000110???0??011011000 0102??????????1000000000?00000?11?0101?1 1?0010???0???0100000?0101000000000110?0? 00100??0000000000100?11101?0002?01?????? ???01???2?10000?0???00?000000001100111?? ?0000001?000?0??0000101????????00000?100 $001 ? ? 11011010121 ? 11000000000 ? 0101 ? 10010 ?$ ??????????000???????

Sillosuchus_longicervix ???????????????????????????????????????? ???????????????????????????????????????? ???????????????????????????????????????? ???????????????????????????????????????? ????????????????1???10?0???1100000??0001 111011110???????0????10000100??????1????? ??????????????????????11111?00121?1010001 11002?102?1?000??10??0??00?00?0?1001??0? ?0?????????????????????????????????????? ??????????????????????????????????????0? ????????????????0-0?

Effigia_okeeffeae

100014?000?200?0?1001??11100000000000000 0011???0000000010020?01?0010????000000?0 $1100 ? 0010 ? 01012211010010000 ? 0 ? ? ? ? ? 101100$ 0??00??0??0?00012100?000110??000?0100100 011102????????111???00?01?0?1100?01?00111 1111011?0110??0000??10000110??0?101?1?000 00100??00?00?0???????11111200021010?00011 $11021212010000 ? ? 30100 ? ? 00000011 ? ? ? 1110110$ $000001 ? 01000100010101100100110000 ? ? 10000$
$11011011 ? 1 ? 121 ? 1100000000110101 ? 00 ? 10 ? ? ? ?$ ??????00001??0-00

Shuvosaurus_inexpectatus 100014?000?20????1?0????????????0?0??000 ?0110001000000010020?0100010??00000000?0 $1100 ? 0010 ? ? 10122110100100000010000101100$ 0??00100??0000012100?000110???0000100100 011??2????????111000000000011100????00?11 1111011??11???0??0??1000?1100000101110???

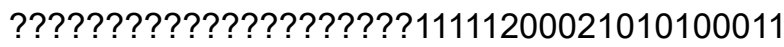
$11021212010000 ? 030100100000001112 ? 1110110$ $000001 ? 000001000101011001001100001 ? 10000$ $11011011010121 ? 1100000000110101 ? 00 ? 10 ? ? ? ?$ ?????????0???0-00

Presto._chiniquensis_lectotype

?????1000???0????0????????????1???????? ???????????????????????????????????????? ???????????????????????????????????????? ??????????????0??1????????????00000????0 00 ?10001?00001??1???00?0?00000?00???1??0 ?11000000???001?1?110100100010000??0???? ???????????????????????00--

??100000001000010001??010110101011000100 0000001100100000000000100000010110010010 $00000 ? 0000001000011 ? 11021010221-$

$1100000000000101 ? 10 ? 2 ? ? ? ? ? ? ? ? ? ? 0 ? ? ? 11110$ 11

Presto._chiniquensis_paralectotype

???????????????????????????????????????? ???????????????????????????????????????? ???????????????????????????????????????? ???????????????????????????????????????? ???????????????????????????????????????0 0110?0000??????????????????????????????? ???????????????????????00--

?0100??000?????????????????????????????? ???????????????????????????????????????? ???????????????????????????????????????? ?????????????11100000010???????????

Presto._chiniquensis_type_series

?????1000???0????0?????????????1???????? ???????????????????????????????????????? ???????????????????????????????????????? ??????????????0??1????????????00000????0 00 ?10001?00001??1???00?0?00000?00???1??0 011000000???001?1?110100100010000??0???? ???????????????????????00--

?0100000001000010001??010110101011000100 0000001100100000000000100000010110010010 00000?0000001000011?11021010221-

1100000000000101?10?211100000010???????? ???

UFRGS_PV_156_T

0100010000000000?0000?000010110?0?000000 
Desojo, von BAczKo, \& RaUhut: Type materials of PREstosuchus

?00000010?11000?000?00100000?100000000?0 0000?00?0??1??2211010000?00100000?0????? 0??0??0??????0?12100?100111?100?000010?? $000100010000011110000000000000 ? 0001 ? 100$ ? ??????????????????????????????????????? ???????????????????????????????????????? ???????????????????????????????????????? ???????????????????????????????????????? ???????????????????????????????????????? 1110?000?10?0101??????

UFRGS_PV_152_T

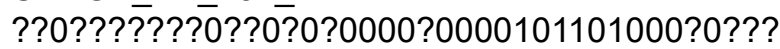
??0?00010?1?00000????0???0?0???000100000 0000?0010??111221101000000010000020???00 $01100000 ? 00 ? ? 00121000 ? 0 ? 11 ? ? ? 00000001010$ 000??0?1000001111????????????????01?1000 00?0000001?????010?????0100?10000?00????

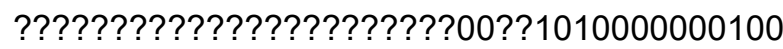
0110001010101101010110001000000001100100 ? 000000001000000?01100100???????????0??? ??????11021010221?1?000000000??????100?1 1?0?000?1??????1?0-01

\section{CPEZ_239b}

?????1?0000?00???0?0?00?0010?11??00?0??? $00 ? 0 ? 00 ? 0 ? 1,000 ? 0 ? 0 ? 0$ 1???????????????00 0??????????????????????????????????????? ?????0?????????????????????????????????? ???????????????????????????????????????? ???????????????????????????????????????? ???????????????????????????????????????? ???????????????????????????????????????? ???????????????????????????????????????? ???????????????????????????????????????? ??????????????????????

"P._loricatus"_paralectotype ??????????????????????????????????????? ???????????????????????????????????????? ???????????????????????????????????????? ????????????????????????????????????????

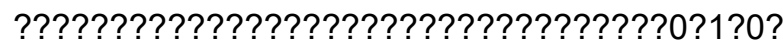
???????????????????????????????????????? ???????????????????????????????????????? ???????????????????????????????????????? ???????????????????????????????????????? ?????????021010?21?1??????????????????? ??????????????????????

Luperosuchus_fractus

?1000????????0???0???00000?011???0001100 0100????0?1?0??000??????000?????0?000??? ??????0?0???????????????00?????????????? ?????10????????12?00?100??111??????????? ???????1?????111??????????????????????? ???????????????????????????????????????? ????????????????????????????????????????
???????????????????????????????????????? ???????????????????????????????????????? ???????????????????????????????????????? ?????????????11???????

Stagonosuchus_nyassicus

???????????????????????????????????????? ????????????????????????????????????0??? ????????????????????????????????????????

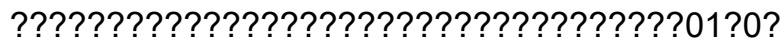
???????????????????0000000000010001?1?00 011000000????????????100?????0?00010???? ???????????????????????00--

1010000000?00001000100010110100?????????

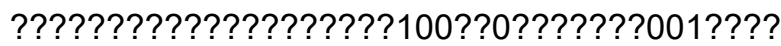
???????????????????????????????????????? ?????????????1??????0??????????1001

Mandasuchus_tanyauchen

?????????????00?00?0000??00??011???????? ???????????????????????????????????????? ???????????????????????????????????????? ???????????????12??????????????????????? ???????1????01??1?00100000000010001?1000 0?10??00???????0??0???????1??0?0?00????? ???????????????????????00--

$10 ? 00 ? 000000000100 ? ? ? 001011 ? 0 ? 10 ?[0$

1]00000000000011001?????00??0010000001010 101??????????000010100001111102101022111???????????????????1111?00??0???????00$0 ?$

Saurosuchus_galilei

0100010000?00000000000?00010110100000000 010100010011000?00000010000011??00100000 $0000000100011122110100000100000002001 ? ? 0$ 0?100100?00????12?0001001111100??0??????? ????00??00001111000000000000020001?1000? 01000000???????????????????????????????? ??????????????????????010010100000001000 ?100010001011000??1?0001000000?011001010 $0 ? 000000 ? 000000101100 ? 00100000 ? ? 00001 ? 10$ $0001 ? ? 1102101 ? 121 ? 110 ? 000000000101 ? 10021$ 110?000010?011???1?00

Batrachotomus_kuperferzellensis

??0001001001000100000001100001010110100? $01100001101 ? 0000001000101000 ? 10000100000$ $000000011001112211010000010100000 ? 0011000$ $1100100001110012100110111 ? ? 00000001101000$ 01000100000111100000000000002000111000011 $00010010000 ? 01011 ? 1001 ? 000000000011110 ? ? ?$

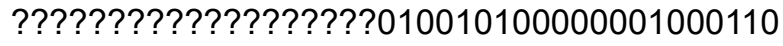
0010001001000101000010000000011001110000 0000010000001001001001 ????????0?1?????? ?1?110?1010221?1?0000000??00????10?21111? 010?010010??01100 
Fasolasuchus_tenax

$01000100000101 ? ? 0000010000100101 ? 10 ? 1 ? ? ?$

??????????????????????????????????????

????????????????????????????????????????

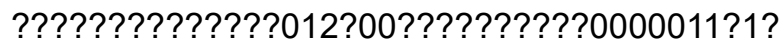

??0??001000001??1?00000000000010001?100?

????????????????????????????????????1110

??????????????????????????????????????00

1????010?01???0?0?010000?000000100100111 00?0000???????????0100110??01001110001?1

000111111021011121 ?11???????????????????1

??1?0???????00???1000

Rauisuchus_tiradentes

010?01000?010????????????????????11?????

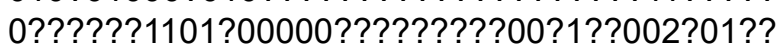

???0?0011???????????????????0???????????

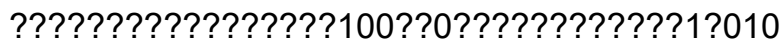
??0?0??10000?11110?100?0010000?0001?000? ?0??000?010?????101?????1?1?0??????????? ????????????????????????????????????0?00 ????????????????????????????????????????

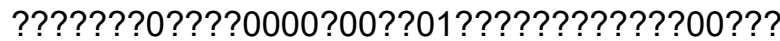
0?0?1?1110??????????1??????????????????? 1111?011001??00?1????0

Polonosuchus_silesiacus $01000100000100 ? 000000100021011010110100$ ? ????10011?0200001??????0?100?111002?0100 0010???1111???????0?????????????????????

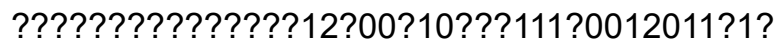

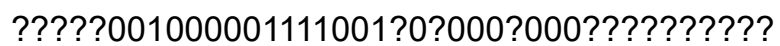
?????????1?????????????????????????????? ???????????????????????????????????????? ???????????????????????????????????????? ???????????????????????????????????????? ???????????????????????????????????????? 111??0?0?????00???????

Postosuchus_kirkpatricki 010001000001001000000100021011010110100 ? $011010 ? 1100200001010001011001111002001000$ 010?0011??1112211010??011010010020011001? ?01??0???1?001210011011111100002011010000 10001000001111??????????000?1?01?0000001 $000000 ? ? 0 ? ? ? 01001110 ? 101000010000111 ? 0 ? 00$ 100??00????0??0100?01001?10000000??????? ??1???1011000?0100001000000?0010011100?0 $000001000000100110110 ? ? ? ? ? ? ? ? 10001 ? 10001$ $11111021011121 ? 1100000000110101 ? 10 ? 01111$ ? 01000??000??01100

Postosuchus_alisonae

??????????????????????????????????1????? ????????1??????????????????????????????? ?????????????1??????????1??110?????+1???

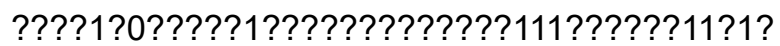
??????010?0001??100100000?0000210011000?

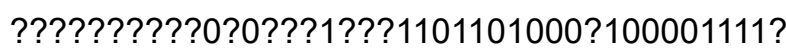
00?100000000?000?0100?????????????????? ?100???????????????????????????????????? ??????0?10?00001001101101001001110001?100 $0111111021011121 ? 110000000010010101010111$ 1?0100010?????????0

CM_73372 ???????????????????????????????????????? ???????????????????????????????????????? ???????????????????????????????????????? ????????????????????????????????????????

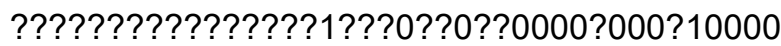
??100000?1??????1????????????0?????0???? ?0001000?00??0????0????010011?002?000100 ?11000??10101000?1010?00?000000100???1?? ??00???0010000001001101101?01001110001?10 $00111111021011121 ? 110000000011010 ? 0101011$ 1100?000?0??????????

Hesperosuchus_agilis

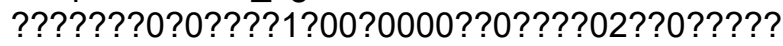

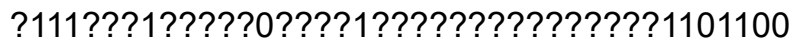
00????????????????1???01?01?0??0111????? ????????????0012??0??01??????00020?????? ????001000001??100000000000001?00?1??0?? 0??000?0??0???010011111101000011100111101

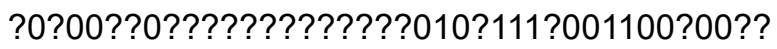
$100 ? ? ? 10 ? ? ? ? ? ? ? ? 01000010000001001001 ? ? 1 ?$ ?00?000100000010??1011010010??1?0001???? ???1?1?0?10???21?110?000?00??0?0??002?11 11?010?010?????0????

Dromicosuchus grallator $0001020000110110000000000010010 ? 0100001$ ? ?11110011000001?00100010?1001111001?01100 00????????????????????????100??????????? ????????????0012100?00111??00000?02101?0 0010001000001 ??1???????0??000000??10000? 01000000?00201010011111101000011100011?01 00100?10?????????????010?1110000100?00?? ???01??????????010000100000110010011100 ?0000001000000100010110????????00?1???? ???1?11021011?21?1?1?000??????????????111 1001000100010?0???0

Hesperosuchus_agilis 0001020000110110000000000010010201000011 ?111100110?0001?0010001001001111001?01100 000?00111?1???????????0?1?100????1??1??1 ??????????????12100?00111110000?20210??00 ?100010000011110?00000??0000?00??1?0????

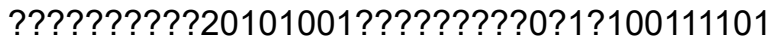
00?00?100000000?0100???????????????1001? 10001010????????0100001000000100???111?? 00???0???000?01?00101101001001110001?100 $0111111021011121 ? 11000000001 ? 0101 ? 00 ? ? 111$ 100100010?01??????? 
Desojo, von BAczKo, \& RaUhut: Type materials of PREstosuchus

Dibothrosuchus_elaphros ?0010200001?011000000000?000000201000011 1111???11000001?0120101??1?01??????101100 $0000001 ? ? 1111221101 ? ? 10111100110111 ? 1 ? 112$ $11010111 ? ? ? 0 ? 12100100111 ? ? ? 00 ? ? 002 ? 0 ? 0000$ $100010000011110000000000000100001 ? ? 0 ? ? ? ?$ ????????????10011111101000?1010011110110 ?00?100000?0??0100?00??1100021100??????? ???????????????????????????????????????? ???????????????????????????????????????? ???????????????????????????????????????1 ????????101??0????

Terrestrisuchus_gracilis

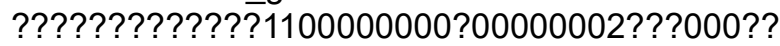
??111001110000????20?01??1001111000??1100 000?00??0???????????????11??0??0?1?????? ???0?0??????001210??00111????000002?0?00 $001 ? 001000001111 ? ? 00 ? 000000000000 ? 100000$ 01000000100201110011111101000010100111101 $00100 ? 100 ? ? 0000 ? 0100 ? 010 ? 110002110010011$ 0??0100010000020010000101000010010010100 $10000001000000100010 ? 111001001110001 ? 1000$ $111111021011121 ? 111000010 ? 1001011011011 ? ? 0$ 01000100????00-0?

Sphenosuchus_acutus ?1010?00001?0110000000000010??020100?011 $011110011000001 ? 0120101001001111101101100$ $0000001111111221101 ? ? ? 011110011011111111211$ $010111111 ? ? 12100100111 ? ? ? 00002021010000 ? 0$ 001000001111?000???000000??00?1????????? ???????201010011111101000?1?100????????? ?????????????????????????????????????? ???????????????????????????????????????? ?00100000010???????????????????????????1 ???????????????100??????0???1?????1????0 ?????00?1??0???0

Litargosuchus_leptorhynchus $00010100001 ? 011000000 ? 00 ? 000010 ? 0000001 ?$ ?011???111??001??1010?1?0?001111101?01?0? 0?0?0??????????1??????????110???????????

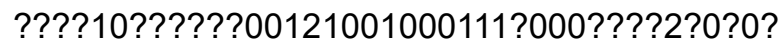
$0 ? 10 ? 0 ? 000 ? 01 ? 11 ? ? ? 00 ? 00000000000 ? 1000 ? ?$

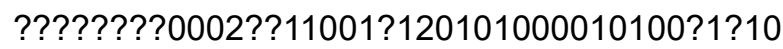
1?0???????????????????????11???????????? ?????????0?00????1??????????????????1??1 ??0?0?00?????????001???11?0????????????? ???1??1?0??0??121?1?1??000?????????012?1 ?1?000?001?00????????

Kayentasuchus_walkeri

?10101000011011000000??000100102??0??01?

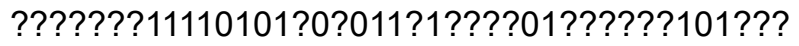

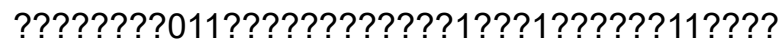

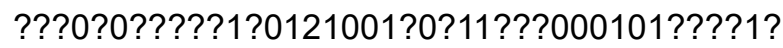
0???00??000?1??????????????????????????
???????????????????????????????????????? ??????????????????????0?????0??21??????? ??????????????????10?001?11000110100???1 ???????????????????????????????????????? ???????????????????????????????????????? ?1?????????0?1???????

Orthosuchus_stormbergi $00020100001 ? 01 ? 0100000000010 ? ? 020 ? 00 ? 011$ ?01110011100101??1011011?10??111001101110 00000011?01???21?10???0?11110???11?????2? ????0??????0012100100011110000?202?0?000 ?1000?0010?11110?00000000000?000?10010?0 100000???02??0100111201000000101001111011 $0 ? 10 ? ? 00000000 ? 0100 ? 010 ? 1100020100000 ? 10$ ??01??000000120010000000000010010010110? $000000100000010 ? ? ? 0 ? 1110010 ? ? ? 10001 ? 1000$ ?11111021011121?11??00???0??0????002?1110 ?021?01??01??00-0?

Alligator_mississippiensis 0?02020000000?10000?010000?0??020000???1 1011100110?010??01011011010??111000101111 $0000001 ? ? ? 1 ? 1221110 ? 0 ? 0110000110111111122$ $1 ? 00011101 ? 000 ? 1011001111 ? 000010000000000$ $100000010 ? 1111000000000000 ? 11000100100010$ 00000100201010110120100000001100101111001 00??000?000020100??0????00021000000?00?? 01???0000012101000010?000110010010110000 $00001000000100010111[0$ 1]001001110001?1000111111011011111?:1101000 $00010011110020110011[0$ 1]?1011?010?0???0 Protosuchus_haughtoni $000201000011001000000 ? 000010010 ? 00000011$ ?011100111??101?0101101?01001111101??1110 00000?1??????221?10?0?0?11110????1?????2 ?????0??????0?1210010001111000??002101102 ?10?01000?011110?10?000??00000???1001??? ??????????????????1????????????????????? ??????1????????????????????????????????? ???????????????????????????????????????? ???????????????????????????????????????? ??????????????????????????????????????11 10?021101?0010??????

Protosuchus_richardsoni $000201000011001000000 ? ? 00010010200000011$ $1011100111 ? 0101 ? 0101101101001 ? 11 ? 01101110$ $00000011001 ? ? 221110 ? 0 ? 01111101101111 ? 1 ? 2 ?$ ??0001??1??001210010001111000??002101102? $1000 ? ? 00001111 ? ? 10000000000 ? 0 ? 0 ? 10010 ? 01$ 00000???0?011000111201000000?010011111110 100???0?0000??0100?010?1100021100000?10? ?010?000000120010?0010000001001001111000 $00000100 ? 0001000101111 ? 0100 ? 010001 ? 100011$ $1111021011121 ? 111000000010010110020111010$ 211010001??00-00 
Eudimorphodon_ranzii

10?0?100000?00?000000?011000000?0?0??0??

????0??????????????????00?0001000?0?0??0

010?????????????????????????????????????

?????????????101?000?00?110??00?000000?0 0?0?001?0000?1011???1???00000000???100?0 0??????0?0100010??????1?1?0??0001100?0?0 0001??????0000101101?1?00??11???0?00?000 000??00??00??000001????????0?00????2?1?? 0??0?0??????0????????????11?00?????01??? 1???1???11?01??????111?00010?1?010101000 0??????????1000-??????

Dimorphodon_macronyx 10??1200000000??00000?011000000??????00?

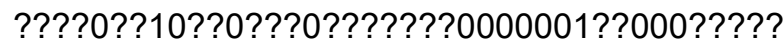
?0??????????????????????????????????????

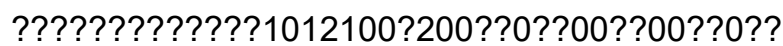
0??1?01?0000?1??1???1?1??????000???1000?

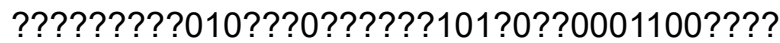
?001?0???00000??1101?1?00??11?000100?000 ?00??00??0???00000110000?000000000???101 $0020000000 ? 00 ? 000 ? 00 ? ? 1 ? ? 111000 ? 0 ? ? 01 ? ? ?$ 101?1???11??1??????111000010?01?10??1?00 0???????????000???????

Lagerpeton_chanarensis ???????????????????????????????????????? ???????????????????????????????????????? ???????????????????????????????????????? ???????????????????????????????????????? ???????????????????????????????????????0 001000000???????????????????????????????

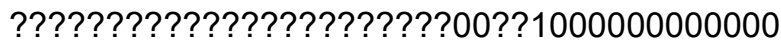
$000 ? ? 000000000010011110011000100 ? 01101010$ $0 ? 0010100 ? 00000000010101111000 ? 1 ? 10100110$ 10110?11?01????201111000000000000001200?? ??????????????????

Dromomeron_gregorii ???????????????????????????????????????? ???????????????????????????????????????? ???????????????????????????????????????? ???????????????????????????????????????? ???????????????????????????????????????? ???????????????????????????????????????? ????????????????????????????????????????

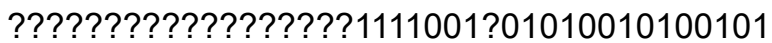
011011110000000000???????????????1?????? ????10?????????????????????????????????? ?????????????????????

Dromomeron_romeri

??????????????????????????????????????? ???????????????????????????????????????? ???????????????????????????????????????? ???????????????????????????????????????? ????????????????????????????????????????
???????????????????????????????????????? ????????????????????????????????????????

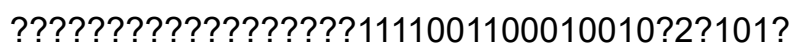
1101111000000000000101 ??????????10100110 10110?1??01????2?1????????????????????0? ????????????????????

Marasuchus_lilloensis ??????????????????????????????????????? ????????????????????????????????????????

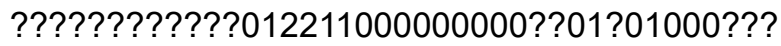
0??00?00????0??????????????????????????? ????????????????10100?0000000000000?0000 $001000000000 ? ? ? 01 ? 0 ? ? ? ? 0 ? ? 1 ? ? 000 ? 1001 ? ? ?$ 0??????????????????????00??1000001000000 010??1100000000111110000100100101010010?0 $0 ? 000010000000001001010011100001 ? 01100110$ $00110 ? 101000012001111000000000100 ? 012 ? 0 ? ?$ ???????????????????

Asilisaurus_kongwe

???????????????????????????????????????? ????????????????????????????????????0?00 000?????????????????????????????????????

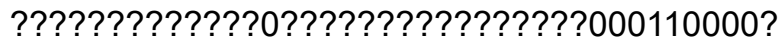
??0??1010?1?10??11?010100000000000100000 00?00001000?????1?01?1001?100000?100??00 ???????????????????????02??1000010000?00 ??0??110?010010?1??1000110111010111001010 ?1100010000010001??1110??????????01100110 $00100 ? 10100001 ? 00111 ? ? ? ? ? ? ? ? 1 ? 10 ? ? ? ? ? 10 ?$ ???????????????????

Eucoelophysis baldwini ???????????????????????????????????????? ???????????????????????????????????????? ???????????????????????????????????????? ???????????????????????????????????????? ???????????????????????????????????????? ???????????????????????????????????????? ????????????????????????????????10??????

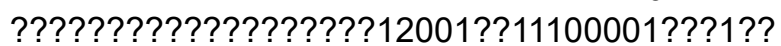
??1100010?100??????????????????????????? ???????????????????????????????????????? ?????????????????????

Sacisaurus_agudoensis ?????????????010?0?0??000000000????????? ??????????????????????????????????????? ????????????????????????????????????????

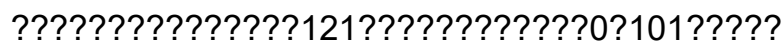
?????102001110??1??????????????????????? ????????????????1?01?????0100???????????

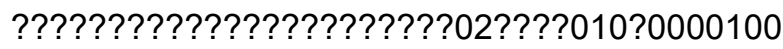
0?0??1???0?0???????10011101110000110010?? ??100010010110001????????????????????? ???????????????????????????????????????? ???????????0????????? 
Desojo, von BACZKo, \& RAUHut: TyPE MATERIALs of PREstosuchus

Lewisuchus_admixtus

?????????????01000?00?0?0000?00????????? ????0001?0??000????????0001??1??000000?0 0001?011????012211001000000001??110????0 0?10??10??0??0?12??0?00?1?????01000?????

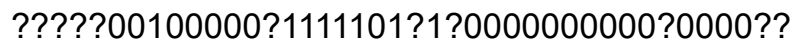
??????????????11010100101000?00??0????? ???????????????????????????????????????? ???????????????????????????????????????? ???????????????????????????????????????? ???????????????????????????????????????0 ???????????0????0????

Pseudolagosuchus_majori ???????????????????????????????????????? ???????????????????????????????????????? ???????????????????????????????????????? ???????????????????????????????????????? ???????????????????????????????????????0 001000000??????????????????????????????? ???????????????????????02????0?010000100 0?0???1010??????1?1100011?110010111?01010 ??000010000010001001?10??????????0110011 000100?10?00001?0011???????????????????0 ?????????????????????

Lewisuchus_Pseudolagosuchus

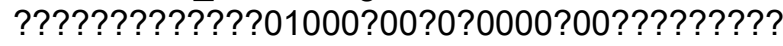
????0001?0??000????????0001??1??000000?0 $0001 ? 011 ? ? ?, 012211001000000001 ? ? 110 ? ? ? ? 0$ 0?10??10??0??0?12??0?00?1?????01000????? ?????00100000?11111101?1?0000000000?000000 01000000???????11010100101000?00??0?????

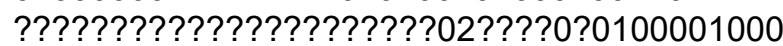
?0???1010??????1?1100011?110010111?01010? ?000010000010001001?10??????????01100110 00100?10?00001?0011???????????????????0? ??????????0????0????

\section{Eocursor parvus}

???????????????????????????????????????? ??????????????????00001????????????????? ????????????0?2211001000?0??????????????

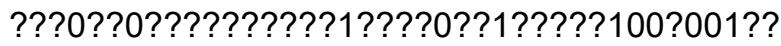
1001?0?2011?11??1???????0?0001????0??010 ?0?01?1?0??????01101??????1??1?0?1001???

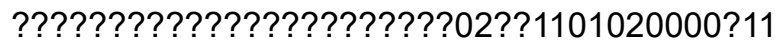
0????01??0100?012?11000210120000111111010 0?000020000?20101001?101??????????1????? ????????????????????11?????00??????????0 ?????????????????????

Silesaurus_opolensis

??00020000000010?0000?0000000001??000?0? ?00?00010?0000?1000?00100000?1100010000? 0001???10???0102110010000000?01011000100 $01100 ? 100000100121 ? 0 ? 000110 ? ? 00112100100$ 00010101001010111110100000000000001000000
$0 ? 000110000 ? ? ? 01101010010100000010010 ? 00$ ??0?00??0?????????????02??10010100001000 10??1101010000011012011101110[0 1]001100101?0110001001011000100111011?10? ????0110011010100?10?01????20111110??0001 0101001210???????????0????00-0?

Pisanosaurus_mertii

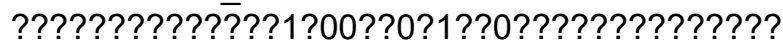
???????????????????????????????????????? ????????????????????????????????????????

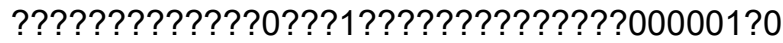
12??00?2111111??1????0?0???0000??????0??? ???????????????????????????????????????? ????????????????????????????0????????000 ???????????????2????????????????????1010 ??0000?00000100010011101?????????0110??11 1?1?0?10?01????211111?????0?1?10??????0?? ??????????????????0

Heterodontosaurus_tucki 0100000010100110000001100000000100000000 1011000100000000002000100000013000100000 $0001 ? 011 ? ? ? 1012211001110000000100110 ? ? 000$ ??00?0???0??001210010011111001?0[0

2]00010012010[0

2]121001111111100000001000000000?2011?0?011 $100001 ? 1 ? 01101 ? 0 ? 0101 ? 010011001000100011$ $00010000111201000 ? 2 ? ? 1100021000111010 ? ? 01$ ??0100001211?0??????20?0?1011110100?00002 $00001101 ? ? 00110 ? 1111000 ? 0 ? ? 110 ? ? 1 ? 1 ? 1 ? ? ? 1$ 1?01??????111110000?0101010?1200????????? ?20010?00-0?

Lesothosaurus_diagnosticus

0100030000000110000000100000000100000000 ?0110001000000000[0

1]00001000000130000000100001001?00010122 $11001000000000 ? 00 ? 10 ? ? ? 00 ? ? 00100 ? 00 ? ? 001$ 21001001111100110000010012010002011011111 ??000000100000???0?001??0??111?0??1???01 1010?????1??100?10000?0100010???000?0?0? ?0100002??1101021000111010??01??01000012 $111000210120000101111 ? 1000000020000020101$ ??111??1??????0?01100?11101?0?10?01????21 1111100000010101????00???????????001??011 0 ?

Scutellosaurus_lawleri

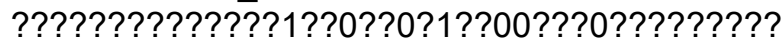

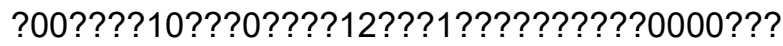
0?0?????0????????????????0????????1?????

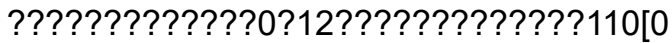

2]0???????????02011011??10??00?00??0?0000

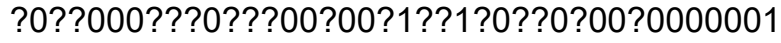
1001000?????????0?????????????02??110102 ?1001110?????1??00??????111000?1?120000?0 111101?0000002000002010?001?1011???????0 
1100111101?0?1??01????211?10????????????? ???01?????000????????0???0

Herrerasaurus_ischigualastensis $01000100100100000000 ? 0000000000 ? 00000100$ $00 ? 1000100000000000000100000013000100000$ $0001 ? ? 1 ? ? 0 ? 10 ? 22 ? 1011000 ? 0000000 ? ? 1 ? ? ? ? 0$ 0??0?100?????00121001001110??00??00000?0 $0001 ? 001000001111100 ? 01001100100001 ? 20000$ 01000001011?1??1?01??????1??110110010000 $000112011001110130110102 ? ? 100002100010001$ 1101101010200121010102102100101011110101 ? $0000200100101010011101111011 ? 0 ? 0110111110$ 1?0?10?01????201111100000011101?01100???? ???????0011????0?

Staurikosaurus_pricei

???????????????????????????????????????? ???????????????????????????????????????? ???????????????????????????????????????? ?????????????????1????????????00000?00?0 00 0.1?001000001??1???????01?00??0????0000 00100?00101????????????????????????????? ???????????????????????02??1000021000100 ?1110110101?1?01?11?000210110010111111010 ??0000200100100010011101???????????????? ???????????????????????????????????????0 ?????????????????0-00

Eoraptor_lunensis $01000100 \overline{1} 1012000000000 ? 000100000 ? ? 0011110$ $00 ? 100010 ? 00000 ? 0 ? 0 ? ? 0100000113000100000$ 0001?01?????0??21?01?000???0?0?????????? 0????????????0012100?001110??000?00000??

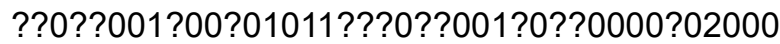
0010?000?0?1?1?01001?0??1010011011001000 1000111??10011110??110102??100112?0011000 11???100010100??11??0??1?110?00????110?0? ??000[1

2]0010?10001001?1011110110???1?0???1?01?0 ?10?0?????2?111110000001?1010?1?00??????? ???10110101100

Saturnalia_tupiniquim

?????????????????0??0????????????????11? ???????????????1???????????????????????? ??????????????????????????0????????????? ???0??????????1??????????????????0?????? ?????002001001??1??????0??100000?01?0000 $00 ? 000001001 ? ? ? 0100100 ? 01010010001101 ? ? 0$ 1??0???????????????????02??1001011000100 0110011000102101210100021021001011111101 ? $1 ? 000020000111101001110111101100 ? 011011111$ 01?0?10?01????201111100000011101001?00??? ???????????0100-00

Plateosaurus_engelhardti 1010120010010010000000001010000100011110 0001000100000001000000100000013001000000
0001001100010122110010000000000001100100 01100?00?020?01121001?01110??001010001100 00110020110011111100010011000000010000000 $100100100001 ? 0100100 ? 0101001001110100010$ $00101010111111120100 ? 02 ? ? 1000021000100011$ 00110001021012101000210210000111111010100 $00020000011101001110111101100 ? 01101111101$ ? 0?10?01????201110100000011101001100?????? ?????0100101000

\section{Efraasia_minor}

?01011001001001000000000?0000001?00??110 ?001???10?0000?10???0??????00????1?00000 000?????????012211001000000000000110???0 0?100100?0???0112100?001?????0000000?1?0 $00 ? 1 ? 002001001 ? ? 11 ? ? 10 ? 001100 ? 0 ? 00100000$ $001000001001 ? 1 ? 01001 ? 0 ? 01010010011101000$ $100010 ? 01011 ? 1 ? 11 ? 0100 ? 02 ? ? 1000021000100$ 010??110001021012101000210210000111111010 $100000200000111010011101111011 ? 0 ? 0110 ? ? 11$ 1?1?0?10?01????201110100000011101001100?? ????????1???0101??0

\section{Tawa_hallae}

$10000000101 ? 00000000010 ? 00000001000 ? ? 110$ $0001000100000000000 ? ? ? 100001 ? 130000000 ? 0$ 0001 ??110??101221101?000000000000?1?1?00 $01100100000010012100 ? 001110 ? ? 000000000 ? 0$ $00 ? 1 ? 001000001 ? ? 1110111111110100001000000$ 010?000?011?1?01101??????1??1101100100000 $0011200 ? 001110120110102 ? ? 1001120001100 ? ? 1$ 10?1010??1???2?1200022011000012110101011 $000020011010001001110111101100 ? 01101 ? 1110$ 1?0?10?01????211111100000010101?01200???? ??????1?0????????

Coelophysis_bauri

10101100101 ? $0000 ? 0000 ? 01010000010 ? 010110$ 000100010?000001000?001000011130001000?? $0001001100010122110110100000 ? 0100110 ? ? 000$ ?10??00?000?00121?01001110??000?00000?00 $001 ? 0010000011111101111111110000010000100$ ? 01110101111?01101?0?010100110110010001000 112111001111130 ?10112??1102121111100011101 1 ?1010111?211200021021001012110101?110000 21011111101001110111100100?01100111101?0?1 1?01????211111110001010??10012?0??????0?? ??0001100-?0

Dilophosaurus_wetherilli

10101100?01?0000?00001??000100010?0??110 ???100010?0000000??????0?0011?300000000? 000?0????00?0122110110000000?11001100?0?0 1100?00102??00121?01101??0??00000001000? 00110010000011111000111111200000010000000 ?011101??1?1?11101?100101001100100100010? 0112??10011?1120?10112??11021210111000?11 $0 ? 1010101111210200021 ? 12000012110101 ? 110 ?$ 
$0021011121101001110111100100 ? 01100111101 ? 0$ ?10?01????2111111100010101?1001200??????? ???10?0?1?0-10

Allosaurus_fragilis

$101012001001010 ? 0000010010210001001111100$ 0010001000000000000001000001130000000000 $0010111000101221101100000000110011 ? ? ? ? 00 ?$ ?00000??2??00121001101110??0000000100000 01100100000111110010101112000000100000001 $01111111111 ? 00101010010100110110010001000$ 1121111011111?1???102??1102021011100?11011 10201011112102000220020000101101010110000 210111211010011101111001?0?02100?11101?0? 10?01????211110110000010101001200???????? ??11000100-10

Velociraptor_mongoliensis

$101011001000010100000 ? 0000010001 ? 001111 ? 0$ $0010001000000010000 ? 01000000131000000000$ $001011100010122110 ? 10000001011 ? 01111 ? ? ? 0 ?$ ?0[0

1]?00?????00121001001110??000000000?00001 1001000001111???????????????0010?00100111 $11110 ? 111 ? 00101 ? 1101010010011001000000001$ 21110000111?1???102??11020210111100111011 ?200001012102010220?20000101101010110000 2101?12110?001?00?111??????0210??111?1?0? 11?01?????11110110000010101001200???????? ??1000[0 1]?????0

Parringtonia_gracilis

????????????00?01000100?0020?011????????

???????????????????????????????????????? ??????????????????????????????????????? ????????????????????????????????????????

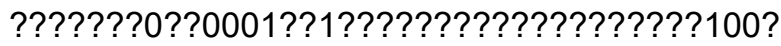
?????????0??????1011???????????????????? ???????????????????????????????????????? ???????????????????????????????????????? ???????????????????????????????????????? ???????????????????????????????????????? 1101??00??????????????

Erpetosuchus_granti $0000 ? 100000000 ? 010001 ? 000020 ? 101000 ? 000 ?$ ?00?1001?000000?0?2?0010000001110010??10 0000000????????21?0??000??0000??????????

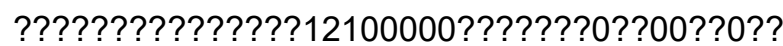
00?1?0000000011?1???0?0000000010????????

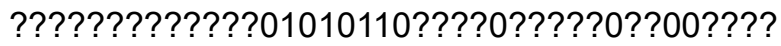
0000??0??00??0????0?0??????????????????? ???????????????????????????????????????? ????????????????????????????????????????
???????????????????????????????????????? 11010111?0??00?0??????

Pagosvenator_candelariensis

$01030100000000 ? 010001 ? 000010110 ? 0000000$ ? ?00000010?00?000?11?001000000100?01???00 000????????1???????????????000??????????

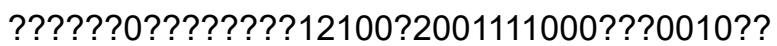
???1?0010?0001?????????????????????????? ???????????????????????????????????????? ???????????????????????????????????????? ???????????????????????????????????????? ???????????????????????????????????????? ???????????????????????????????????????? 1100??10????0011??????

Teleocrater_rhadinus

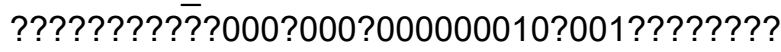
?0??????????????????????????????????0?00 0?0?????????????????????0000?????10????? 0?????0????????12??????1???????????????? ???????1?00001??1?00101101000030101???00 0?100?????0?????1001??????0??1?000101000

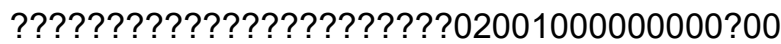
??????0???1010010?0010001001000001100100 $0001000000000000000010100 ? ? ? ? ? ? ? ? ? ? ? ? ? ?$ ???????110000100?001??????????????????? ???????????1?????100?

Dongusuchus_efremovi ?????????????????????????????????????? ???????????????????????????????????????? ???????????????????????????????????????? ???????????????????????????????????????? ???????????????????????????????????????? ???????????????????????????????????????? ????????????????????????????????????????

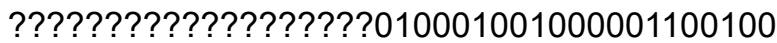
000100?????????????????????????????????? ???????????????????????????????????????? ?????????????????????

Yarasuchus_deccanensis ?????????????????????????????????????? ???????????????????????????????????????? ???????????????????????????????????????? ????????????????????????????????????????

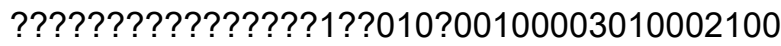
00100?00000????01?0??10???0??1?00010100? ???????????????????????020010?0000000000 ?00---

$0100 ? 010 ? ? 000010001001000001100100000100$ 000000000000??????????????????????????? ?1100001001001?????????????????????????? ??????0????????? 


\section{APPENDIX 2}

\section{New characters and coding changes.}

296. Ischium, ventral margin: (0) continuous ventral margin; (1) abrupt change in angle between the proximal end and the shaft. (Modified from Nesbitt 2011)

The character state 1 defined by Nesbitt (2011) as a notch present in the ventral margin of the ischium is here considered independent of the angle of said margin, and therefore the presence or absence of a notch or incision is proposed as a separate character (char. 421)

416. Dentary, ratio of length to basal height of ventral angular process: (0) equal or more than 1.5, (1) less than 1.5 (New)

417. Proximal ends of chevrons: (0) with two separate articular heads, (1) both articular facets connected by a bony bar, so that a closed haemal canal is present (New)

418. Scapula-coracoid suture, posterior margin: (0) entire margin, (1) presence of an oval incision on the coracoid (Desojo and Rauhut 2008)

419. Ischium, dorsolateral margin: (0) smooth, (1) with longitudinal depression delimited medially by a ridge (Modified from Desojo and Rauhut 2008)

420. Ischium, position of longitudinal depression: (0) dorsal, (1) lateral.

Inapplicable for those without longitudinal depression (New)

421. Ischium, ventral margin: (0) continuous, (1) obturator plate separated from the ischial shaft by a small incision (Desojo and Rauhut 2008)

422. Fibula, "lunate" fossa on posteromedial surface of the distal end: (0) absent, (1) present (New)

\section{Coding changes}

Character 51 :

Luperosuchus fractus: $0->1$

Character 201:

Prestosuchus chiniquensis lectotype: 0->?

Character 210:

Prestosuchus chiniquensis lectotype: 0->?

Character 229:

UFRGS-PV-0152-T: ?->1

Character 269:

Prestosuchus chiniquensis lectotype: 0->?

Character 293:

Ticinosuchus ferox: 1->?

Qianosuchus mixtus: 0->?
Mandasuchus tanyauchen: 0->1

Character 296:

Alligator mississippiensis: 0->1

Asilisaurus kongwe: 0->?

Coelophysis bauri: 0->?

Dilophosaurus wetherilli: 0->1

Efraasia minor: 0->1

Eocursor parvus: 0->1

Eoraptor lunensis: 0->?

Fasolasuchus tenax: 0->?

Herrerasaurus ischigualastensis: 0->1

Heterodontosaurus tucki: 0->1

Lagerpeton chanarensis: 0->1

Lesothosaurus diagnosticus: 0->1

Longosuchus meadei: 0->?

Mandasuchus tanyauchen: ?->0

Marasuchus lilloensis: 0->1

Orthosuchus strombergi: 0->1

Plateosaurus engelhardti: 0->1

Prestosuchus chiniquensis lectotype: 2->1

Protosuchus richardsoni: 0->1

Qianosuchus admixtus:0->?

Riojasuchus tenuisceps: 0->?

Saturnalia tupiniquim: 0->1

Staurikosaurus pricei: 0->1

Teleocrater rhadinus: 0->1

UFRGS-PV-0152-T: 2->1

Velociraptor mongoliensis: 0->1

Character 401:

Prestosuchus chiniquensis lectotype: 1->?

Character 402:

Prestosuchus chiniquensis lectotype: 1->?

Character 403:

Prestosuchus chiniquensis lectotype: 1->?

Character 404:

Prestosuchus chiniquensis lectotype: 0->?

Character 405:

Prestosuchus chiniquensis lectotype: 0->?

Character 406:

Prestosuchus chiniquensis lectotype: 0->?

Character 407:

Prestosuchus chiniquensis lectotype: 0->?

Character 408:

Prestosuchus chiniquensis lectotype: 0->?

Character 409:

Prestosuchus chiniquensis lectotype: 0->?

Character 410:

Prestosuchus chiniquensis lectotype: 1->?

Character 411:

Prestosuchus chiniquensis lectotype: 0->? 